\title{
The significance of subthreshold symptoms of anxiety in the aetiology of bruxism
}

\author{
Reneda A Basson
}

\author{
A thesis submitted in fulfilment \\ of the requirements for the degree of \\ MA Research Psychology \\ in the Department of Psychology, \\ Faculty of Community and Health Sciences, \\ University of the Western Cape \\ Supervisor: $\quad$ Professor K Mwaba \\ Co-Supervisor: $\quad$ Professor GAVM Geerts
}

May, 2007. 


\section{Declaration}

I, the undersigned, declare that The significance of subthreshold symptoms of anxiety in the aetiology of bruxism is my own work, that it has not previously in its entirety or in part been submitted at any other university for a degree, and that all the sources I have used or quoted have been indicated and acknowledged by complete references.

Full name...Reneda Anna Basson Date...

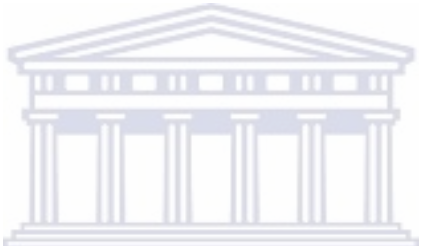

Signed 


\section{Acknowledgements}

I wish to express my sincere gratitude to the individuals listed below, without whose assistance this study would not have been possible:

Theuns Kotze - Statistical analysis and guidance

Roelof Rossouw - Scoring of toothwear and guidance

Dr Martin Stuhlinger - Impressions, mouth opening measures and clinical findings

Annette Olivier - Guidance and support

Nicky Basson - Guidance and support

Neville Fredericks - Instructions on dental casts

Prof GAVM Geerts - Guidance and support

Prof K Mwaba - Guidance and support 
This thesis is dedicated to my husband Nicky, and my three sons Nicholas, Lionel and Riaan.

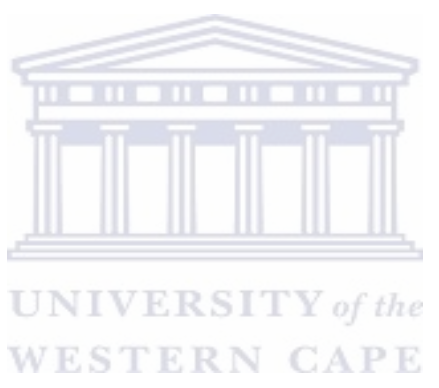




\begin{abstract}
Introduction: Bruxism is an oral parafunctional habit involving clenching and grinding of the teeth that occurs mainly unconsciously, diurnally and nocturnally. It is considered an important contributory factor in the aetiology of myofascial pain (MFP) and temporomandibular disorders (TMD). The aetiology of bruxism is considered to be multifactorial, involving physiological and psychological factors. Statement of the problem: Do subthreshold symptoms of anxiety have an effect on bruxing behaviour? Aim: The aim of this study was to examine the relationship between the subthreshold symptoms (subtle, prodromal, atypical and subclinical symptoms of which the severity precludes diagnosis as a disorder) of anxiety and bruxism in a sample of subjects using a spectrum model. Method: Firstly, a self report screening measure consisting of the Spielberger State Trait Anxiety Inventory (SSTAI); the Kessler-10 (K-10); demographic and bruxism criteria were used to determine levels of anxiety, stress and bruxism on a continuum. Secondly, in order to determine a bruxism score, a standardized clinical examination; intra-oral photographs and dental casts were used in the study. Thirdly, the diagnosis of bruxism according to specified criteria was performed. Results: Forty one percent $(n=12)$ of the sample of 29 subjects was diagnosed as bruxers. A possible relation between subthreshold symptoms of anxiety, stress and bruxism was observed in the results. In approximately half of the subjects with higher than average anxiety and stress scores, bruxism behaviour was found. Clinical significance: The dentist could play a role in recognizing that a patient may be experiencing stress or anxiety, expressed through bruxing behaviour and refer the patient for therapy or counseling. The treatment of bruxism could be complimented by therapy or counseling which focuses on addressing the subthreshold symptoms of anxiety. Conclusions: An understanding of
\end{abstract}


the psychological factors involved in the aetiology of bruxism could encourage a more holistic approach to the treatment of bruxism.

Key words: bruxism; spectrum model; stress-response style; masticatory muscle tension; subthreshold symptoms of anxiety. 
Declaration

Acknowledgements

Dedication

iv

Abstract

$\mathbf{v}$

Table of Contents

vii

LIST OF FIGURES .

IX

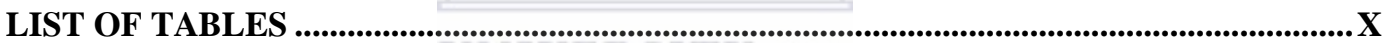

CHAPTER 1 .........................................................................................................1

INTRODUCTION ...................................................................................................1

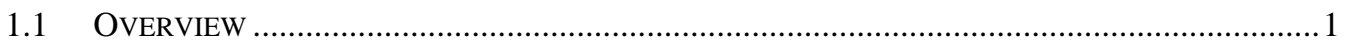

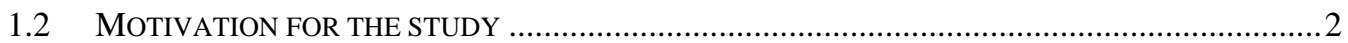

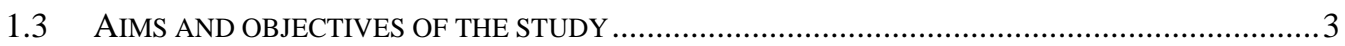

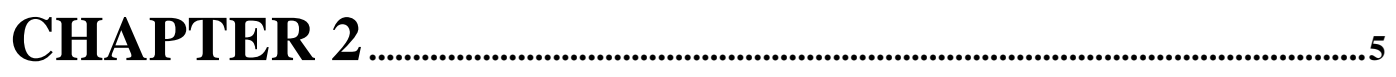

LITERATURE REVIEW .......................................................................

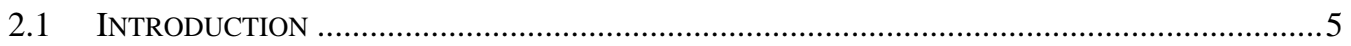

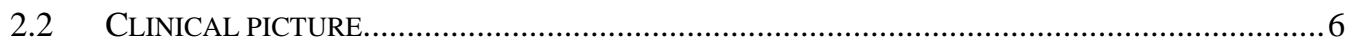

2.3 RELATION BETWEEN BRUXISM AND TEMPOROMANDIBULAR DISORDERS ..............................

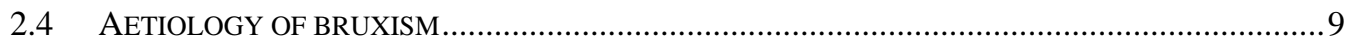

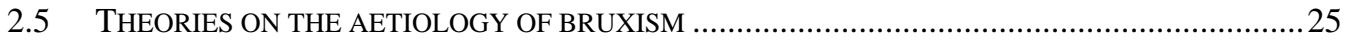

2.6 METHODS FOR THE EVALUATION OF PSYCHOLOGICAL AND PSYCHOSOCIAL FACTORS........29

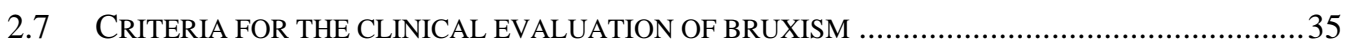

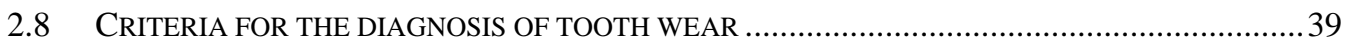

2.9 TREATMENT OF BRUXISM, MFP AND TMD ………........................................................

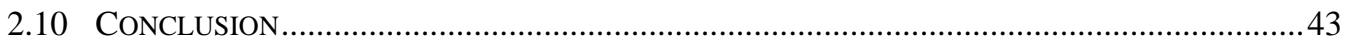

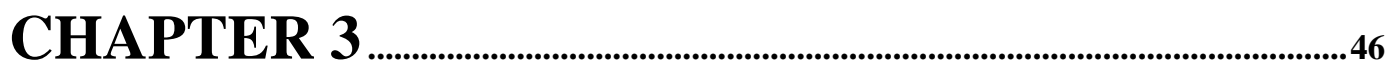

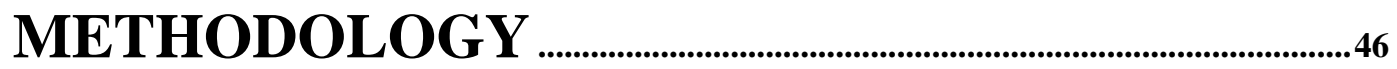

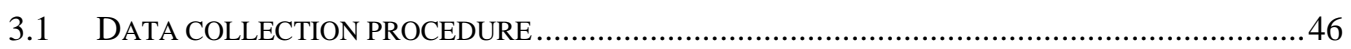

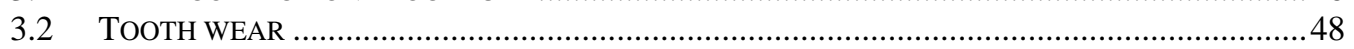




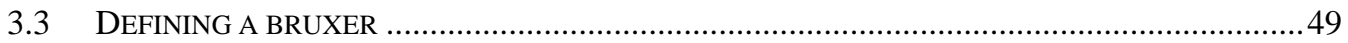

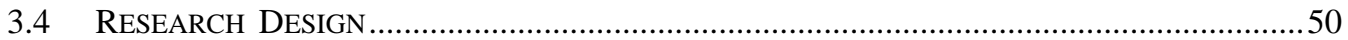

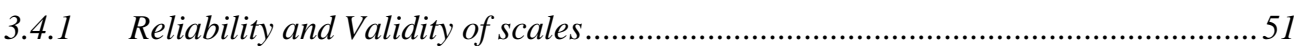

3.4.2 Inter- and Intra-rater reliability for the scoring of tooth wear ................................51

CHAPTER 4 .................................................................................................................5

RESULTS

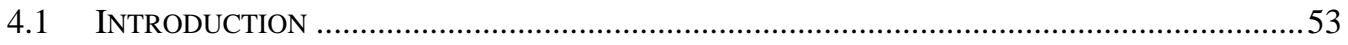

4.2 INTRA-RATER RELIABILITY FOR THE SCORING OF TOOTH WEAR .....................................54

4.3 THE RELATION BETWEEN THE DIFFERENT PSYCHOLOGICAL AND PHYSIOLOGICAL

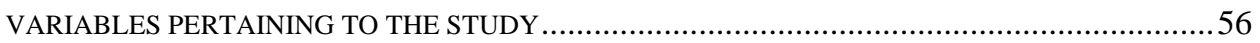

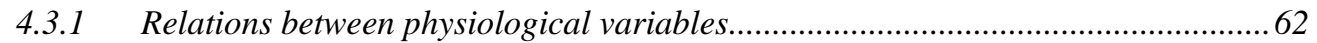

4.3.2 Psychological versus physiological variables .................................................. 73

4.3.3 Psychological versus psychological variables ................................................... 78

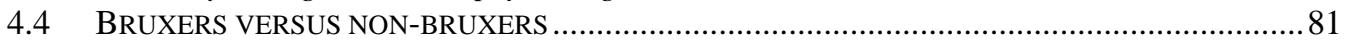

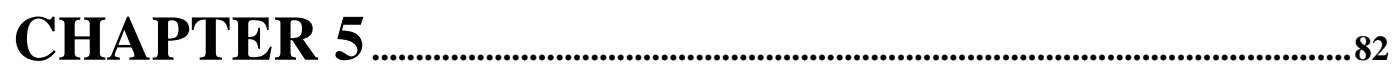

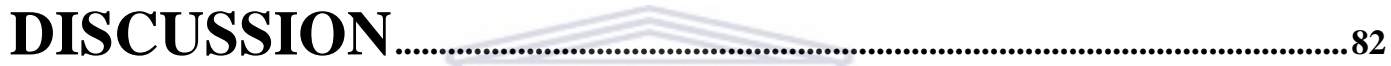

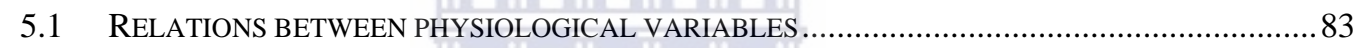

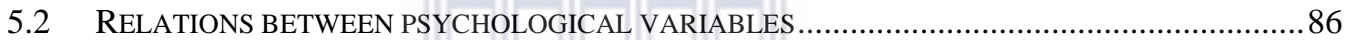

5.3 RELATIONS BETWEEN PSYCHOLOGICAL AND PHYSIOLOGICAL VARIABLES ...........................87

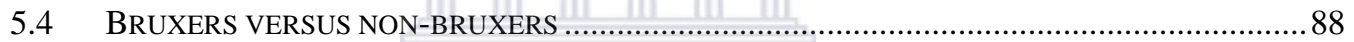

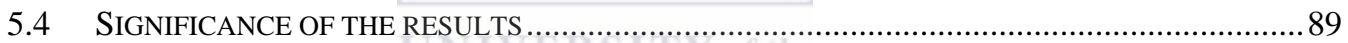

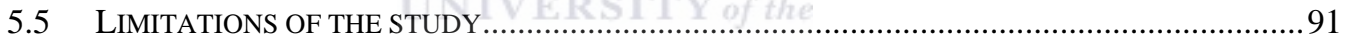

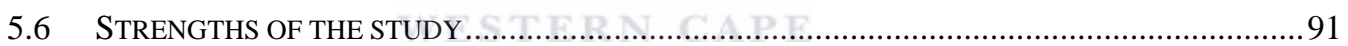

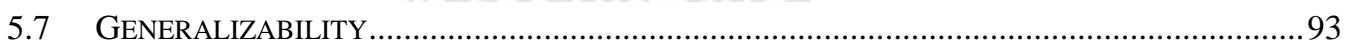

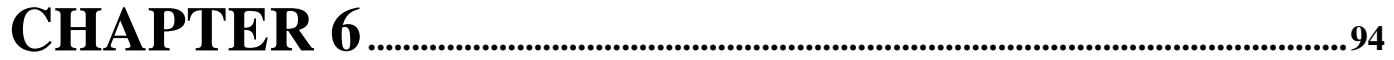

CONCLUSIONS AND RECOMMENDATIONS ....94

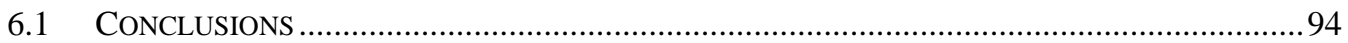

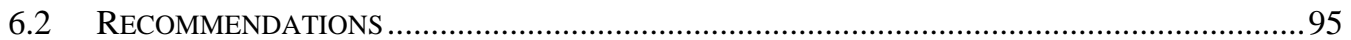

6.3 PRACTICAL IMPLICATIONS AND POSSIBLE TREATMENT APPROACHES ...................................96

REFERENCES ............................................................................................................

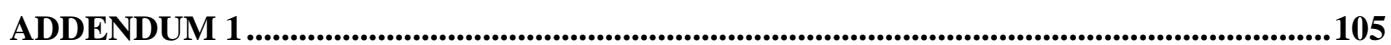

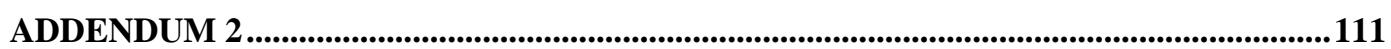

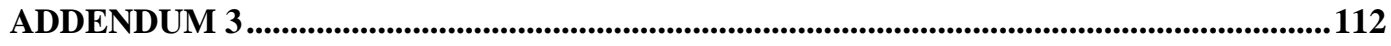

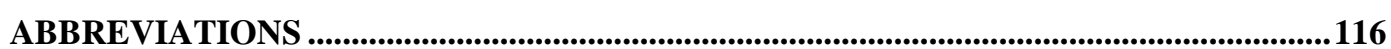




\section{List of Figures}

Figure 1. Schematic model of anxiety (Tyrer \& Seivewright, 1985).................. 20

Figure 2. Mind map showing the relations found in the study between psychological and physiological variables................................................... 53

Figure 3. Mind map showing the relations found in the study between physiological variariables 54

Figure 4. Scatter plot indicating the relation between the Anterior Mean tooth wear scores of the maxilla and the mandible

Figure 5. Scatter plot indicating the relation between the MeanTooth wear score of the Maxilla and age................................................................................. 65

Figure 6. Scatter plot showing the relation between Trismus (mouth opening) and

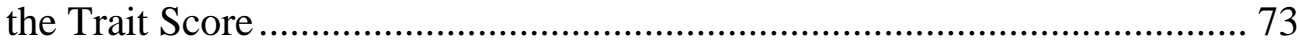

Figure 7. Scatter plot indicating the relation between the TraitY2 scores and the Bruxism Score .................................................................................... 75

Figure 8. Scatter plot indicating the relation between the State Y1 scores and the

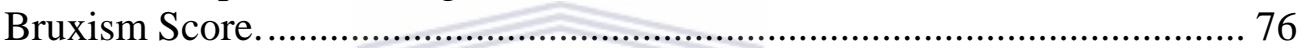

Figure 9. Scatter plot indicating the relation between the Kessler 10 score and the Brux Index.

Figure 10. Scatter plot on the relation between Kessler 10 and Trait Y2 scores . 78

Figure 11. Scatter plot of the relation between the Trait Y2 and State Y1 scores 79

Figure 12. Scatter plot of the relation between the Kessler 10 and State Y1 scores

Figure 13. Mind map showing the relations between the variables in the study .. 83 


\section{List of Tables}

Table 1. Causes of bruxism (Balatsouras et al., 2004) ..................................... 10

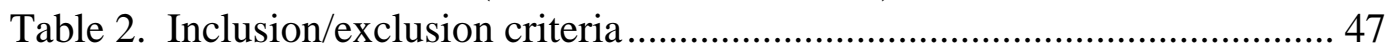

Table 3. Ordinal scale used for grading severity of occlusal wear ...................... 49

Table 4. The concordance with respect to intra-rater agreement of the full dentition and the descriptive statistics thereof. (Concordance within readings on two occasions (10-14 days apart)............................................................................. 55

Table 5. Stem-and-leaf Diagram of the number of exact Concordances over ten maxilla specimens for Rater B .................................................................. 55

Table 6. Stem-and-leaf Diagram of the number of exact Concordances over ten Mandible specimens for Rater B............................................................. 56

Table 7. Spearman Rank Order Correlation Matrix on the relation between

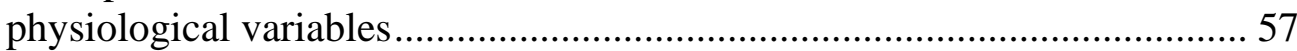

Table 8. Spearman Rank Order Correlation Matrix on the relation between Psychological \& Physiological Variables ..................................................... 58

Table 9. Spearman Rank Order Correlation Matrix on the relation between Psychological Variables

Table 10. Table created from data in an Analysis of variance report - KruskalWallis One-Way ANOVA on Ranks

Table 11. Table compiled from a Correlation Matrix using the Spearman Rank Order Sum

Table 12. Table showing the relation between tooth wear scores........................ 62

Table 13. Correlation between opposing tooth wear scores ............................... 63

Table 14. Table showing the descriptive statistics with respect to use of an Appliance; Gender and the Total Average of the Mandible Mean Score..... 65

Table 15. Table indicating the relation between appliance, gender and the Total Average of Maxilla Mean Score

Table 16. Table indicating the relation between the combined Diagnosis of Bruxism and TMJ Sensitivity (\#Yes) (defined by the number of "yes" answers to these questions), gender and Total Average of Mandible Mean Score.

Table 17. Table indicating the relation between the combined Diagnosis of Bruxism and TMJ Sensitivity (\#Yes) (defined by the number of "yes" answers to these questions), gender and Total Average of Maxilla Mean Score

Table 18. Table indicating the relation between Restless Legs, gender and Total Average of Mandible Mean Score

Table 19. Table showing the relation between Diagnosis of Bruxism /TMJ Sensitivity (\#Yes) (defined by the number of "yes" answers to these questions) and Average Bruxism Score

Table 20. Table indicating the relation between Restless Legs; Diagnosis of Bruxism /TMJ Sensitivity (\#Yes) (defined by the number of "yes" answers to these questions) and Total Average of Bruxism Score 


\section{Chapter 1 \\ Introduction}

\subsection{Overview}

Subjects clench or grind their teeth and many are not aware of the activity when it occurs during sleep and because they experience no discomfort or pain. They remain ignorant of the tooth wear associated with nonfunctional clenching/grinding unless observed by a dentist during a consultation. The subjects who do experience uncomfortable symptoms like jaw muscle pain or stiffness, possibly in conjunction with neck and shoulder pain/stiffness and headache, will consult a dentist who will check for occlusal problems and prescribe the use of an occlusal splint/appliance to be worn during sleep.

Although the use of a splint is effective for the prevention of further tooth wear during sleep, it does not necessarily eliminate the unconscious clenching/grinding activity nor the accompanying pain or discomfort (Koyano, Tsukiyama, \& Ichiki, 2005). At this stage the question arises as to the cause of the activity and what more can be done to address it.

The relation between the soma and the psych has been the focus of considerable research. Anxiety and stress can be physiologically manifested in different ways. Individuals show response-specific reactions to anxiety and stress.

Hyperactivity of the masseter muscles and consequent bruxism are considered to be physiological manifestations of psychological anxiety and stress (De Leeuw et al., 1994).

Bruxism is an oral parafunctional habit involving clenching and grinding of the teeth that occurs mainly unconsciously, diurnally and nocturnally. It is considered an important contributory factor in the aetiology of temporomandibular disorders (TMDs). The incidence of bruxism is 
conservatively estimated to be between $5 \%$ and $10 \%$ of the adult population (Hicks \& Chancellor, 1987; Pingitore, Chrobak, \& Petrie, 1991).

Bruxism has been described as a socially acceptable stress-releasing activity (Mikami, 1977) and researchers believed that psychological factors and stress play a major role in promoting and perpetuating bruxism (Biondi \& Picardi, 1993). Bruxism has also been defined as an anxiety response to environmental stress (Rosales et al., 2002; Slavicek \& Sato, 2004; Van Selms, Lobbezoo, Wicks, Hamburger, \& Naeije, 2004).

Although various studies have examined the relationship between bruxism and psychological factors and several models and theories have been developed to explain this relationship, the need for further research has been emphasized (Bracha, Person, Bernstein, Flaxman, \& Masukawa, 2005; Bracha, Ralston, Williams, Yamashita, \& Bracha, 2005; Lobbezoo, Van der Zaag, \& Naeije, 2006). A lack of uniformity makes it difficult to compare results, since different criteria for the diagnosis of bruxism and TMD are used. The use of subthreshold symptoms of anxiety does not feature in many articles.

The aetiology of bruxism is considered to be multifactorial, involving physiological and psychological factors. The close relationship between bruxism, temporomandibular pain and attrition (tooth wear) warrants an integrated approach which could be achieved through the new discipline called oral kinesiology, a multidisciplinary approach, that focuses on the diagnosis and treatment of TMD, bruxism, tooth wear and sleep disorders (Lobbezoo, Van der Zaag, Visscher, \& Naeije, 2004).

\subsection{Motivation for the study}

According to the spectrum model, subtle prodromal, atypical and subclinical (subthreshold) symptoms of anxiety can be measured on a continuum, which could play a role in the occurrence of a parafunctional habit like bruxism (Manfredini, Bandettini di Poggio, Cantini, Dell'Osso, \& Bosco, 2004). The Panic-Agoraphobic Spectrum (PAS) (Cassano et al., 
1997) and the Mood Spectrum (Moods-SR) (Manfredini, Bandettini di Poggio et al., 2004) both provide additional important clinical information on respectively panic and mood disorders thus complementing the information contained in the Diagnostic and Statistical Manual of Mental disorders ( fourth edition) (DSM IV). The dimensional approach used in the Spectrum model provides information on subthreshold (subclinical) symptoms that facilitates early diagnosis and treatment. This approach was therefore considered appropriate in this study since the identification of subthreshold symptoms of anxiety and stress in the aetiology of bruxism could likewise be beneficial.

Since bruxism has been considered a response to stress (Ahlberg et al., 2002; Bader \& Lavigne, 2000) and an anxiety response to environmental stress (Lobbezoo et al., 2004), by addressing the individual's "stress sensitivity" and enabling the person to handle stressors more effectively, the severity of bruxing behaviour could possibly be reduced.

The treatment of bruxism could thus be complimented by therapy or counseling which focuses on addressing the subthreshold symptoms of anxiety as either a contributory factor in the aetiopathogenises of the condition or as a comorbid variable which could have a negative effect on treatment. This is in line with the multidisciplinary dental discipline, oral kinesiology (Lobbezoo et al., 2004).

\subsection{Aims and objectives of the study}

The literature review identified a need for further study on the relation between bruxism, anxiety and stress and on the clinical relevance of spectrum subthreshold symptoms of anxiety. The research problem can therefore be formulated as follows: Are subthreshold symptoms of anxiety related to bruxing behaviour?

The aim of this study is to examine the relationship between psychological variables, namely anxiety and stress, and the physiological manifestation thereof in the parafunctional behaviour bruxism. 
The objectives of the study are as follows:-

- To determine a tooth wear score as a possible indicator of bruxism

- To determine the relation between physiological variables related to bruxism (e.g. type of tooth wear; diagnosis of bruxism; TMJ sensitivity; use of an appliance, etc)

- To examine the relation between bruxism and temporomandibular disorders (TMD) by including symptoms of TMD in the questionnaire (pain or tenderness in TMJ; trismus; jaw or muscle pain or fatigue on awakening)

- To consider the value of including physiological symptoms of bruxism in the DSM $V$ as part of the criteria for the diagnoses of anxiety-based disorders and Post-traumatic Stress Disorders (PSTD).

- To consider the value of using a Spectrum approach in determining subthreshold symptoms of anxiety for bruxers. 


\section{Chapter 2}

\section{Literature review}

\subsection{Introduction}

Bruxism is considered to be one of the most significant parafuntional activities of the stomatognathic system (Piquero \& Sakurai, 2000). Bruxers are not a homogenous group, but comprise several subgroups. For example: subjects with or without pain (Kampe, Tagdae, Bader, Edman, \& Karlsson, 1997); nocturnal and diurnal bruxists (Manfredini, Landi, Fantoni, Segu, \& Bosco, 2005); clenching-grinding type; clenchingonly type and grinding-only type bruxists (Manfredini, Landi et al., 2005). A distinction is also made between "strain" and "non-strain" bruxists. Nonstrain bruxists brux nocturnally and they grind their teeth, while strain bruxists clench their teeth as a stress response during the daytime according to Olkinuora's theory (Glaros, 1981). The diagnosis of bruxism can be difficult because often neither the patient nor the dentist is aware of the habit and clear signs and symptoms are not always present (Piquero \& Sakurai, 2000). The International Classification of Sleep Disorders (ICSD) classifies tooth grinding as being in the parasomnia group of sleep disorders. Bruxism usually occurs in non-rapid eye-movement sleep, mostly in stage 2 of the sleep cycle and during sleep-stage shifts. It also occurs during Rapid Eye Movement (REM) sleep with more frequent report of facial and dental pain (Ohayon, Li, \& Guilleminault, 2001).

Prevalence figures are uncertain since subjects are often unaware of their bruxing activity. It is likely that $95 \%$ to $90 \%$ of people will experience brief periods of nocturnal bruxism at some stage of their lives (Bader \& Lavigne, 2000). Often subjects are made aware of their parafunctional habit by sleeping partners, parents or others (Kampe, Tagdae et al., 1997). Certain 
studies on bruxism reported an 8 -10\% prevalence (Lobbezoo et al., 2004; Ohayon et al., 2001), while other studies conservatively estimated that between $5 \%$ and $10 \%$ of the adult population display bruxism (Hicks \& Chancellor, 1987; Pingitore et al., 1991). A twin study reported more bruxism in women than men and that the incidence of bruxism increases with age from 30 to 50 years (Koyano et al., 2005). Could the increased bruxism be due to increased life stress in these years?

\subsection{Clinical picture}

The clinical manifestations of bruxism include several factors as illustrated below (Balatsouras, Kaberos, Psaltakos, Papaliakos, \& Economou, 2004). The first three factors support a relation between bruxism and TMD because they are symptoms of TMD.

- Rigidity or fatigue of masticatory muscles (in the morning or on awakening at night).

- Sensitivity of temporomandibular articulation.

- Cranio-facial pain syndrome, with chronic headache, in particular of temporal region.

- Dental wear.

- Hypersensitivity of teeth to cold air or liquids.

- Feeling of weight in teeth.

- Frequent movements of mandible for no reason.

- Ulceration of oral mucosa behind molar teeth or border of tongue.

The high prevalence for stiffness in the jaw in the morning is indicative of nocturnal bruxism (Kampe, Tagdae et al., 1997). The symptoms of bruxism are directly related to the intensity and the persistence of the abnormal behaviour (Piquero \& Sakurai, 2000). Bruxism causes an overload on the masticatory system and is considered a causative factor for the following problems (Lobbezoo et al., 2004). : 
- dental problems such as toothwear (attrition);

- dental pain and restoration failures;

- periodontal problems such as reversible tooth mobility;

- and musculoskeletal problems such as joint pain and functional disturbances of the jaw complex

Nocturnal or sleep bruxism (SB) is characterized by a combination of clenching and grinding-type activity (Manfredini, Landi et al., 2005). It is associated with rhythmic masticatory muscle activity (RMMA) characterized by repetitive jaw muscle contractions (3 bursts or more at a frequency of $1 \mathrm{~Hz}$ ). RMMA is observed in $60 \%$ of normal sleepers (non-grinding subjects), thus SB could be an extreme manifestation of a masticatory muscle activity, since the RMMA in SB is three times more frequent and higher in amplitude and it is characterized by coactivation of both jaw-opening and jaw-closing muscles compared to the alternating pattern typical of chewing (Lavigne, Kato, Kolta, \& Sessle, 2003).

Questionnaires which include questions on teeth-grinding can be used to identify bruxism in the general population because teeth-grinding is considered a reliable indicator of nocturnal bruxism (Reding, Zepelin, \& Monroe, 1968).

Diurnal or awake bruxism is characterized by clenching-type activity (Manfredini, Landi et al., 2005) and is often associated with nervous tension or physical effort (Piquero \& Sakurai, 2000). The detrimental effects include facial pain, abnormal tooth wear, muscle tenderness on palpation and TMJ sensitivity. These effects are related to the intensity of the abnormal clenching activity (Piquero \& Sakurai, 2000).

Diagnosis of bruxism is difficult since often neither the patient nor the dentist is aware of the activity and clear symptoms/signs are not always present. Diagnosis of diurnal bruxism is a key factor for the 
success of dental treatment in denture wearers and it can be done by measuring the masseter EMG activity (Piquero \& Sakurai, 2000).

\subsection{Relation between bruxism and temporomandibular disorders}

Temporomandibular Disorders (TMD) and Craniomandibular Dysfunction (CMD) are collective terms both used for problems associated with the stomatognathic system (Okeson, 1996). Three symptoms define CMD (or $T M D$ ): 1) pain and tenderness of the masticatory muscles and temporomandibular joint (TMJ), 2) sounds in TMJ, 3) limitation of movements (De Leeuw et al., 1994). CMD (or TMD) may be diagnosed when one or more of these symptoms are present, but is not warranted on sounds alone (Laskin, 1969).

CMD (or TMD) is considered a multifactorial problem with 1) structural (occlusion), 2) functional (bruxism), and 3) psychological (anxiety, tension) factors as well as 4) trauma and arthritic deterioration as interrelated causes (Rugh, 1987; Solberg, 1986). In the absence of a clear somatic or traumatic cause, joint pain is assumed to be the result of muscle hyperactivity (Laskin, 1980).

CMD (or TMD) can have a myogenous component and/or an arthrogenous component.

- If it is athrogenous in nature it can be called Temporomandibular Joint Dysfunction Syndrome (TMJD).

- If it is myogenous in nature (no clinical or radiographic evidence of organic changes) it can be called Myofascial Pain Dysfunction Syndrome (MPD) (Laskin, 1969; Moss, Garrett, \& Chiodo, 1982). In the literature, another term is found for the myogenous subgroup of TMD: Masticatory Myofascial Pain (MFP) (Velly, Gornitsky, \& Philippe, 2003). MPD and MFP may thus be considered the same. 
Theoretically, due to chronic stress causing muscle hyperactivity, CMD (or TMD) with mainly a myogenous component may progress to CMD (or TMD) with both a myogenous and arthrogenous component or to CMD (or TMD) with a mainly arthrogenous component (Lundeen, George, \& Sturdevant, 1988).

Research results revealed a positive association between clenching, alone or combined with grinding, and chronic MFP (Velly et al., 2003); (Lobbezoo et al., 2004). Parafunctional behavior, such as bruxism, and increased muscle tension are considered good predictors of TMD. TMD related symptoms such as TMJ sounds, difficulty in opening the mouth, stiffness or fatigue in the jaw and pain on movement were found in bruxers. Therefore, treatment focusing on reducing parafunction, muscle tension, stress and emotional distress should reduce symptoms of TMD (Glaros, Williams, \& Lausten, 2005). The fact that bruxism leads to prolonged stimuli and mechanical and neuromuscular activity of the masticatory system could render it a causal factor in facial pain and TMD (Ciancaglini, Gherlone, \& Radaelli, 2001). Although Manfredini and coworkers (2003) also found a positive association between bruxism and some TMD symptoms (in particular pain), they could not confirm that bruxism was the cause of these symptoms.

Apart from being positively associated with TMD symptoms, bruxism is also indicated in the destruction of the dentition by causing excessive tooth wear with its negative effects on comfort and appearance (Lobbezoo et al., 2004). Early diagnosis and management of the etiological factors of bruxism may therefore also positively impact on these conditions.

\subsection{Aetiology of bruxism}

The aetiology of bruxism is multifactorial, involving anatomomorphological, psychophysiological, pathophysiological factors, and other 
causes which are illustrated in Table 1 . Only certain aetiological factors pertaining to this study will be discussed.

Table 1. Causes of bruxism (Balatsouras et al., 2004)

\section{Anatomo-morphological factors}

Dental occlusion anomalies (malocclusion)

- Various morphological types of malocclusion

- Functional malocclusion

Anomalies of the oro-facial region

- Condyle height asymmetry

- Larger cranial and bizygomatic widths

- Rectangular form of dental arch of maxilla

- Rectangular morphology of face

2. Psychophysiological factors

- Stress (emotional, physical, psychosocial)

- Anxiety (states of anxiety, psychosocial)

- emotional disorders

- psychosomatic disorders

- personality disorders (hyperactivity, rage, aggressiveness, perfectionist tendency)

3. Pathophysiological factors

- sleep disorders

- Poor quality of sleep

- Micro arousal episodes (short awakening)

- Frequent movements of body

- Behaviour disorders during REM sleep

- Periodic movements of feet

- Agitated sleep syndrome

- Sleep apnoea syndrome

- Sleep epilepsy

- Sleepiness during the day

- Rhythmic muscular activity of masseter muscles

- sensitivity disorders of central dopaminergic neurotransmission 


\section{Other causes}

- genetic predisposition

- allergy (allergic rhinitis, bronchial asthma, swallowing of allergenic foods)

- hemifacial spasm

- various syndromes (Gilles de la Tourette S., Rett S., Shy-Drager S.)

- Whipple disease

- Neurological disease (brain haemorrhage, coma, Huntington disease, Parkinson disease, olivopontocerebellar atrophy)

- Oromandibular dystony

- Drug intake

- Antidepressants (SSRI) (Fluoxetine, sestraline, paroxetine)

- Chronic use of neuroleptic and levodopa

- Amphetamine and analogous drugs (OCT)

- Smoke and alcohol abuse

\section{Anatomo-morphological factors}

A literature review published in 1969 failed to present a correlation between bruxism and the presence of malocclusion (Olkinuora, 1969).

Also more recently, anatomical or occlusal factors could not be indicated as significant etiological factors: no differences in the dentofacial (Menapace, Rinchuse, Zullo, Pierce, \& Shnorhokian, 1994) and craniofacial (Young, Rinchuse, Pierce, \& Zullo, 1999) morphology between bruxers and non-bruxers could be found. Research results showed that occlusal variables were not useful for discriminating between bruxers and non-bruxers (Manfredini, Landi, Romagnoli, \& Bosco, 2004) . The results of these studies support the central regulation theory rather than a peripheral regulation theory (Lavigne, Rompre, \& Montplaisir, 1996); (Lobbezoo \& Naeije, 2001); Manfredini, Landi, et al. 2003). 


\section{Pathophysiological factors}

\section{Neurobiological factors in the etiology of clenching-grinding spectrum disorders}

The following information was considered important to this study since the postulated relation between bruxism, anxiety and stress could possibly be confirmed by the following findings: Catecholamines (or biogenic amines) refer to a class of compounds that includes norepinephrine, epinephrine and dopamine. Catecholamines affect mood. Dopamine is thought to affect motor function, regulation of muscle contractions and emotions. Another neurotransmitter, serotonin causes contraction of smooth muscle and may play a role in sleep and mood states. The pons (a bridge between the medulla and the cerebellum) contains nuclei of cranial nerve $\mathrm{V}$ and helps regulate chewing. In order to help the body to cope with stress, the adrenal medulla releases epinephrine and norepinephrine which increase strength of muscle contraction (Nevid, Rathus, \& Greene, 2003; Solomon, Schmidt, \& Adragna, 1990).

Clenching-grinding, sleep bruxism and temporomandibular disorders are linked and the neurotransmitters norepinephrine (NE), glutamate and dopamine are implicated in the clenching-grinding spectrum disorders (Bracha, Person et al., 2005).

The central dopaminergic system may play a role in the pathophysiology of sleep bruxism (Lobbezoo, Soucy, Montplaisir, \& Lavigne, 1996). Epinephrine and dopamine were found to be significantly and strongly associated with bruxism, providing support for the view that emotional stress is a significant factor in the development of bruxism in children (Vanderas, Menenakou, Kouimtzis, \& Papagiannoulis, 1999). Dopamine is one of the neurotransmitters that could play a role in oral movement. Results indicate that dopaminergic fibres may alter central nucleus of the amygdale (CeA) neurons which supply areas related to oral motor control 
(Mascaro, Bittencourt, Casatti, \& Elias, 2005). In rats, stress induction led to an increase in dopaminergenic transmission in the striatum and parafunctional masticatory activity seems to reduce the amplitude thereof (Gomez et al., 1999). Changes in basal ganglia activity may occur due to an imbalance of dopamine, resulting in jaw motor dysfunctions. This could play a role in bruxism. Oral facial movements may thus be regulated by catecholamines such as dopamine, through the premotor brainstem nuclei, which are related to masticatory control, and forebrain areas related to autonomic and stress response (Mascaro et al., 2005).

In subjects who displayed both diurnal (non-sleep) and nocturnal bruxism, hypersensitive presynaptic dopamine receptors may play a role (Chen, Lu, Lui, \& Lui, 2005).

In the brainstem, the pontine reticular nucleus oralis is a region involved in motor control of mastication. Activation of this latter structure may partly explain the bruxism * reported by 3,4-methylenedioxymethamphetamine (Ecstacy) users (Stephenson, Hunt, Topple, \& McGregor, 1999).

\section{Nerves related to the mandible}

The trigeminal nerve $(\mathrm{V})$, the largest cranial nerve, is attached to the pons by a large sensory root and a small motor root. The sensory root carries information from among other, the teeth, mouth, and temporomandibular joint. The motor root joins the mandibular nerve (V-iii). It supplies the four muscles of mastication (temporalis, masseter, medial and lateral pterygoids). The mandibular nerve ( $\mathrm{V}$-iii) arises from the brain-stem by a sensory and motor root. The sensory root bears the trigeminal ganglion, from which the sensory mandibular nerve emerges to join the motor root, thus forming the mixed mandibular nerve (Viii) (Moore, 1980; Tobias \& Arnold, 1977). 


\section{Sleep disorders}

Sleep bruxism occurs during sleep-stage shifts, particularly in Stage 2 of the sleep cycle and in the REM stage and is considered the oro-motor manifestation of micro-arousal. Sleep RMMA occurs in relation to transient activation of cortical, limbic and autonomic circuits. The prevalence of most anxiety disorders, sleep bruxism and presumably other clenchinggrinding behaviours peaks between 25 and 44 years of age, indicating a possible relation between them (Bracha, Person et al., 2005).

\section{Restless Leg Syndrome}

A study on the association between reported bruxism and restless leg syndrome (RLS) concluded that RLS may negatively influence sleep quality which could affect the frequency of bruxism (Ahlberg et al., 2005). A review by (Bader \& Lavigne, 2000) considers Restless Leg Syndrome and tooth grinding as concomitant but independent sleep movement disorders. This is also confirmed by another study (Porvazova \& Bassetti, 2007).

\section{Muscular activity of masseter muscles}

The relationship between stress and masseter muscle activity will be clearly explained in the section on theories of the aetiology of bruxism. 


\section{Psychological and psychosocial factors}

Numerous research studies have been conducted to investigate the psychological and psychosocial factors involved in the multifactorial aetiology of bruxism. These factors can be grouped into personality type, anxiety, stress (reaction to stress) and mood.

\section{Personality Type}

A small group of unusually competent, successful and effective women with bruxism were found to be exacting, perfectionistic, obsessive, domineering and hostile (Moulton, 1955). In contrast to these findings, research on personality traits of bruxers, revealed that chronic bruxers were shy, stiff, cautious, aloof, rigid, affected by feelings of inferiority, impeded in expressing themselves, apprehensive, and given to worry (Fischer \& O'toole, 1993). These diverse findings do not link bruxism to a specific personality type.

Research findings also do not show statistically significant personality differences between bruxists and controls (Reding et al., 1968). Certain researchers state that the lack of controlled studies, makes it difficult to determine a clear characteristic behavioural pattern or personality traits for sleep bruxism (SB) subjects (Bader \& Lavigne, 2000).

However, there seems to be a relation between bruxism and Type $A$ behaviour. A study (Theorell, Harms-Ringdahl, Ahlberg-Hultén, \& Westin, 1991) found that muscle tension, chewing muscle tension and Type $A$ tension correlates with anger and worry. The Type $A$ individual may be less able to cope with psychological stress due to being chronically more aroused as a result of characteristics such as: exaggerated sense of time urgency; constant struggle for achievement; and high levels of aggressiveness (Hicks \& Chancellor, 1987). The view that bruxism is a 
tension-reducing response that is learned in association with stress could be used to argue that Type A persons who experience chronic levels of stress would be more likely to acquire the habit of bruxism. Type $A$ behaviour is generally a coping style characterized by an extreme desire to control life events that would result in periods of extreme stress that is typically denied by the Type A individual. High bruxing activity is likely to be related to a lack of awareness regarding stressful life events. Type A behaviour increases the risk for stress-related disease because it limits the range of coping strategies for the management of stressful events. Research results showed a positive association between the incidence of bruxism and level of Type A behaviour (Hicks, Conti, \& Bragg, 1990; Pierce, Chrisman, M.E., \& J.M., 1995; Pingitore et al., 1991). It was concluded that stress in conjunction with Type A behaviour was predictive of bruxism. Their results show that behaviour and lifestyle are related to bruxism and that some individuals will continue to brux, despite correction in their dental condition.

The inconsistencies revealed from different personality studies illustrates the need for more research concerning the aetiological significance of psychological factors in bruxism (Kampe, Edman, Bader, Tagdae, \& Karlsson, 1997).

\section{Anxiety}

Anxiety can be defined as an unpleasant emotional state that includes experiential, physiological and behavioural components (Spielberger, 1983).

The feeling of anxiety involves the integration of a background state of physiological and cortical arousal, the process of cognitive labelling and environmental factors to define the emotion experienced by the person (Tyrer \& Seivewright, 1985). This is illustrated in Schachter and Singer's theory. According to their theory the state of arousal leads to an undifferentiated affect which the individual labels using perceptions of the 
present situation and information from past experience to interpret the physiological sensations (Schachter \& Singer, 1962).

The symptoms of anxiety are both psychological and somatic. The psychological symptoms are: apprehension; nervous tension; fear of catastrophe; insomnia; distractibility; inability to concentrate; irritability. Somatic symptoms can be distinguished as autonomic and nonautonomic. Muscular tension is regarded as a non-outonomic symptom of anxiety.

The effect of anxiety on function enables one to distinguish between normal and pathological anxiety. In normal anxiety, these symptoms are appropriate reactions to threatening situations. However, in abnormal anxiety the symptoms occur independently of the stressor or they are inappropriately severe considering the nature of the stressor (Tyrer \& Seivewright, 1985). Pathological anxiety is characterized by avoidance of situations perceived as harmful, exaggerated reactions to threat and a bias to interpret ambiguous situations as threatening (Wood \& Toth, 2001).

The cognitive perspective focuses on the role of dysfunctional thought patterns in the development of anxiety disorders. Therapy would focus on changing these thought patterns to reduce anxiety. The following styles of thinking are linked to anxiety disorders (Nevid et al., 2003):-

\section{- Over-prediction of fear}

The tendency to expect the worst leads to avoidance of the feared situation, preventing the individual from learning to overcome and manage anxiety.

\section{- Self-defeating or irrational beliefs}

These thoughts intensify autonomic arousal, disrupt planning, magnify the threat, lead to avoidance behaviour and decrease self-efficacy perceptions regarding one's ability to control a situation. 


\section{- Over sensitivity to threat}

This is a cardinal feature of anxiety disorders, which leads to inappropriate anxiety reactions and reduces the individual's ability to effectively cope with threats.

\section{- Anxiety sensitivity}

This refers to a fear of anxiety and anxiety-related symptoms

- Misattribution of bodily cues

This further reinforces perceptions of threat, which further heightens anxiety, leading to more anxiety-related bodily symptoms, thus forming a vicious cycle.

\section{- Low self-efficacy}

The individual who believes that he lacks the ability to handle stressful challenges, will be more anxious when faced with challenges.

\section{Neurochemical and neuroanatomical aspects of anxiety}

The limbic system, and specifically, the septo-hippocampal system is the part of the brain most intimately concerned with anxiety. Two afferent pathways, namely the noradrenergic afferents from the locus ceruleus and the serotonergenic afferents from the raphe nuclei, may play a major role, since anxiety-provoking stimuli increase activity in both of these (Tyrer \& Seivewright, 1985).

The involvement of serotonin, norepinephrine, dopamine and neuropeptide transmitter systems has been indicated in the pathophysiology of anxiety (Wood \& Toth, 2001). The neurotransmitters norepinephrine and dopamine are also implicated in the clenching-grinding spectrum disorders (Bracha, Person et al., 2005). This connection is important in considering the relation between bruxism and anxiety. 
Certain neurochemical and neuropeptide systems have effects on cortical and subcortical brain areas that are relevant to the mediation of symptoms associated with anxiety (Neumeister, Daher, \& Charney, 2005).

Besides, serotonin and norepineprine, gamma-aminobutyric acid (GABA) is one of the neurotransmitters involved in anxiety reactions. It is an inhibitory neurotransmitter since it tones down excess acitivity in the nervous system and helps to suppress stress responses (Nevid et al., 2003).

\section{Sources of anxiety}

Normal anxiety and acute stress reactions are due to aversive stimuli and external threat. In pathological anxiety internal stimuli often play an important role, for example, insecurity due to past experiences (particularly separation), a genetic predisposition to anxiety or unresolved psychological conflicts. The individual is often not consciously aware of these stimuli (Tyrer \& Seivewright, 1985).

The schematic model (Figure 1) illustrates the neuropsychology of anxiety. Anxiety may be provoked by both external and internal stimuli. The bodily consequences of previous anxiety can also be important internal stimuli and their anxiety content is examined at the level of the limbic system, most probably the septo-hippocampal system specifically. The form of the anxiety is partly dependent on cognitive elaboration. The perceived anxiety has both bodily and psychological components, since arousal is increased and both the adrenocortical and sympathetic nervous systems are activated simultaneously (Tyrer \& Seivewright, 1985). 


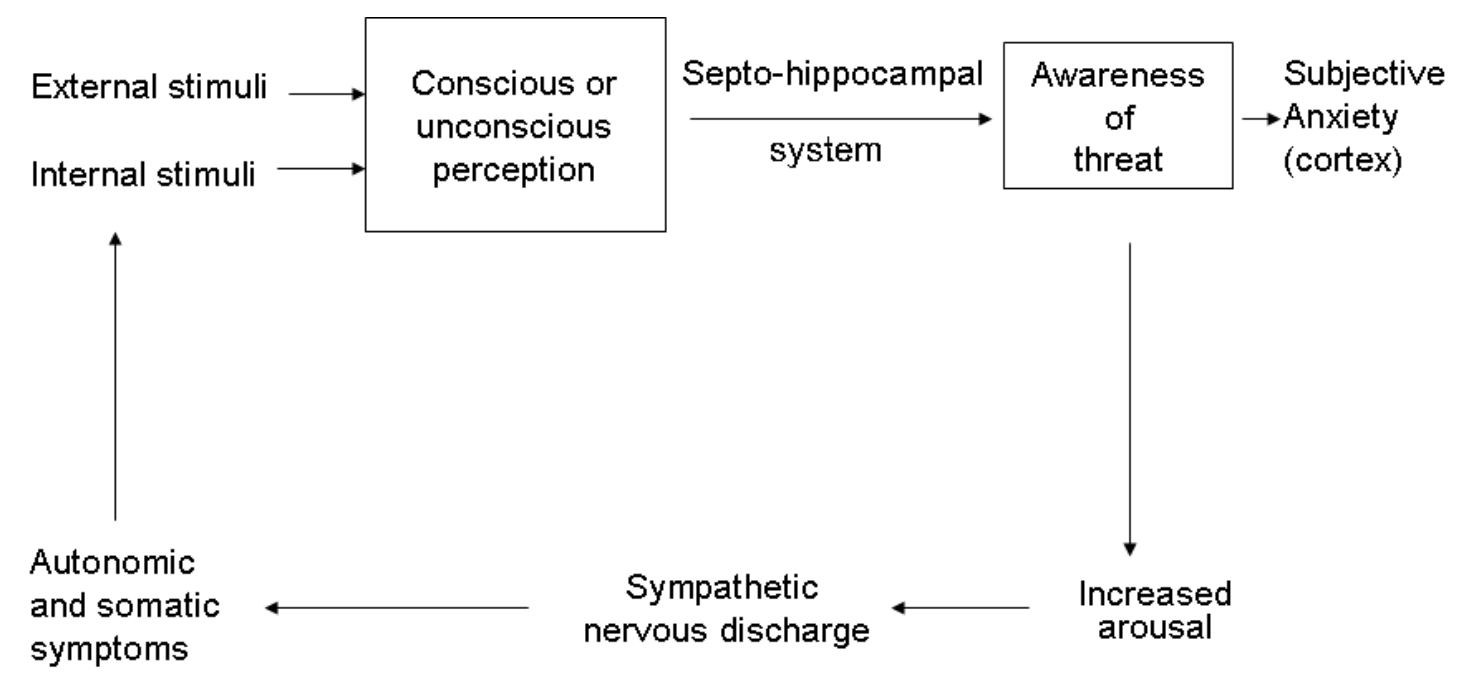

Figure 1. Schematic model of anxiety (Tyrer \& Seivewright, 1985)

(The word autonomic (bottom left in the diagram) should read "psychological").

\section{State and trait anxiety}

State anxiety is a transitory emotional state that may vary in intensity and fluctuate over time, characterized by subjective, consciously perceived feelings of tension and apprehension, as well as heightened autonomic nervous system activity. It occurs in the face of threatening demands or dangers and cognitive appraisal of the situation as a threat is a prerequisite for the experience of state anxiety. Trait anxiety refers to a general tendency to become anxious when threats are perceived in the environment, reflecting stable individual differences in the reaction to threatening situations (Spielberger, 1983).

\section{The relation between anxiety and bruxism}

A report based on psychiatric interviews (Moulton, 1955) linked the following factors to bruxism:- Anxiety, expressed with physical symptoms; chronically tense life situations; emotional stress; and repression of anger due to dependence was evident in the majority of cases. A correlation was found between (1) anxiety, (2) an intra-punitive reaction to frustration and 
(3) bruxism (Thaller, Rosen, \& Saltzman, 1967). It was found that patients with tooth-wear due to bruxism and chronic MFP presented significantly more trait anxiety than controls (Velly et al., 2003). Significant associations between mood, anxiety, adjustment disorders, highly stressful life events and tooth grinding were observed. In one study it was found that anamnestically diagnosed bruxism is not only associated with a transitory state of anxiety, but also with certain psychopathologic symptoms of the anxiety spectra (Manfredini, Landi et al., 2004). There is thus a need for further study of the supposed bruxism-anxiety association in terms of whether the presence of subthreshold manifestations of the anxiety spectrum are an important factor in the pathogenesis of bruxism or a comorbid subclinical entity (Manfredini, Landi et al., 2005).

In neuropsychiatry, signs of jaw clenching may indicate current subjective emotional distress and accelerated tooth wear may assist in detecting or substantiating long-lasting anxiety. The inclusion of physical signs such as grinding-induced incisor wear and clenching induced palpable masseter tenderness into the Diagnostic and Statistical Manual of Mental Disorders, Fifth edition (DSM-V) anxiety disorders criteria as well as sub-criteria of Post Traumatic Stress Disorder (PSTD) should be considered. A need for early detection of clenching-grinding in anxiety disorder clinics was emphasized (Bracha, Ralston et al., 2005). In a study (Velly et al., 2003), higher levels of anxiety were associated with chronic MFP (myofascial pain). Treatment of anxiety would reduce the severity of bruxism and chronic MFP. The need for further studies on the interaction between psychological factors and bruxism was emphasized. Research results support the view that anxiety state is a prominent factor involved in the development of bruxism in children (Monaco, Ciammella, Marci, Pirro, \& Giannoni, 2002). 


\section{Stress (Reaction to stress)}

A relation between stress and bruxism was found (Ahlberg et al., 2002). Difficulty in coping with life stress may predispose individuals to TMD triggered by bruxism. Bruxism could thus be an indication of a stress disorder. Bruxism has been defined as an anxiety response to environmental stress (Rosales et al., 2002; Slavicek \& Sato, 2004; Van Selms et al., 2004). Researchers believe that psychological factors and stress play a major role in promoting and perpetuating bruxism (Biondi \& Picardi, 1993). A case study (Van Selms et al., 2004) confirms the paradigm that experienced stress may be related to daytime clenching and to evening and morning jaw muscle pain. A study (Ahlberg et al., 2002) reported that frequent bruxism may be related to ongoing multifactorial stress in normal life and work.

A study (Rosales et al., 2002) revealed a relationship between emotional stress and bruxism in rats. Emotional stressors induce masseter muscle contractions. While results of studies on animals cannot necessarily be applied to humans, they concluded that difficulty in coping with life stress might predispose individuals to TMD triggered by bruxism.

Notable changes were observed in the hemodynamic parameters in the masseter muscle (Hidaka, Yanagi, \& Takada, 2004) indicating that hemodynamics of jaw muscles is susceptible to mental stress. This implies a potential relationship between jaw muscle dysfunction and mental stress.

Bruxism is considered as an outlet for internal tension and stress (Marbach, 1996). Bruxism is seen as a subconscious attempt to work off psychic tension. Due to the overwhelming literature linking bruxism to stress, it can be concluded that bruxism is centrally regulated, not peripherally (Lobbezoo \& Naeije, 2001). It was found that psychological stress aggravated bruxism (Hartmann, Mehta, Forgione, Brune, \& LaBrie, 1987). Chronic muscle pain around the TMJ is considered to be 
associated with emotional stress and bruxism (Harness \& Rome, 1989). Researchers hypothesized that TMD patients' susceptibility or response to stress differs from controls. Higher percentages of tooth clenching, grinding and muscular discomfort or pain were reported in the TMD group (Hagberg, Hagberg, \& Kopp, 1994). A study (Ohayon et al., 2001) investigated the relationship between sleep bruxism and DSM-IV mental disorders. They found significant associations with mood, anxiety and adjustment disorders. Highly stressful life events were also significantly related to tooth grinding. Stress and anxiety are known factors for exacerbating sleep bruxism (Funch \& Gales, 1980). Manfredini, Landi et al. (2004) confirmed that certain psychic traits are present in bruxers. In males, mood and panic-agoraphobic spectra symptoms differentiate bruxers from controls. In females strong differences for stress sensitivity symptoms were noted. Results showed that bruxers appear to be more sensitive to stress than non-bruxers, indicating a need for studies on the subjective susceptibility to emotional factors (Manfredini, Ciapparelli, Dell'Osso, \& Bosco, 2005).

The clenching and bruxing function of the masticatory organ was considered as an emergency exit during periods of psychic overloading contributing to the individual's ability to manage stress (Slavicek \& Sato, 2004). Bruxism in proper dentition is considered a valid system prophylaxis for all stress related diseases. Results indicate a potential role of mental stress in the etiology of jaw muscle dysfunction (Hidaka et al., 2004).

The principle of individual response specificity, may explain why certain individuals clench/grind their teeth in response to a stressor (Nevid et al., 2003).

The ways in which we handle stress determine our ability to cope with it. In order to reduce stress we need to learn to handle stress more effectively through stress-management counseling. The following factors influence how we handle stress (Nevid et al., 2003):- 


\section{Coping styles}

- Emotion-focused coping: This style of coping does not eliminate the stressor. Subjects reduce the immediate impact of the stressor by denial, avoidance, wish-fulfilment fantasies or withdrawal from the situation.

- Problem-focused coping: In this style of coping subjects examine the stressors, do what they can to change them or modify their reactions to render the stressors less harmful.

- Self-efficacy expectancies (beliefs in one's ability to handle stress): High self-efficacy appears to be associated with lower secretions of catecholamines, making subjects who believe they are capable of coping with a stressor less likely to feel nervous.

- Psychological hardiness: The concept refers to a cluster of stressbuffering traits which include the following:-

Commitment - Hardy subjects are involved in tasks and believe in what they are doing.

Challenge - Seeing change as a challenge and as a normal part of life makes one hardier.

Control - Subjects who have an internal locus of control perceive themselves as having control over their lives and tend to cope more effectively with stress by using more active, problem-solving approaches. In contrast, subjects with an external locus of control perceive that external factors are responsible for their experiences, rendering them to feelings of helplessness.

- Optimism and Social support: A positive attitude fosters hardiness and subjects who experience social support are better able to cope with stressors. 


\section{Mood}

A significantly higher mood psychopathology score (mostly subthreshold symptoms) on the Mood Spectrum Self-Report (MOODS-SR) was found in bruxers. Further studies were considered essential to clarify mechanisms underlying the association between bruxism and mood disorders (Manfredini, Ciapparelli et al., 2005). A spectrum approach was also used in a study on TMD patients in which a significantly higher prevalence of mood symptoms was found in myofascial pain patients (Manfredini, Bandettini di Poggio et al., 2004). These results confirm the value of using a Spectrum approach to examine the relation between bruxism and subthreshold symptoms of anxiety.

\subsection{Theories on the aetiology of bruxism}

\section{Psychoanalytic theory}

According to psychoanalytic theory bruxism is the result of tension and stress producing sources and serves as a release mechanism for overt aggression. Feelings of frustration and rage due to blocked individual drives, find expression in bruxism (Mikami, 1977). According to the psychodynamic approach, bruxism relates to the discharge of oralaggressive drives (Reding et al., 1968). The carry-over of bruxism from childhood into adulthood has been considered as the reason for mental stability (Pond, 1968). The term "strain bruxism" was formulated for patients who admit a connection between bruxism and mental efforts, difficulties and worries (Olkinuora, 1972).

\section{A stress-related muscular hyperactivity theory of MFP}

Research studies indicate the existence of a response-specific (i.e. masticatory muscles) reaction to stress in MFP patients (Haber, Moss, Kuczmierczyk, \& Garrett, 1983; Rosales et al., 2002). Psychological and/or physical stress leads to increased activity of the masticatory muscles 
(Haber et al., 1983). Physical stress is the direct result of some physical activity or event, while psychological stress results from the individual's subjective interpretation of an event. Support for a stress-related muscular hyperactivity theory of MFP is provided by researchers who found increases in activity in masseter and temporal muscles of dental students when questioned about their future performance during professional assessment (Perry, Lammie, Main, \& Teuscher, 1960). Other research results (Yemm, 1971) also showed increases in the activity of the jawclosing muscles due to experimentally induced stress and suggested that MFP patients exhibit tension in the masticatory muscles as a characteristic response to life stress. These results indicate the existence of a response-specific (i.e. masticatory muscles) reaction to stress in MFP patients. The need for further research on the assessment of stress as a factor in MFP was mentioned. A study found that muscle tension, Chewing muscle tension and Type A tension correlates with anger and worry (Theorell et al., 1991). Several studies found a relation between bruxism and muscle tension (Kampe, Edman et al., 1997; Kampe, Hannerz, \& Ström, 1996). Emotional factors such as anxiety, fear, frustration and emotional stress have been recorded in a clear relationship with muscular hyperactivity (Yemm, 1969).

Harber's conceptual model of psychological stress (Haber et al., 1983) may be used to better determine the degree to which stress is involved in MFP. With psychological stress the response depends on the individual's interpretation of the event. The conceptual model illustrates that increased masticatory activity can result in pain which is likely to be positively or negatively reinforcement. De Leeuw et al (1994) discuss Haber's conceptual model of stress-induced symptoms of TMD (craniomandibular dysfunction), in which excessive stress results in masticatory muscle hyperactivity. This hyperactivity is expressed in tooth grinding and clenching which can lead to the major symptoms of TMD. In this study, Haber's model was extended to include the impact of coping. 
The increased masticatory muscle activity responsible for tooth contact and tension may be an important mechanism in the etiology and maintenance of myofascial pain in TMD patients (Glaros, Williams, Lausten, \& Friesen, 2005).

\section{Bruxism as a centrally mediated disorder}

Bruxism appears to be mainly regulated centrally, not peripherally. Central etiological factors associated with bruxism are pathophysiological and psychological factors. Peripheral (morphological) factors related to bruxism refer to occlusal and articulation discrepancies and anomalies in the anatomy of the orofacial region.

Malocclusion does not increase the probability of bruxism (Khan, Young, \& Daley, 1998). Occlusal adjustment does not stop bruxism. No significant difference in occlusion is seen in bruxism and control groups. While an occlusal splint which covers the occlusal surface of the dentition may not stop bruxing behaviour, tooth wear is minimized by using it (Koyano et al., 2005).

Pathophysiological factors refer to the relation between bruxism and the sleep arousal pattern, neurotransmitters in the central nervous system and disturbances in the central dopaminergic system. Psychological factors refer to the relation between bruxism and stress, personality, etc (Lobbezoo \& Naeije, 2001). The investigation into the significance of a relationship between subthreshold manifestations of the anxiety spectrum and bruxism must be interpreted according to the theory that bruxism is a centrally mediated multifactorial disorder which could share certain neurological deficits with other centrally mediated disorders (Manfredini, Landi et al., 2005).

\section{Spectrum approach}

The concept "spectrum" refers to a group of signs, symptoms and behaviours that persist, to a higher or lesser degree throughout the 
lifespan. These clinical features shape the individual's ongoing experiences (Shear et al., 2001). The DSM $1 \mathrm{~V}$ diagnostic criteria may not provide sufficient information on clinically significant symptoms. A validated spectrum model has been adopted which assesses subtle prodromal, atypical, subthreshold and subclinical symptoms and associated features including signs, isolated symptoms, symptoms clusters and behavioural patterns related to the core symptoms; temperamental; and/or personality traits associated with a given DSM axis-1 disorder. Clinical evaluation and treatment strategies could be improved by the spectrum model with the use of new assessment instruments, namely the MOODS-SR and Panic-agoraphobic spectrum self-report (PAS-SR) (Manfredini, Bandettini di Poggio et al., 2004). The panic-agoraphobic spectrum is a culturally transferable construct with important clinical implications for patients with mood and anxiety disorders (Shear et al., 2002). The panic-agoraphobic spectrum model complements the categorical approach and expresses a unitary pathophysiology. It is considered useful in terms of patient-therapist communication (Cassano et al., 1997). Likewise, the mood spectrum model provides a unitary view of mood disturbance (Cassano et al., 2002). The Spectrum Project has been developed to address the fact that knowledge of the clinical implications of prodromal, co-occurring and residual symptomatology is limited (Beroccal et al., 2005).

\section{Other theories}

A neuro-evolutionary perspective supports the view that clenching and grinding may be a manifestation of experiencing acute fear or chronic emotional distress (Bracha, Ralston et al., 2005). The strengthening of oro-facial muscles for survival in early man through jaw clenching, may be the basis of clenching-grinding spectrum disorders and masticatory muscle pain. Explaining to the patient the archaic origins of bruxism may enhance their understanding of the condition (Bracha, Person et al., 2005). 
Interactional stress theories emphasize that personality variables and coping style determine an individual's interpretation of and reaction to environmental stressors. The individual's perceptual and cognitive processes interact with the environmental aspects to change the impact of stressors. Few studies have used an interactional stress approach to investigate psychosocial correlates of TMD, thus emphasizing the need for further research (De Leeuw et al., 1994).

This relates to the functional model that underscores the role of stress, emotional tension and personality characteristics in temporomandibular joint pain dysfunction (TMJPD) and bruxism (Biondi \& Picardi, 1993).

\section{Conclusion}

In this study a Spectrum approach was used to assess the relation between subthreshold symptoms of anxiety, stress and bruxism. The theory that bruxism is a centrally mediated disorder was used in this study whereby psychological factors like anxiety and stress are examined as possible aetiological factors related to bruxism. The stress-related muscular hyperactivity theory and Harber's conceptual model of psychological stress was used to explain the relation between stress and masticatory muscle pain/fatigue as a symptom of bruxism.

\subsection{Methods for the evaluation of psychological and psychosocial factors}

Various questionnaires have been used to determine the relationship between bruxism and psychological and psychosocial factors:-

\section{Questionnaire Battery}

In a study based on an interactional approach, a correlation was found between TMD and stress (major life stress and daily hassles) and stronger stress-related emotional reactions (anxiety and depression). A Questionnaire Battery (QB) used in this study assesses psychosocial 
variables. Seven questionnaires measure different aspects of the 3 dimensions of stress as defined interactionally, namely environmental stressors, stress-related emotional reactions and mediating personality variables. The questionnaires used were as follows: Major life events were measured using the Recently experienced events questionnaire (REEQ). Daily hassles were measured using the Everyday problem checklist (EPCL). Anxiety was measured using the Spielberger state-trait anxiety inventory (STAl). Depression was measured using the Depression Symptom Inventory (DSI). Coping styles were measured using the Ways of Coping Checklist (WCC). Locus of control was measured using the Multidimensional Health Locus of Control scale (MHLC). Personality characteristics were measured using the Dutch Personality Questionnaire (DPQ) (De Leeuw et al., 1994).

\section{Kessler Psychological Distress Scale}

The Kessler Psychological Distress Scale (K10) was developed for screening populations on psychological distress, consisting of 10 questions on non-specific psychological distress. It is widely used in surveys and as a clinical outcome measure. Regarding the factorial composition of the Kessler 10 (K-10), it was found to consist of 4 factors labelled: Nervous, Negative Affect, Fatigue and Agitation and a 2-factor second-order factor structure (Depression and Anxiety) (Brooks, Beard, \& Steel, 2006). The K-10 is concerned with the level of anxiety and depressive symptoms a person may have experienced in the most recent four-week period. The K-10 is considered a moderately reliable instrument. Two different scoring methods of the $\mathrm{K}-10$ have been documented. It is a simple, brief, valid and reliable screening tool (The Kessler Psychological Distress Scale (K10), 2002). The K-10 is considered useful in generalpurpose health surveys and clinical studies because it has strong psychometric properties and can be used to discriminate DSM-IV cases from non-cases (Kessler et al., 2002). 


\section{The State -Trait Anxiety Inventory}

The State -Trait Anxiety Inventory (STAI) is the most frequently used scale in research on anxiety worldwide. It is a self-report inventory consisting of 20 items to assess state anxiety and 20 items to assess trait anxiety (Spielberger, 1983).

Trait anxiety refers to individual differences in anxiety-proneness. It refers to individual tendencies in perception of and reaction to stressful situations. The individual's level of Trait anxiety will influence his/her State anxiety, which refers to the individual's reaction to a specific stressful situation at a specific point in time. Past experience plays a role in both Trait and State anxiety by influencing the individual's perception of a situation as psychologically threatening. Individuals who display high Trait anxiety tend to interpret a wide range of situations as threatening. The individual's perception of a situation as stressful plays a more important role in determining the level of State anxiety than the actual danger inherent in the situation. Psychological threat (e.g. experience of personal failure or negative evaluation of personal adequacy) as opposed to physiological threat is perceived as more threatening by individuals who display high Trait anxiety.

While the State anxiety Scale evaluates how an individual feels "right now" or in a specific situation, the Trait anxiety Scale assesses how the person generally feels. The State anxiety Scale evaluates feelings of worry, tension, apprehension and nervousness (Spielberger, 1983).

The Modified and Perceived Stress Scale and the State-Trait Anxiety Inventory showed that tooth-wear patients presented significantly more trait anxiety than controls. They indicated the need for further research to clarify the importance of trait anxiety and other psychosocial factors in toothwear (Da Silva, Oakley, Hemmings, Newman, \& Watkins, 1997). 


\section{Panic-agoraphobic spectrum self-report}

The reliability of assessment instruments for Panic-Agoraphobic Spectrum (PAS-SR) has been confirmed for both the interview and self-report formats. The PAS describes all the features associated with DSM IV Panic Disorder and provides additional important clinical information (Shear et al., 2001).

The PAS is a dimensional approach, which complements the DSM IV categorical approach. The spectrum model provides objective criteria, indicates episodic symptoms and the role of atypical and subclinical symptoms (symptoms that do not reach the diagnostic threshold), rendering this model a flexible and comprehensive means of describing the panic-agoraphobic clinical complex and expressing a unitary pathophysiology. The high prevalence of atypical and subclinical panic spectrum symptoms has been found to be associated with an increased use of health and mental health care facilities. The PAS could be useful in terms of patient-therapist communication and treatment planning (Cassano et al., 1997). Subclinical presentations of clinical features of the 8 domains measured in the PAS may be present as prodromal (early or premonitory symptom), residual and/or co-morbid symptoms of the major disorder (i.e. panic disorder) or of other DSM Axis I disorders, which could affect the presentation, course and response to treatment. Failure to note such features may hinder understanding of a presenting condition and affect prevention and treatment strategies (Beaton, Egan, NagakawaKogan, \& Morrison, 1991; Beroccal et al., 2005). The PAS-SR is focused on typical symptoms of panic disorder (the DSM-1V criteria) in addition to atypical and subthreshold panic and phobic symptoms (Manfredini, Bandettini di Poggio et al., 2004; Manfredini, Landi et al., 2005). The 8 domains of the PAS-SR measure a unitary construct (Beroccal et al., 
2005). Results based on the PAS-SR indicate that subclinical symptoms of the anxiety spectrum could differentiate bruxers from controls. Of the 8 domains in the PAS-SR, significant differences were found in scores of the panic, stress sensitivity and reassurance sensitivity domains, providing support to the existences of an association between certain psychopathological symptoms and bruxism (Manfredini, Landi et al., 2005). The PAS allows for improved detection of treatable cases and future research should further examine subgroups of patients according to the PAS with regard to prognosis and treatment implications (Beroccal et al., 2005). The PAS-SR represents a dimensional and longitudinal perspective of psychopathology and measures a spectrum of lifetime Panic-Agoraphobic features. A high score on the atypical and subclinical symptoms on the panic-agoraphobic spectrum has been found to be associated with a high level of impairment, increased medical morbidity and psychiatric co-morbidity, and increased use of health care and mental health care services (Beroccal et al., 2005).

Three domains have been associated with bruxism, namely: typical and atypical panic, stress sensitivity and reassurance sensitivity symptoms. It was thus concluded that certain subthreshold manifestations of anxiety as indicated on the panic-agoraphobic spectrum are more prevalent in bruxers. What needs to be verified is whether subthreshold manifestations of the anxiety spectrum are involved in the pathogenesis of bruxism or whether they should be considered as a manifestation of a comorbid subclinical entity (Manfredini, Landi et al., 2005). Researchers (Shear et al., 2001) underscore the need for further research on the likelihood that higher spectrum scores on subclinical symptoms of anxiety will be related to more functional impairment, lower treatment responsiveness and poorer long-term course. The domain, stress sensitivity, focuses on the presence of symptoms of abnormal reactions to stressors. Bruxism could thus somehow be related to inadequate methods of coping with stress. It therefore appears that bruxers tend to be more sensitive to stress than non-bruxers, indicating the relevance of investigating subjective 
susceptibility to emotional factors (Manfredini, Landi et al., 2005). This could possibly relate to Haber's conceptual model of stress.

\section{Other methods}

Support for the reliability of the self-report version (MOODS-SR) has been provided by other findings (Dell'Osso et al., 2002). The MOODS-SR separately rates the major DSM-1V depressive and manic symptoms, as well as subthreshold and atypical manifestations. The questionnaire consists of 161 items and takes 15-30 min to complete (Manfredini, Bandettini di Poggio et al., 2004).

The relationship between anxiety and the development of bruxism in children was determined by means of an Anxiety Scale for evolutive age using the "Odds Ratio" on statistically significant values (Monaco et al., 2002).

A modified version of the Holmes and Rahe Life Events Scale (LEPS) SOS inventory (Symptoms of stress self-report inventory) was used in a study (Beaton et al., 1991). The TMJ was related to more frequent somatic, psychological and behavioural symptoms on the SOS inventory (Symptoms of stress self-report inventory), compared to healthy controls. TMD patients obtained the highest scores on the anger and muscle tension subscales. Half of the TMD patient sample suffered from orofacial pain, bruxism and/or an arthritic condition.

The Occupational Stress Questionnaire consists of a 5-point scale and was used in a study which indicated a positive association between continual stress and bruxism (Ahlberg et al., 2002). Findings obtained on the Cornell Medical Index and the Rosenzweig Picture Frustration Study indicated a correlation between anxiety; mode of reacting to frustration, and presence or absence of bruxism (Thaller et al., 1967).

The Jenkins Activity Survey (JAS) provides an overall score for type A behaviour, plus separate scores for 3 sub factors, namely: impatience, job 
involvement, and competitiveness. Using the Jenkins Activity Survey and a modified version of the Holmes and Rahe Life Events Scale, (Pingitore et al., 1991) concluded that stress in conjunction with Type A behaviour was predictive of bruxism.

In the personality study (Karolinsk Scales of Personality (KSP) done by (Kampe et al., 1996) it was found that frequent tooth clenchers had increased and significantly higher values on the Muscular Tension scale than non-clenchers. The KSP (Karolinsk Scale of Personality) used by (Kampe, Edman et al., 1997) revealed that bruxers had significantly higher scores in the somatic and psychic anxiety and muscular tension scales and lower scores in the socialization scales compared to a normal population. The results of this study indicate a possible aetiological relationship between personality, tooth clenching and craniomandibular dysfunction (TMD). Due to the small sample size, the results cannot be generalized and further studies on larger samples are required.

\section{Conclusion}

The Kessler 10 and The State -Trait Anxiety Inventory (STAI) were considered appropriate psychological tests to use with the Spectrum approach to assess subthreshold symptoms of anxiety and stress in this study. The Kessler 10 is a simple, brief, valid and reliable screening tool for determining non-specific psychological distress. The STAI is considered reliable and it is the most frequently used scale in research on anxiety worldwide to assess both trait and state anxiety. Answers to both tests are rated on a Likert scale.

\subsection{Criteria for the clinical evaluation of bruxism}

Bruxism has been defined as non-functional (parafunctional) movements of the mandible, with or without audible sound occurring during the day or night (Khan et al., 1998). 
Excessive tooth wear is the most frequently cited sign of bruxism (Khan et al., 1998). However, tooth wear status cannot solely be used to predict bruxism (Baba, Haketa, Clark, \& Ohyama, 2004). Other signs and symptoms need to be present as well. Results showed that tooth wear patterns are unreliable indicators of bruxism (Khan et al., 1998).

Bruxism is usually evaluated by means of the following methods: selfreport questionnaires; a clinical oral examination; electromyography (EMG) (Lobbezoo et al., 2004; Marbach, Raphael, Janal, \& HirschkornRoth, 2003) and polysomnography recordings in sleep laboratories (Lavigne et al., 1996). Laboratory studies using EMG recordings of masseter and anterior temporal muscle activity (Piquero \& Sakurai, 2000; Reding et al., 1968; Rugh \& Solberg, 1975) and polysomnographic studies (Lavigne et al., 1996) have indicated that teeth-grinding is a reliable indicator of nocturnal bruxism. Polysomnographic recordings are conducted in sleep laboratories by electrode placement and scoring criteria based on three parameters: electroencephalography (EEG), electro-oculography (EOG) and chin electromyography (EMG) (Lavigne et al., 1996). They are thus more comprehensive than using only EMG recordings.

Based on research findings (Lavigne et al., 1996), the suggested polysomnographic diagnostic cut-off criteria were as follows:

- more than 4 bruxism episodes per hour.

- $\quad$ more than 6 bursts per episode and/or 25 bursts per hour of sleep.

- at least 2 episodes with grinding sounds

Other studies (Pierce et al., 1995; Piquero \& Sakurai, 2000) used an interview and examination conducted by the same physician and either trained the subject to use a portable EMG monitor or performed the EMG recordings in a dental chair. Selection criteria focused on EMG activity indicating bruxism during sleep; a self-report history of bruxism; tooth wear 
facets indicative of bruxism; and report of someone else hearing the subject brux (Pierce et al., 1995).

The International Classification of Sleep Disorders (ICDS) specify the minimal criteria for nocturnal bruxism as follows: the presence of teeth grinding during sleep and one of the following: abnormal tooth wear; muscular discomfort, or sound associated with tooth grinding (Ohayon et al., 2001).

Electromyography (EMG) and polysomnographic recordings are costly, time consuming and impractical when large sample sizes are studied. Depending on the focus of the research, the criteria can be confined to the following: Bruxism is diagnosed if subjects present tooth wear facets and grinding/clenching occurs during sleep as confirmed by a partner or family member (Velly et al., 2003). In a study (Manfredini, Landi et al., 2004) two indicators, clinical and anamnestical, served as a control for each other. The presence of wear facets were considered a clinical indicator of bruxism and a positive response to one of the following anamnestical indicators was required for the diagnosis of bruxism: report of nocturnal teeth grinding by family or partner; clenching during the day; muscular tension or stiffness of the face or jaw on awakening and/or during the day; masseter and/or temporalis muscle pain and/or fatigue during the day and/or on awakening; frequent awakening at night grinding or clenching. These indicators were also used by others (Pergamalian, Rudy, Zaki, \& Greco, 2003). These criteria were modified in recent studies (Manfredini, Ciapparelli et al., 2005; Manfredini, Landi et al., 2005). Validated clinical diagnostic criteria based on data obtained from polysomnographic studies (Lavigne et al., 1996) was considered to be as follows:

(1) Report of grinding sounds, at least 5 nights a week during sleep during the last 6 months as reported by a bed partner.

(2) The presence of at least one of the following adjunctive criteria: 
- Clinical observation of tooth wears facets or shiny spots on restorations.

- Report of morning masticatory muscle fatigue or pain.

- Masseteric hypertrophy upon digital palpation.

Since polsomnography showed that teeth-grinding is an indication of SB, reports by a bed partner or family member on the sounds of teeth-grinding were therefore also considered a good indicator for SB (Manfredini, Landi et al., 2005; Pingitore et al., 1991; Reding et al., 1968). This feature was included in the present study's questionnaire.

(Khan et al., 1998) used the following clinical items for the diagnosis of bruxism:

1). Clenching or grinding during the day (Question: Are you conscious of clenching or grinding your teeth when concentrating or stressed during the day?)

2). Clenching or grinding during the night (Question: Has your partner told you that they hear or see you grinding or clenching when you are asleep?)

3). Muscle or TMJ tenderness in the morning. Recollection of stiffness or tenderness of the muscles of mastication or TMJ on waking in the morning, particularly if under stress, was taken as a positive indicator.

4). Muscle or TMJ tenderness upon palpation. Pain, clicking or tenderness on bilateral palpation in the muscles of mastication or TMJ on opening and closing confirmed this.

5). Tongue indentations, i.e. impressions of teeth on the tongue or lips.

6). Buccal mucosa:linea alba i.e. thickening of the buccal mucosa near the occlusal surfaces of the posterior teeth.

7). Bruxism - diagnosed/suggested.

8). Bruxism treated - splint made 
According to the literature, consensus on the criteria for diagnosis of bruxism has not been reached. The number of subjects defined as bruxers in a particular study will therefore depend on the criteria used. There is thus a need to establish valid criteria and a method of defining a bruxer that will be used universally. An objective measurement of bruxism, which can be used in clinics, should be devised. Bruxism must be defined using a reliable, possibly quantitative method. Better understanding of the definition, causes, pathophysiology, consequences, and management of parafunction is needed (Koyano et al., 2005).

Other shortcomings in the clinical approach to the diagnosis of bruxism discussed in this literature review that limit the generalizability of results, relate to the lack of distinction between awake and sleep bruxism and the issue of grading the severity of bruxism. The latter shortcoming will be addressed in this study by means of scoring bruxism on a continuum.

\subsection{Criteria for the diagnosis of tooth wear}

Tooth wear (attrition) occurs in different ways, namely, abrasion, erosion and abfraction. Abrahamsen (2005) redefined attrition as the pathologic wear of teeth from abrasion and erosion. Abrasion can be defined as the pathologic wear of teeth from a mechanical/rubbing process due to bruxism (the major cause) and toothpaste abuse, while erosion is considered to be the pathologic wear of teeth from a chemical/dissolving process such as regurgitation, coke-swishing, fruit-mulling (Abrahamsen, 2005). Soft drink consumption is also an erosive factor in tooth wear (Pigno, Hatch, Rodrigues-Garcia, Sakai, \& Rugh, 2001).

There is clinical evidence that erosion predisposes to severe attrition, and that the two mechanisms often act in tandem to cause tooth tissue loss. If the parafunctional habit of bruxism is superimposed, it may accelerate tooth tissue loss in an erosive environment (Khan et al., 1998). 
Tooth wear from abrasion can readily be discriminated from tooth tissue loss by erosion on teeth worn into the dentin using scanning electron microscopic criteria. The habit of bruxism may produce wear patterns characteristic of abrasion on occluding tooth surfaces which are different from the patterns of occlusal tooth tissue loss associated with dental erosion. Flat planes of wear characterize attritional facets on anterior teeth, with well-defined margins in enamel of incisal edges or as step-like areas on palatal aspects. Wear due to attrition was found equally on the mandibular and maxillary teeth in bruxers. Attrition was commoner on the mandibular premolars in the bruxers. Subjects diagnosed as bruxers displayed significantly more attrition in the mandibular anterior sextants (Khan et al., 1998).

The indicator generally used for diagnosis of bruxism is a history of clenching or grinding the teeth reported by the subject, parent or partner. Bruxofacets have been defined as atypical facets on teeth, with flat, smooth, shiny areas with sharp edges that correspond with similar opposing areas when the mandible is moved more than $3.5 \mathrm{~mm}$ from centric occlusion in a lateral excursion. Caution has been expressed against inferring bruxism from tooth wear patterns (Khan et al., 1998).

A study (Restrepo, Pelaez, Alvarez, Paucar, \& Abad, 2006) using digital imaging of patterns of dental wear found irregularity of form of wear facets to be the main difference between the dental wear found in bruxist and non-bruxist children. The irregular forms of dental wear could be due to the irregular movements of the mandible during non-masticatory function as in sleep bruxism.

The dental wear as a result of bruxism is characterized by the following (Restrepo et al., 2006):-

- a plane surface with a central zone that sometimes reaches the dentine, surrounded by enamel zones 
- Dental facets with horizontal form indicate a grinding pattern rather than a clenching pattern of bruxism

The effect of bruxism on teeth depends on several factors listed below (Restrepo et al., 2006):

- Type and severity of the parafunction

- Localization of the teeth

- Position of the teeth in the arch

- Intermaxillary relationship

- Number of teeth

- Cusp height

- Mobility

- Inter-dental contacts

Quantitative methods to measure dental wear are as follows (Restrepo et al., 2006):-

- Number of wear facets

- Number of teeth

- Area and amount of tooth or restorative material involved

Dental wear is not indicative of the actual level of bruxism in the patient, because dental wear due to bruxism is not present in persons who recently started bruxing. On the other hand, patients with longstanding bruxing behaviour who have stopped bruxing, will show permanent dental wear (Restrepo et al., 2006). While Restrepo et al (2006) used digital imaging of patterns of dental wear, tooth wear was examined and scored using a Nikon HFX-II microscope with a $5 \mathrm{X}$ magnification in the present study. 
Malocclusions, premature contacts, environment, diet, etc. represent some of the factors that could account for pathological dental wear. It is therefore imperative to include associated anamnestical factors in addition to tooth wear for the diagnosis of the parafunctional habit of bruxism (Restrepo et al., 2006). These factors were included in the present study.

Researchers (Pigno et al., 2001) used a five-point (0-4) ordinal scoring system in which each tooth is given a score describing the severity of wear. This system was used in the present study. Pigno et al's (2001) results showed a significant difference between the mean wear score of anterior (front) teeth and posterior (back) teeth. Maxillary (upper jaw) tooth wear was significantly greater in males and in subjects with reported teeth clenching/grinding. They concluded that age, gender, bite force, functional/parafunctional habits (for example, teeth clenching/grinding), number of teeth, occlusion, diet, number of daily snacks/meals, saliva, regurgitation/vomiting and environmental conditions are potential factors that may have contributed to tooth wear in their study sample. This indicates the multifactorial nature of the etiology (Pigno et al., 2001) and several of these factors were included in the present study.

The concept of functional/parafunctional activity as significant factor in tooth wear should not be discounted. Mair (1999) (in Pigno et al 2001) describes the tooth wear mechanisms of slurry wear and surface-tosurface wear that cause functional and parafunctional tooth wear. Slurry wear occurs during functional jaw activity such as mastication (chewing), and surface-to-surface wear occurs during parafunctional jaw activity such as teeth clenching/grinding (Pigno et al., 2001).

Research (Koyano et al., 2005) on parafunction and tooth wear showed that many systems use a five-point scale based on the severity of tooth wear as determined from study casts. Digitization and scanning electron microscopy have also been introduced. The present study differs because a microscope was used. According to the literature (Abrahamsen, 2005) 
accurate casts made from alginate impressions are the best diagnostic tool to determine and differentiate the exact aetiology of worn dentition.

\subsection{Treatment of Bruxism, MFP and TMD}

Research findings (Heller \& Forgione, 1975) showed that neither massed negative practice nor relaxation training reduced bruxism significantly in two separate groups of subjects. A different study (Rosenbaum \& Ayllon, 1981) showed that bruxism could be reduced or eliminated by using the habit-reversal technique. The reduction of bruxism was calculated using self-reported rating cards of behaviours such as teeth grinding, clenching, facial pain and jaw popping in four subjects.

Anxiety levels, signs of bruxism and TMD were significantly reduced in children who received two psychological interventions, namely, 'directed muscular relaxation' and 'competence reaction' for 6 months (Restrepo, Alvarez, Jaramillo, Velez, \& Valencia, 2001).

A combination of counseling and physical therapy was found effective for the treatment of MFP (De Laat, Stappaerts, \& Papy, 2003). Cognitive Behavior Therapy was found effective in the management of TMD in 112 of 134 TMD patients with regard to the disappearance and improvement of symptoms (Morishige, Yatani, \& Hirokawa, 2006).

These results are encouraging considering the aim of this study as regards the relation between anxiety and bruxism. This reflects a paradigm shift from a mechanistic approach to the current biopsychosocial approach which advocates a multidisciplinary treatment plan in which cognitive behavior therapy is included in the management of TMD (Kalamir, Pollard, Vitiello, \& Bonello, 2006).

\subsection{Conclusion}

In the literature bruxism has been discussed In relation to anxiety and stress in numerous ways. It would be interesting to investigate whether a study using a South African example with the questionnaire, tests, criteria 
for the scoring of tooth wear and criteria for the definition of bruxism proposed for the present study would provide similar findings.

The psychoanalytic theory considers bruxism as the result of tension and stress and a release mechanism for overt aggression. The interactional stress theories consider coping style as a factor in the individual's reaction to environmental stress. The functional model also underscores the role of stress and emotional tension. The stress-related muscular hyperactivity theory points to a relationship between stress and increased activity of the masticatory muscles as a characteristic response to life stress. This is in accordance with the neuro-evolutionary perspective that considers clenching and grinding as a manifestation of experiencing chronic emotional distress.

The above-mentioned theories thus support the view that bruxism is mainly a centrally regulated multifactorial disorder, which strengthens the need for further investigation into the significance of a relationship between subthreshold symptoms of anxiety and bruxism. The Spectrum approach acknowledges subtle prodromal, atypical, subthreshold and subclinical symptoms and associated features including signs, isolated symptoms, symptom clusters and behavioural patterns related to the core symptoms. However, knowledge of the clinical implications of these subthreshold symptoms and signs is limited, indicating a need for further study (Beroccal et al., 2005).

An updated review (Lobbezoo et al., 2006) emphasizes the need for more, well-designed studies on the relation between bruxism, anxiety and stress. Tooth grinding and masticatory muscle tenderness should be examined as sub-criteria of Post Traumatic Stress Disorder (PTSD) and other anxietybased disorders according to (Bracha, Ralston et al., 2005).

In a review on the aetiopathogenesis of parafunctional habits of the stomatognathic system, Manfredini stated: "From this review, despite the number of clinical opinions, there emerges a lack of methodologically 
appropriate associative works and controlled clinical trials which consent to clarify the effective importance of psychic and/or occlusal factors in the aetiopathogenesis of parafunctional habits" (Manfredini, Landi, Romagnoli, Cantini, \& Bosco, 2003), p. 339).

Further research on the role of subthreshold symptoms of anxiety and stress in the aetiology of bruxism would contribute to a multidisciplinary approach as advocated in oral kinesiology and reflected in the current paradigm on treatment approaches. Besides the alleviation of symptoms associated with bruxism, for example, myofascial pain and TMJ pain, the subject's anxiety and stress is also addressed, constituting a holistic approach to treatment.

Research results showing the beneficial effect of cognitive behaviour therapy in the treatment of MFP and TMD strengthens the argument for addressing the role of psychological factors in the etiology of bruxism, because bruxism could be a contributory factor. Likewise, the neurobiological basis for anxiety, stress and bruxism also indicates a possible connection. 


\section{Chapter 3}

\section{Methodology}

\subsection{Data collection procedure}

All the third $(n=122)$ and fourth $(n=101)$ year dentistry students and the first $(n=28)$ and second $(n=28)$ year Oral Hygiene students for 2006, present at the time, were briefed on the purpose of the study and requested to volunteer as subjects (bruxers and non-bruxers). A few staff members and dental patients also volunteered. They were appropriately informed of the aim of the study. Volunteers were subjected to a selection on the basis of specific inclusion/exclusion criteria (Table 2). Prior to the start of the study, all subjects were requested to complete an informed consent form. Participation in the study conducted at the Oral Health Centre, University of the Western Cape (UWC), South Africa, was voluntary. The Senate Research Committee of UWC had approved the study protocol.

The 32 volunteers who participated in the study met the inclusion criteria and were prepared to sign the informed consent form, complete the various questionnaires, undergo a clinical examination, have intra-oral photographs and impressions taken of their teeth and their mouth opening measured.

Three of the 32 subjects were excluded because their dental casts could not be scored due to malocclusion, leaving a total of 29 subjects in the study. 
Table 2. Inclusion/exclusion criteria

\section{Inclusion criteria}

Good health

Age $18-50$

Own teeth

5 of 7 teeth per quadrant (excluding wisdom teeth)

\section{Exclusion criteria}

Artificial or partial dentures

More than 2 teeth missing per quadrant (excluding wisdom teeth) (Baba et al., 2004)

On antidepressants, tranquilizers or sleeping pills

(Baba et al., 2004)

Presence of serious malocclusion (Baba et al., 2004)

Subjects were requested to complete a questionnaire (Refer to Addendum 1), which provides demographic information and bruxing behaviour as well as two anxiety scores and a stress score. The demographic and bruxism questionnaire was based on criteria used by other researchers pertaining to indicators of bruxism and factors affecting tooth wear (Baba et al., 2004; Johansson, Haraldson, Omar, Kiliaridis, \& Carlsson, 1993; Khan et al., 1998; Ohayon et al., 2001). Questions pertaining to TMD were also included in the questionnaire (e.g. pain or tenderness in TMJ; trismus; jaw or muscle pain or fatigue on awakening) (Ciancaglini et al., 2001; Manfredini, Cantini, Romagnoli, \& Bosco, 2003) (Refer to Addendum 1). The bruxism score was rated on a continuum and compared to the SSTAI scores and the Kessler 10 scores.

The English version of the Spielberger State Trait Anxiety Inventory (SSTAI) and the Kessler-10 (K-10), a measure of general psychological distress was used (Refer to Addendum 1). Both the SSTAI and K-10 are self-report measures. Assistance was provided if required. 
The SSTAI is appropriate for students and adults, consists of 40 items (2 domains of 20 items each); takes 10 minutes to complete and has been compiled for a $6^{\text {th }}$ grade reading level. It allows differentiation between state and trait anxiety rated on a 4-point Likert scale.

\subsection{Tooth wear}

Orthoplaster casts were made from alginate impressions which were taken of both the maxillary and mandibular arch for every participant for the identification of tooth wear facets in order to determine a tooth wear score (Abrahamsen, 2005).

Intra-oral photographs were taken as follows:

- Occlusal (upper and lower teeth)

- Lateral - teeth apart (right and left)

- Anterior - teeth apart with a smile

- Anterior - teeth apart with retractors

Total: 6 photographs for each subject

Tooth wear was scored using a Nikon HFX-II microscope with a $5 \mathrm{X}$ magnification. Refer to Addendum 2 for the score sheet used in the study. One rater was used to determine the score. The intra-oral photographs were used to confirm and complement the findings on the dental casts, especially in the detection of early enamel wear and wear into dentin. The casts of subjects that could not be scored due to severe malocclusion were excluded from the study.

An ordinal scale (Johansson, Omar et al., 1993; Pigno et al., 2001) was used for grading severity of occlusal wear (Table 3). 
Table 3. Ordinal scale used for grading severity of occlusal wear

\begin{tabular}{|l|l|}
\hline Score & \multicolumn{1}{c|}{ Criteria } \\
\hline $\mathbf{0}$ & $\begin{array}{l}\text { No visible facets in the enamel. Occlusal/incisal morphology } \\
\text { intact. }\end{array}$ \\
\hline $\mathbf{1}$ & $\begin{array}{l}\text { Marked wear facets in the enamel. Occlusal/incisal morphology } \\
\text { altered. }\end{array}$ \\
\hline $\mathbf{2}$ & $\begin{array}{l}\text { Extensive wear into the dentin. Larger dentin area (>2mm2) } \\
\text { exposed occlusally / incisally or adjacent tooth surface. } \\
\text { Occlusal/incisal morphology totally lost or generally. Substantial } \\
\text { loss of crown height. }\end{array}$ \\
\hline $\mathbf{3}$ & $\begin{array}{l}\text { Extensive wear into the dentin. Larger dentin area (>2 } \mathrm{mm}^{2} \text { ) } \\
\text { exposed occlusally / incisally or adjacent tooth surface. } \\
\text { Occlusal/incisal morphology totally lost or generally. Substantial } \\
\text { loss of crown height. }\end{array}$ \\
\hline $\mathbf{4}$ & \begin{tabular}{l} 
Wear into secondary dentin (verified by photographs). \\
\hline
\end{tabular} \\
\hline
\end{tabular}

The fact that bruxers present more anterior tooth wear than posterior (Pigno et al., 2001) was considered and it was deemed appropriate to provide an anterior and a posterior mean score in addition to the total mean score for the maxilla (upper jaw) and the mandible (lower jaw) separately and combined as well as a canine mean score. This was obtained by dividing the sum of the scores for each segmental sub-index by the number of teeth scored (Johansson, Omar et al., 1993).

The maximum mouth opening was measured with a Willis gauge or ruler. The size of the mouth opening is considered an indication of muscle tension and TMD (Ciancaglini et al., 2001). The temporomandibular joint area was also checked for sensitivity on palpation. This information was included in the questionnaire in a section labelled: "clinician's comment" (Refer to Addendum 1).

\subsection{Defining a bruxer}

For the purpose of this study, an individual was considered to be a bruxer if the following criteria were met:- 
A score greater than or equal to 1 on either the mean of 6 anterior or 8 posterior maxillary or mandibular teeth, or mean of the 4 canines, plus 2 of the following:-

1. A previous diagnosis of bruxism by a dentist.

2. Sounds of clenching or grinding reported by a family member or bed partner (Manfredini, Landi et al., 2004; Ohayon et al., 2001; Pergamalian et al., 2003).

3. Reporting of jaw muscle pain or fatigue on awakening (Manfredini, Landi et al., 2004; Ohayon et al., 2001; Pergamalian et al., 2003).

The data in Addendum 3 was used to determine the number of subjects who met the criteria for the definition of bruxers. This would provide a group of bruxers and non-bruxers (control group).

\subsection{Research Design}

A correlational design was used in this study in order to determine the relationship between psychological and physiological variables by means of regression analysis. The psychological variables were the scores for the State Y1, Trait Y2 and Kessler 10 tests. The physiological variables pertain to the Demographic and clinical criteria questionnaire and Tooth wear scores (Refer to Addendum 1 and 2). Scatter plots were created to graphically represent the linear relationship between variables.

After the inter- and intra-rater reliability was determined for the tooth wear scores, a preliminary survey was conducted of all the raw data to form an overall view of the trends and relations as well as to identify any discrepancies or interesting phenomena.

Regression analysis was done using scatter plots and the Pearson product moment correlation coefficient ( $r$ ). A Pearson correlation matrix was created. The NCSS Data Program was used for data analysis on the 29 subjects. A One-way Non-parametric Anova was used. The Kruskal-Wallis 
test, a non-parametric test equivalent to the Wilcoxon Rank Sum Test, was performed. A Spearman Rank Correlation Matrix was created. This is a non-parametric measure of association based on rank order.

\subsubsection{Reliability and Validity of scales}

\section{a) The State -Trait Anxiety Inventory (STAI)}

The STAI is the most frequently used scale in research on anxiety worldwide. It is a self-report test consisting of 20 items to assess state anxiety and 20 items to assess trait anxiety (Spielberger, 1983).

\section{b) Kessler Psychological Distress Scale (K -10)}

The $\mathrm{K}-10$ is a simple, brief and valid screening tool for determining the level of anxiety and depressive symptoms experienced by an individual in the most recent four-week period. It is considered a moderately reliable instrument (The Kessler Psychological Distress Scale (K10), 2002).

\section{c) Ordinal scale for tooth wear}

The reliability of the ordinal scoring system used in the study by (Pigno et al., 2001) was confirmed in another study (Johansson, Haraldson et al., 1993) and this system was used in this study.

As revealed in the above-mentioned paragraphs, the reliability of the tests and scales has been confirmed. Therefore it was deemed unnecessary to repeat the questionnaires with subjects to establish the reliability.

\subsubsection{Inter- and intra-rater reliability for the scoring of tooth wear}

Two raters scored 21 sets of dental casts independently using the index used by Johansson, Omar et al (1993) and Pigno et al (2001). Concordance rating (more appropriate for a medium sample) was used instead of Cohen's Kappa coefficient for comparing the inter- and intra- 
rater reliability of 2 independent raters. The most reliable rater's scores (Rater B) were used in the study.

Rater B scored 10 random dental casts of the total number of sets, 10-14 days after the first rating in order to assess the intra-rater reliability. Descriptive statistics were used to show the concordance for the inter- and intra-rater agreement and Stem and Leaf Diagrams were constructed of the number of exact concordances over the maxilla and mandible, individually and together.

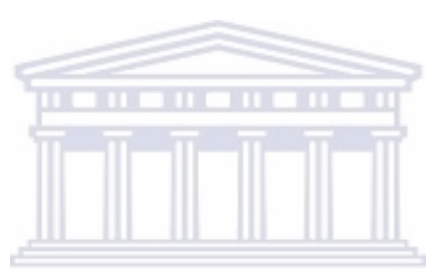




\section{Chapter 4}

\section{Results}

\subsection{Introduction}

A cohort of 29 individuals met the inclusion criteria for the study with a male to female ratio of $8: 21$. Subjects varied in age between 18 and 50 years with a mean age of 24.3 years. The majority were students.

The statistical analysis of the data in this correlational research design revealed relations between the different psychological and physiological variables pertaining to the study as illustrated in Figures 2 and 3.

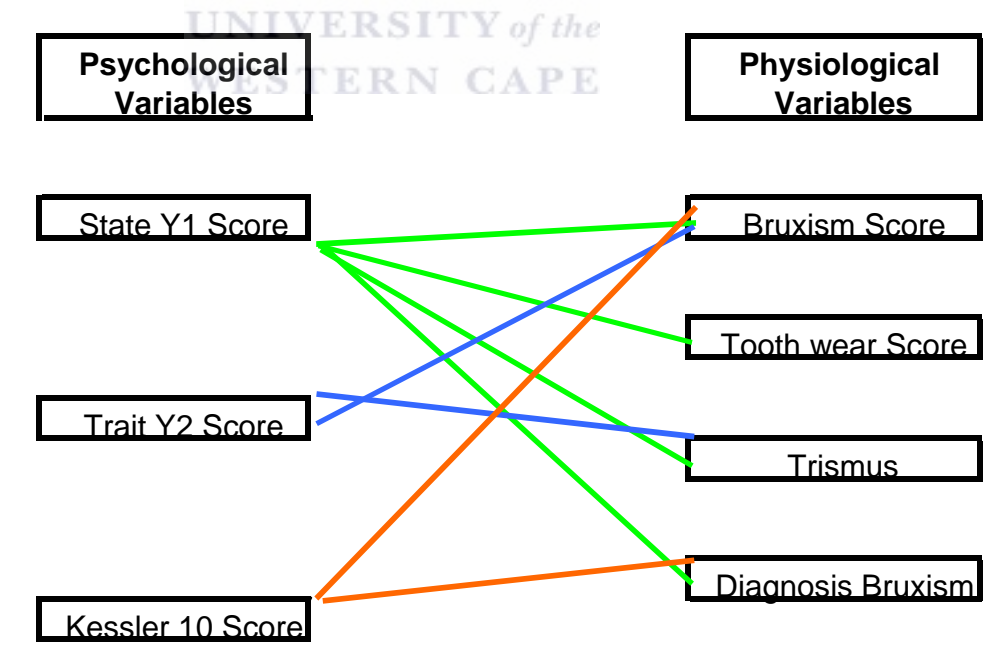

Figure 2. Mind map showing the relations found in the study between psychological and physiological variables 


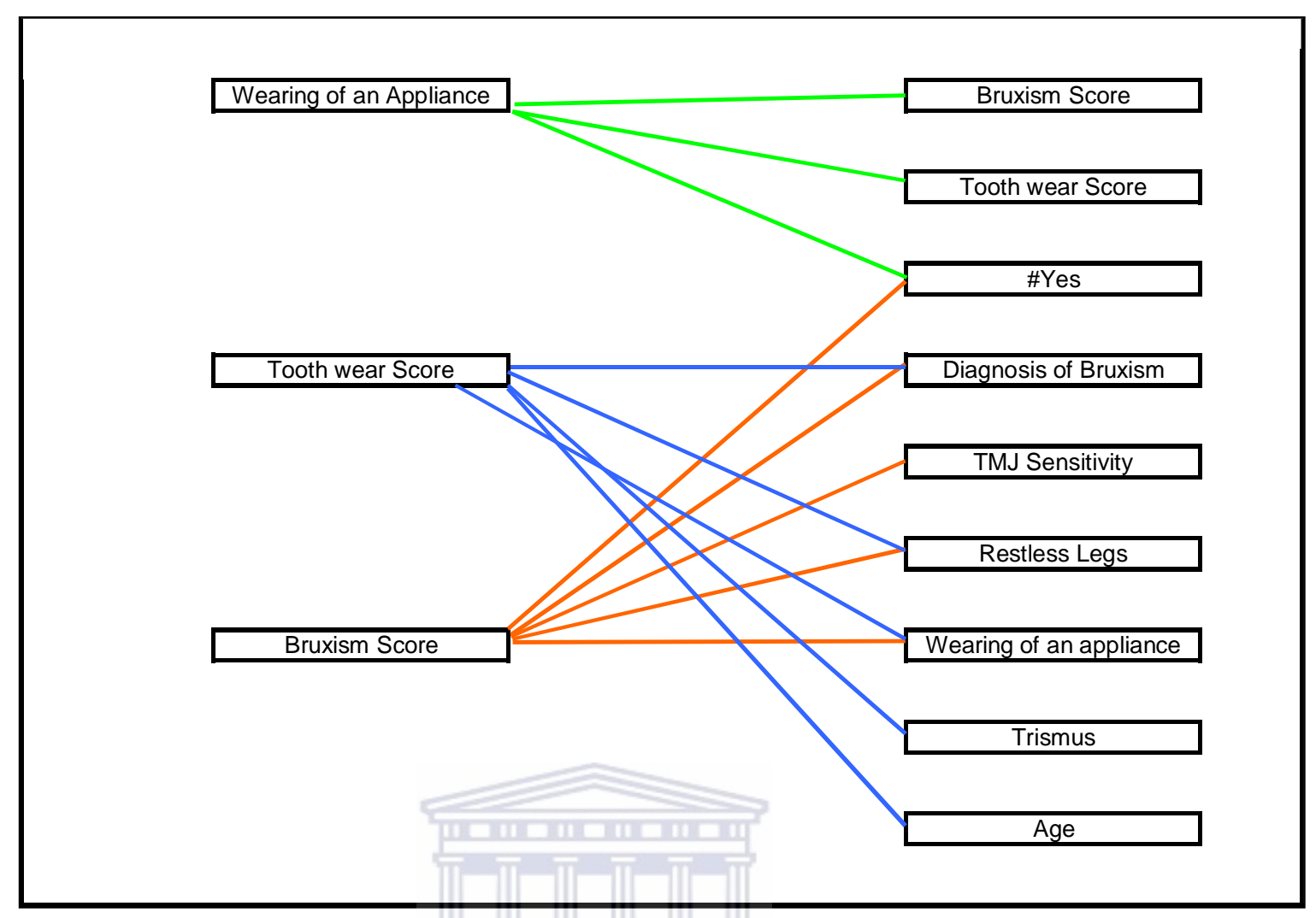

Figure 3. Mind map showing the relations found in the study between physiological variariables

It should be noted that in this study the term "bruxism score" refers to the score derived from the questionnaire titled: "Demographic and Clinical criteria" (Refer to Addendum 1) and is separate from the tooth wear score (Addendum 2).

\subsection{Intra-rater reliability for the scoring of tooth wear Intra-rater reliability}

280 teeth were rated by rater B. For the rater it was possible to agree with himself within 10 teeth, therefore the maximum agreement per tooth position was equal to ten. 
Table 4. The concordance with respect to intra-rater agreement of the full dentition and the descriptive statistics thereof. (Concordance within readings on two occasions (10-14 days apart)

\begin{tabular}{|c|c|}
\hline & Rater \\
\hline Number of dentitions compared & 10 \\
\hline $\begin{array}{l}\text { Number of individual teeth } \\
\text { assessed }\end{array}$ & 280 \\
\hline $\begin{array}{l}\text { Total number of teeth for which the } \\
\text { rater concurred exactly }\end{array}$ & 225 \\
\hline Average concordance per tooth & 7.04 \\
\hline Standard Deviation & 1.37 \\
\hline Minimum & 5 \\
\hline 1stQuartile & 6 \\
\hline 2ndQuartile_Median & 7 \\
\hline 3rdOuartile & 8 \\
\hline 4thQuartile_Maximum & 9 \\
\hline Concordance rate & $70.4 \%$ \\
\hline
\end{tabular}

Rater B concurred on 225 teeth out of the 280 assessed. This gave an average concordance per tooth of 7.04 . The final concordance rating was $70.4 \%$.

Intra-rater agreement for maxilla and mandible for rater B

Table 5. Stem-and-leaf Diagram of the number of exact Concordances over ten maxilla specimens for Rater B

\begin{tabular}{l|l|l|} 
Stem & Leaves & Frequency \\
3 & 33 & 2 \\
4 & 44 & 2 \\
5 & 55 & 2 \\
6 & 66 & 2 \\
7 & 7777 & 4 \\
8 & 88 & 2 \\
\cline { 3 - 3 } & &
\end{tabular}


Table 6. Stem-and-leaf Diagram of the number of exact Concordances over ten Mandible specimens for Rater B

\begin{tabular}{l|l|l|} 
Stem & Leaves & Frequency \\
3 & 3 & 1 \\
4 & 444 & 3 \\
5 & 5555 & 4 \\
6 & 66666 & 5 \\
7 & 7 & 1 \\
8 & & 0
\end{tabular}

For the maxilla the median number of concordances was 6 and the average thereof was 5.71 (Table 5) and for the mandible, the median number of concordances was 5 and the average thereof was 5.14 (Table 6). For the maxilla there is better agreement (correspondence) between the two repeat readings of wear.

\subsection{The relation between the different psychological and physiological variables pertaining to the study}

The relation between the different psychological and physiological variables pertaining to the study as mentioned in Chapter 3 (Methodology) and illustrated in Figures 2 and 3 (mind maps) was statistically analyzed and presented in the following tables and figures. 
Table 7. Spearman Rank Order Correlation Matrix on the relation between physiological variables

\begin{tabular}{|c|c|c|c|c|c|c|c|c|c|}
\hline & & Age & \#Yes & $\begin{array}{l}\text { Bruxism } \\
\text { Score }\end{array}$ & $\begin{array}{l}\text { Bruxism } \\
\text { Score } \\
\text { W1 }\end{array}$ & $\begin{array}{l}\text { Bruxism } \\
\text { Score } \\
\text { W2 }\end{array}$ & Appliance & Trismus & $\begin{array}{l}\text { All } \\
\text { Mean } \\
\text { Tooth } \\
\text { wear } \\
\text { Score }\end{array}$ \\
\hline & $r$ & 1 & -0.220 & -0.104 & -0.182 & -0.175 & 0.075 & 0.038 & 0.187 \\
\hline Age & $\mathbf{p}$ & 0 & 0.25088 & 0.59268 & 0.34521 & 0.36321 & 0.69765 & 0.86135 & 0.33219 \\
\hline & & 29 & 29 & 29 & 29 & 29 & 29 & 24 & 29 \\
\hline & & -0.220 & 1 & 0.565 & 0.701 & 0.750 & 0.535 & 0.062 & 0.291 \\
\hline \#Yes & & 0.25088 & 0 & 0.00141 & 0.00002 & 0.00000 & 0.00279 & 0.77193 & 0.12545 \\
\hline & & 29 & 29 & 29 & 29 & 29 & 29 & 24 & 29 \\
\hline & & -0.104 & 0.565 & 1 & 0.943 & 0.940 & 0.477 & -0.247 & -0.001 \\
\hline $\begin{array}{l}\text { Brux } \\
\text { Scor }\end{array}$ & & 0.59268 & 0.00141 & 0 & 0.00000 & 0.00000 & 0.00883 & 0.24509 & 0.99694 \\
\hline & & 29 & 29 & 29 & 29 & 29 & 29 & 24 & 29 \\
\hline & & -0.182 & 0.701 & 0.943 & 1 & 0.996 & 0.433 & -0.189 & 0.030 \\
\hline & & 0.34521 & 0.00002 & 0.00000 & 0 & 0.00000 & 0.01897 & 0.37740 & 0.87855 \\
\hline & & 29 & 29 & 29 & 29 & 29 & 29 & 24 & 29 \\
\hline & & -0.175 & 0.750 & 0.940 & 0.996 & 1 & 0.456 & -0.159 & 0.056 \\
\hline $\begin{array}{l}\text { Brux } \\
\text { Scol }\end{array}$ & & 0.36321 & 0.00000 & 0.00000 & 0.00000 & 0 & 0.01301 & 0.45878 & 0.77266 \\
\hline & & 29 & $29 \cup N$ & 29 RSIT & 29 the & 29 & 29 & 24 & 29 \\
\hline & & 0.075 & 0.535 & 0.477 & 0.433 & 0.456 & 1 & -0.117 & 0.412 \\
\hline Appl & ance & 0.69765 & 0.00279 & 0.00883 & 0.01897 & 0.01301 & 0 & 0.58702 & 0.02628 \\
\hline & & 29 & 29 & 29 & 29 & 29 & 29 & 24 & 29 \\
\hline & & 0.038 & 0.062 & -0.247 & -0.189 & -0.159 & -0.117 & 1 & 0.341 \\
\hline Trisn & & 0.86135 & 0.77193 & 0.24509 & 0.37740 & 0.45878 & 0.58702 & 0 & 0.10252 \\
\hline & & 24 & 24 & 24 & 24 & 24 & 24 & 24 & 24 \\
\hline All & lean & 0.187 & 0.291 & -0.001 & 0.030 & 0.056 & 0.412 & 0.341 & 1 \\
\hline & & 0.33219 & 0.12545 & 0.99694 & 0.87855 & 0.77266 & 0.02628 & 0.10252 & 0 \\
\hline Scor & & 29 & 29 & 29 & 29 & 29 & 29 & 24 & 29 \\
\hline
\end{tabular}

\#Yes = Diagnosis of Bruxism/TMJ Sensitivity

$r=$ correlation $\quad p=$ probability of error $n=$ sample size 
Table 8. Spearman Rank Order Correlation Matrix on the relation between Psychological \& Physiological Variables

\begin{tabular}{|c|c|c|c|c|c|c|c|}
\hline & $\begin{array}{l}\text { InCtotState } \\
\text { Y1 }\end{array}$ & $\begin{array}{l}\text { DeCtot } \\
\text { State } \\
\text { Y1 }\end{array}$ & StateY1 & $\begin{array}{l}\text { InCtot } \\
\text { Trait Y2 }\end{array}$ & $\begin{array}{l}\text { DeCtot } \\
\text { TraitY2 }\end{array}$ & TraitY2 & $\begin{array}{l}\text { Kessler } \\
10\end{array}$ \\
\hline \multirow{3}{*}{ Age } & 0.128 & 0.114 & -0.132 & -0.132 & 0.339 & -0.204 & -0.172 \\
\hline & 0.50876 & 0.55713 & 0.49625 & 0.49641 & 0.07186 & 0.28770 & 0.37142 \\
\hline & 29 & 29 & 29 & 29 & 29 & 29 & 29 \\
\hline \multirow[t]{3}{*}{ \#Yes } & -0.225 & 0.253 & 0.216 & -0.084 & -0.079 & -0.055 & 0.009 \\
\hline & 0.24118 & 0.18592 & 0.26143 & 0.66537 & 0.68482 & 0.77632 & 0.96101 \\
\hline & 29 & 29 & 29 & 29 & 29 & 29 & 29 \\
\hline \multirow{3}{*}{$\begin{array}{l}\text { Bruxism } \\
\text { Score }\end{array}$} & 0.077 & -0.184 & -0.151 & 0.183 & -0.187 & 0.159 & 0.100 \\
\hline & 0.69085 & 0.33816 & 0.43462 & 0.34195 & 0.33093 & 0.41123 & 0.60576 \\
\hline & 29 & 29 & 29 & 29 & 29 & 29 & 29 \\
\hline \multirow{3}{*}{$\begin{array}{l}\text { Bruxism } \\
\text { Score W1 }\end{array}$} & -0.007 & -0.140 & -0.058 & 0.130 & -0.213 & 0.127 & 0.097 \\
\hline & 0.97191 & 0.46766 & 0.76642 & 0.50175 & 0.26799 & 0.51214 & 0.61668 \\
\hline & 29 & 29 & 29 & 29 & 29 & 29 & 29 \\
\hline \multirow{3}{*}{$\begin{array}{l}\text { Bruxism } \\
\text { Score W2 }\end{array}$} & -0.034 & -0.092 & -0.027 & 0.110 & -0.204 & 0.111 & 0.077 \\
\hline & 0.86086 & 0.63432 & 0.89021 & 0.56832 & 0.28728 & 0.56793 & 0.69017 \\
\hline & 29 & 29 & 29 & 29 & 29 & 29 & 29 \\
\hline \multirow{3}{*}{ Appliance } & -0.233 & 0.128 & 0.209 & -0.210 & 0.137 & -0.223 & -0.170 \\
\hline & 0.22401 & 0.50856 & 0.27708 & 0.27364 & 0.47759 & 0.24587 & 0.37835 \\
\hline & 29 & 29 S 7 & 29 & 29 & 29 & 29 & 29 \\
\hline \multirow{3}{*}{ Trismus } & -0.287 & 0.251 & 0.295 & -0.423 & 0.232 & -0.408 & -0.325 \\
\hline & 0.17424 & 0.23607 & 0.16131 & 0.03922 & 0.27483 & 0.04782 & 0.12177 \\
\hline & 24 & 24 & 24 & 24 & 24 & 24 & 24 \\
\hline \multirow{3}{*}{$\begin{array}{l}\text { All_Mean } \\
\text { Tooth } \\
\text { Wear } \\
\text { Score } \\
\end{array}$} & -0.410 & 0.423 & 0.397 & -0.347 & 0.154 & -0.331 & -0.387 \\
\hline & 0.02707 & 0.02227 & 0.03296 & 0.06482 & 0.42474 & 0.07985 & 0.03784 \\
\hline & 29 & 29 & 29 & 29 & 29 & 29 & 29 \\
\hline
\end{tabular}

\#Yes = Diagnosis of Bruxism/TMJ Sensitivity 
Table 9. Spearman Rank Order Correlation Matrix on the relation between Psychological Variables

\begin{tabular}{|c|c|c|c|c|c|c|c|}
\hline & $\begin{array}{l}\text { InCtot } \\
\text { State } \\
\text { Y1 }\end{array}$ & $\begin{array}{l}\text { DeCtot } \\
\text { State } \\
\text { Y1 }\end{array}$ & StateY1 & $\begin{array}{l}\text { InCtot } \\
\text { Trait Y2 }\end{array}$ & $\begin{array}{l}\text { DeCtot } \\
\text { TraitY2 }\end{array}$ & TraitY2 & $\begin{array}{l}\text { Kessler } \\
10\end{array}$ \\
\hline \multirow{3}{*}{$\begin{array}{l}\text { InCtot } \\
\text { State } \\
\text { Y1 }\end{array}$} & 1 & -0.616 & -0.990 & 0.585 & -0.357 & 0.562 & 0.605 \\
\hline & 0 & 0.00038 & 0.00000 & 0.00085 & 0.05700 & 0.00150 & 0.00051 \\
\hline & 29 & 29 & 29 & 29 & 29 & 29 & 29 \\
\hline \multirow{3}{*}{$\begin{array}{l}\text { DeCtot } \\
\text { State } \\
\text { Y1 }\end{array}$} & -0.616 & 1 & 0.640 & -0.510 & 0.584 & -0.572 & -0.451 \\
\hline & 0.00038 & 0 & 0.00018 & 0.00473 & 0.00088 & 0.00118 & 0.01411 \\
\hline & 29 & 29 & 29 & 29 & 29 & 29 & 29 \\
\hline \multirow{3}{*}{ StateY1 } & -0.990 & 0.640 & 1 & -0.599 & 0.335 & -0.551 & -0.588 \\
\hline & 0.00000 & 0.00018 & 0 & 0.00060 & 0.07563 & 0.00193 & 0.00080 \\
\hline & 29 & 29 & 29 & 29 & 29 & 29 & 29 \\
\hline \multirow{3}{*}{$\begin{array}{l}\text { InCtot } \\
\text { Trait Y2 }\end{array}$} & 0.585 & -0.510 & -0.599 & 1 & -0.644 & 0.949 & 0.803 \\
\hline & 0.00085 & 0.00473 & 0.00060 & 0 & 0.00017 & 0.00000 & 0.00000 \\
\hline & 29 & 29 & 29 & 29 & 29 & 29 & 29 \\
\hline \multirow{3}{*}{$\begin{array}{l}\text { DeCtot } \\
\text { TraitY2 }\end{array}$} & -0.357 & 0.584 & 0.335 & -0.644 & 1 & -0.826 & -0.635 \\
\hline & 0.05700 & 0.00088 & 0.07563 & 0.00017 & 0 & 0.00000 & 0.00022 \\
\hline & 29 & 29 & 29 & 29 & 29 & 29 & 29 \\
\hline \multirow{3}{*}{ TraitY2 } & 0.562 & -0.572 & -0.551 & 0.949 & -0.826 & 1 & 0.815 \\
\hline & 0.00150 & 0.00118 & 0.00193 & 0.00000 & 0.00000 & 0 & 0.00000 \\
\hline & 29 & $29 \quad W$ & $29 \mathrm{E}$ & $29 \mathrm{CAP}$ & 29 & 29 & 29 \\
\hline \multirow{3}{*}{$\begin{array}{l}\text { Kessler } \\
10\end{array}$} & 0.605 & -0.451 & -0.588 & 0.803 & -0.635 & 0.815 & 1 \\
\hline & 0.00051 & 0.01411 & 0.00080 & 0.00000 & 0.00022 & 0.00000 & 0 \\
\hline & 29 & 29 & 29 & 29 & 29 & 29 & 29 \\
\hline
\end{tabular}


Table 10. Table created from data in an Analysis of variance report Kruskal-Wallis One-Way ANOVA on Ranks

\begin{tabular}{|lllll|}
\hline Variable 1 & Variable 2 & p-value & Median No & MedianYes \\
Brux scr & Diagnosis Yes/No & 0.08 & 12 & 16 \\
Brux scrW1 & Diagnosis Yes/No & 0.03 & 14 & 18.5 \\
Brux scr W2 & Diagnosis Yes/No & 0.01 & 15 & 20.5 \\
AllmeanScr & Diagnosis Yes/No & 0.01 & 0.72 & 1.37 \\
InCtotStateY1 & Diagnosis Yes/No & 0.04 & 21 & 15.5 \\
DeCtotStateY1 & Diagnosis Yes/No & 0.08 & 28 & 31 \\
StateY1 & Diagnosis Yes/No & 0.05 & 32 & 37.5 \\
InctotTraitY2 & Diagnosis Yes/No & 0.34 & 23.5 & 21 \\
DeCtotTraitY2 & Diagnosis Yes/No & 1.00 & 27 & 26 \\
TraitY2 & Diagnosis Yes/No & 0.39 & 41 & 40 \\
Kessler10 & Diagnosis Yes/No & 0.50 & 22 & 20 \\
\hline
\end{tabular}

The p-values in the above Table show a significant relation between the Diagnosis of Bruxism and the Brux Scores (Demographic and clinical criteria questionnaire as is and weighted); AllmeanScr (mean tooth wear score of full dentition); and StateY1 (State Anxiety test). The p-values indicate no relation with respect to Diagnosis of Bruxism and the Trait Anxiety and Kessler 10 tests. 
Table 11. Table compiled from a Correlation Matrix using the Spearman Rank Order Sum

\begin{tabular}{|llrl|}
\hline Variable1 & Variable 2 & p-value & \multicolumn{1}{l|}{$\mathbf{r}$} \\
\hline \#Yes & BruxScr & $<0.01$ & 0.57 \\
\#Yes & BruxScrW1 & $<0.01$ & 0.70 \\
\#Yes & BruxScrW2 & 0.00 & 0.75 \\
\#Yes & Appliance & $<0.01$ & 0.54 \\
\#Yes & AllMeanScr & 0.13 & 0.29 \\
\#Yes & DeCtotStateY1 & 0.19 & 0.25 \\
BruxScr & Appliance & 0.01 & 0.48 \\
Appliance & AllMeanScr & 0.03 & 0.41 \\
trismus & AllMeanScr & 0.10 & 0.34 \\
trismus & IncCtotStateY1 & 0.17 & -0.29 \\
trismus & StateY1 & 0.16 & 0.30 \\
trismus & TraitY2 & 0.05 & -0.41 \\
trismus & Kessler10 & 0.12 & -0.33 \\
AllMeanScr & IncCtotStateY1E ST & 0.03 & -0.41 \\
AllMeanScr & StateY1 & 0.03 & 0.40 \\
AllMeanScr & TraitY2 & 0.08 & -0.33 \\
AllMeanScr & Kessler10 & 0.04 & -0.39 \\
State Y1 & Trait Y2 & $<0.01$ & -0.55 \\
State Y2 & Kessler10 & $<0.01$ & -0.59 \\
\hline
\end{tabular}

According to the Correlation matrix (Table 11) the relationship between tooth wear (AllMeanScr) and the 3 tests, namely, StateY1; TraitY2; and Kessler 10 differed, with a negative correlation found between tooth wear and the Trait Anxiety test, $r=-0.331(p=0.08)$ and also with the Kessler 10 Test $(p<0.05 ; r=-0.387)$. A positive relation was found between tooth wear and the State Anxiety scores $(p<0.5 ; r=0.397)$. 
A relation was also shown on the correlation matrix between $T M J$ sensitivity / Diagnosis Bruxism (\#Yes) and BruxScr (Bruxism Score) ( $p$ $<0.01 ; r=0.565)$ as well as wearing of an appliance $(p<0.01 ; r=0.54)$.

A significant correlation was observed between the mouth opening and the Trait Score, $r=-0.408(p<0.05)$. A relation between the Bruxism Score and wearing of an appliance could also be seen, $r=0.477(p<0.01)$. The StateY1 and Trait Y2 were negatively related, $r=-0.551(p<0.01)$ and the Trait Y2 and Kessler 10 were negatively related, $r=-0.588(p<0.01)$.

It can be seen that the relationships between the other variables in the correlation matrix were generally weaker.

\subsubsection{Relations between physiological variables}

\section{Tooth wear versus other physiological variables}

The relation between the anterior and posterior teeth of respectively, the maxilla and mandible, was analyzed as shown in Table 12.

Table 12. Table showing the relation between tooth wear scores

\begin{tabular}{|c|c|c|c|c|c|c|c|c|}
\hline & age & $\begin{array}{l}\text { MxAnt } \\
\text { Mean } \\
\text { Scr } \\
\end{array}$ & $\begin{array}{l}\text { MxPost } \\
\text { Mean } \\
\text { Scr }\end{array}$ & $\begin{array}{l}\text { Max } \\
\text { Mean } \\
\text { Scr } \\
\end{array}$ & $\begin{array}{l}\text { MdAnt } \\
\text { Mean } \\
\text { Scr } \\
\end{array}$ & $\begin{array}{l}\text { MdPost } \\
\text { Mean } \\
\text { Scr }\end{array}$ & $\begin{array}{l}\text { Mand } \\
\text { Mean } \\
\text { Scr }\end{array}$ & $\begin{array}{l}\text { All } \\
\text { canine } \\
\text { score }\end{array}$ \\
\hline age & 1 & 0.432 & 0.400 & 0.474 & 0.426 & 0.269 & 0.406 & 0.339 \\
\hline $\begin{array}{l}\text { MxAnt } \\
\text { Mean Scr }\end{array}$ & 0.432 & 1 & 0.549 & 0.915 & 0.885 & 0.478 & 0.799 & 0.806 \\
\hline $\begin{array}{l}\text { MxPost } \\
\text { Mean Scr }\end{array}$ & 0.400 & 0.549 & 1 & 0.840 & 0.519 & 0.805 & 0.758 & 0.536 \\
\hline $\begin{array}{ll}\text { Max } & \text { Mean } \\
\text { Scr } & \\
\end{array}$ & 0.474 & 0.915 & 0.840 & 1 & 0.826 & 0.699 & 0.885 & 0.783 \\
\hline $\begin{array}{l}\text { MdAnt } \\
\text { Mean Scr }\end{array}$ & 0.426 & 0.885 & 0.519 & 0.826 & 1 & 0.495 & 0.878 & 0.821 \\
\hline $\begin{array}{l}\text { MdPost } \\
\text { Mean Scr }\end{array}$ & 0.269 & 0.478 & 0.805 & 0.699 & 0.495 & 1 & 0.851 & 0.500 \\
\hline $\begin{array}{l}\text { Mand Mean } \\
\text { Scr } \\
\text { All canine }\end{array}$ & 0.406 & 0.799 & 0.758 & 0.885 & 0.878 & 0.851 & 1 & 0.773 \\
\hline score & 0.339 & 0.806 & 0.536 & 0.783 & 0.821 & 0.500 & 0.773 & 1 \\
\hline
\end{tabular}

The boxed measurements do not share elements of scoring (e.g. the scores of individual teeth) 
Table 13. Correlation between opposing tooth wear scores

\begin{tabular}{lccccccc}
\hline & \multicolumn{2}{c}{$\begin{array}{c}\text { MxAnt } \\
\text { Mean }\end{array}$} & $\begin{array}{c}\text { MxPost } \\
\text { Mean }\end{array}$ & $\begin{array}{c}\text { MdAnt } \\
\text { Mean } \\
\text { Scr }\end{array}$ & $\begin{array}{c}\text { MdPost } \\
\text { Mean } \\
\text { Scr }\end{array}$ & $\begin{array}{c}\text { All } \\
\text { canine } \\
\text { score }\end{array}$ \\
\hline age C & 1 & 0.432 & 0.400 & 0.426 & 0.269 & 0.339 \\
MxAnt Mean Scr & 0.432 & 1 & 0.549 & 0.885 & 0.478 & 0.806 \\
MxPost Mean Scr & 0.400 & 0.549 & 1 & 0.519 & 0.805 & 0.536 \\
Max Mean Scr & 0.474 & 0.915 & 0.840 & 0.826 & 0.699 & 0.783 \\
MdAnt Mean Scr & 0.426 & 0.885 & 0.519 & 1 & 0.495 & 0.821 \\
MdPost Mean Scr & 0.269 & 0.478 & 0.805 & 0.495 & 1 & 0.500 \\
Mand Mean Scr & 0.406 & 0.799 & 0.758 & 0.878 & 0.851 & 0.773 \\
All canine score & 0.339 & 0.806 & 0.536 & 0.821 & 0.500 & 1 \\
\hline
\end{tabular}
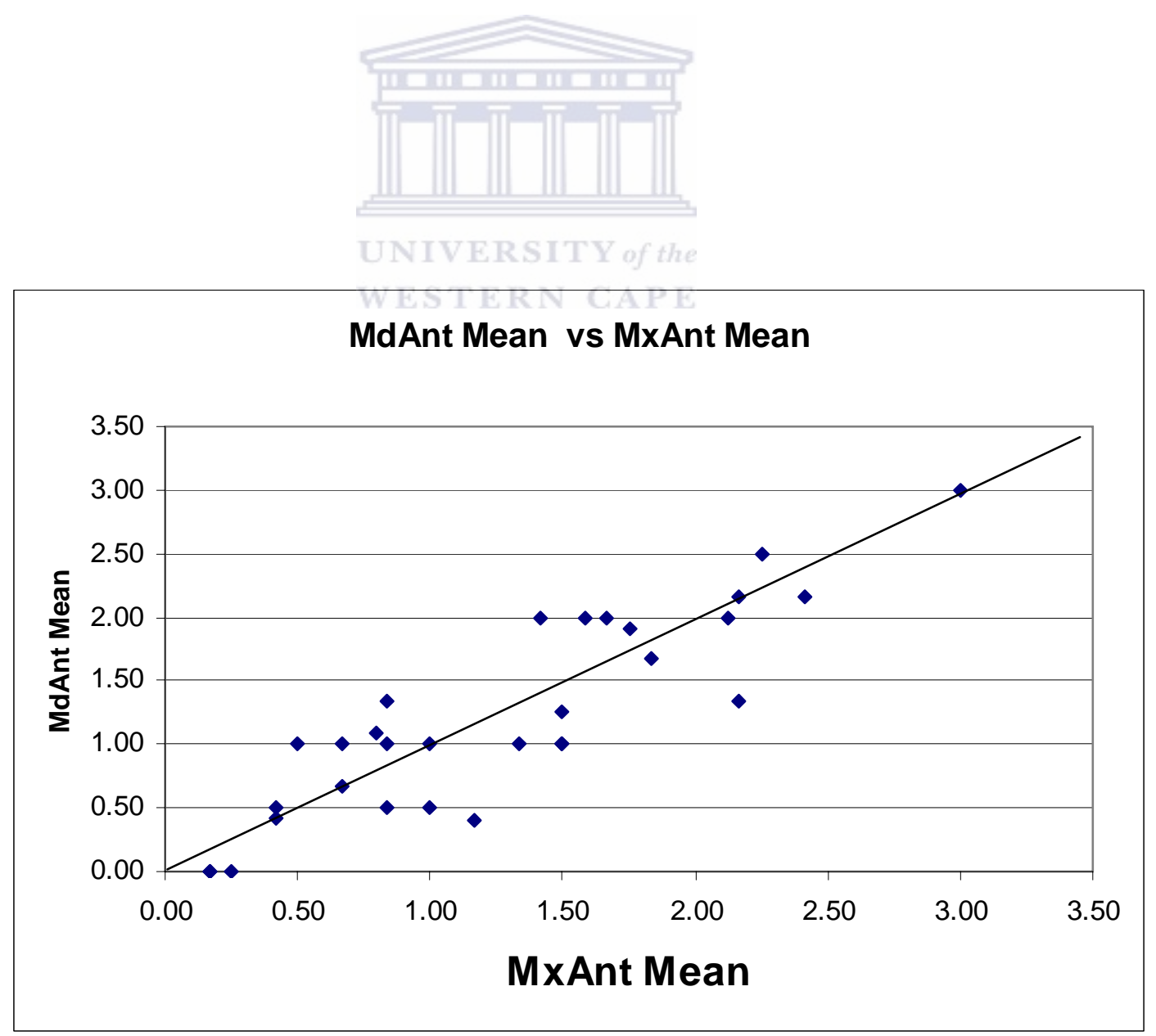

Figure 4. Scatter plot indicating the relation between the Anterior Mean tooth wear scores of the maxilla and the mandible 
According to Table 13, the correlation between MxAnt Mean and MdAnt Mean was $r=0.78$. A strong positive correlation was evident from the above scatter plot (Figure 4). This result confirms that tooth wear on the maxilla anterior teeth is accompanied by wear on the opposing mandible anterior teeth in concordance with the expectation of wear in the case of bruxism.

The correlation between MxPost Mean and MdPost Mean was $r=0.64$ (Table 13). It can therefore be seen that a stronger correlation exists between the tooth wear scores of the Maxillary and Mandibular anterior teeth than between the posterior teeth.

A reasonably strong tendency for the wear to increase with age is apparent in Figure 5. It was observed that four observations were below the estimated trend. These four observations were marked with a larger symbol. 


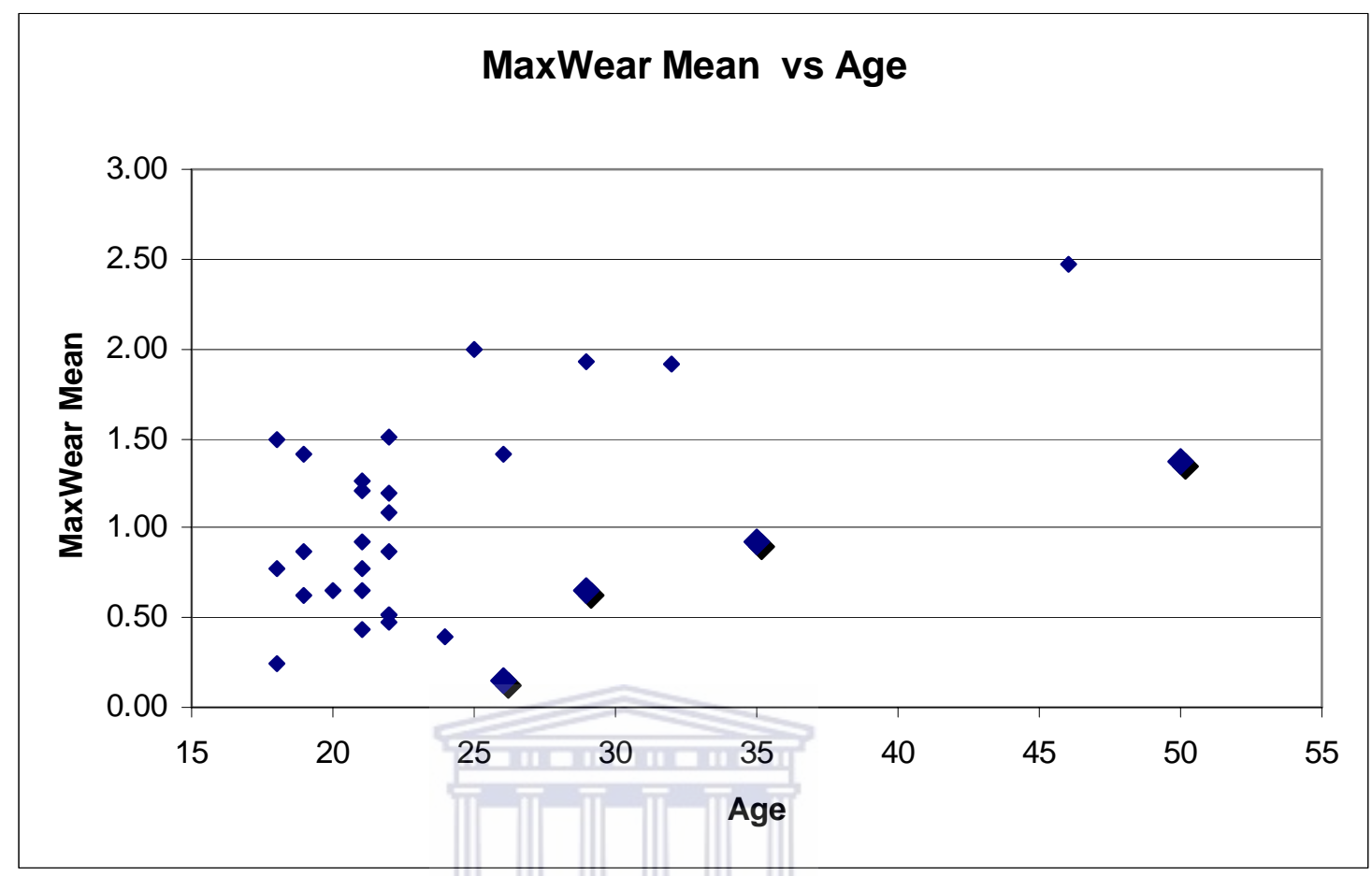

Figure 5. Scatter plot indicating the relation between the MeanTooth wear score of the Maxilla and age

Table 14. Table showing the descriptive statistics with respect to use of an Appliance; Gender and the Total Average of the Mandible Mean Score

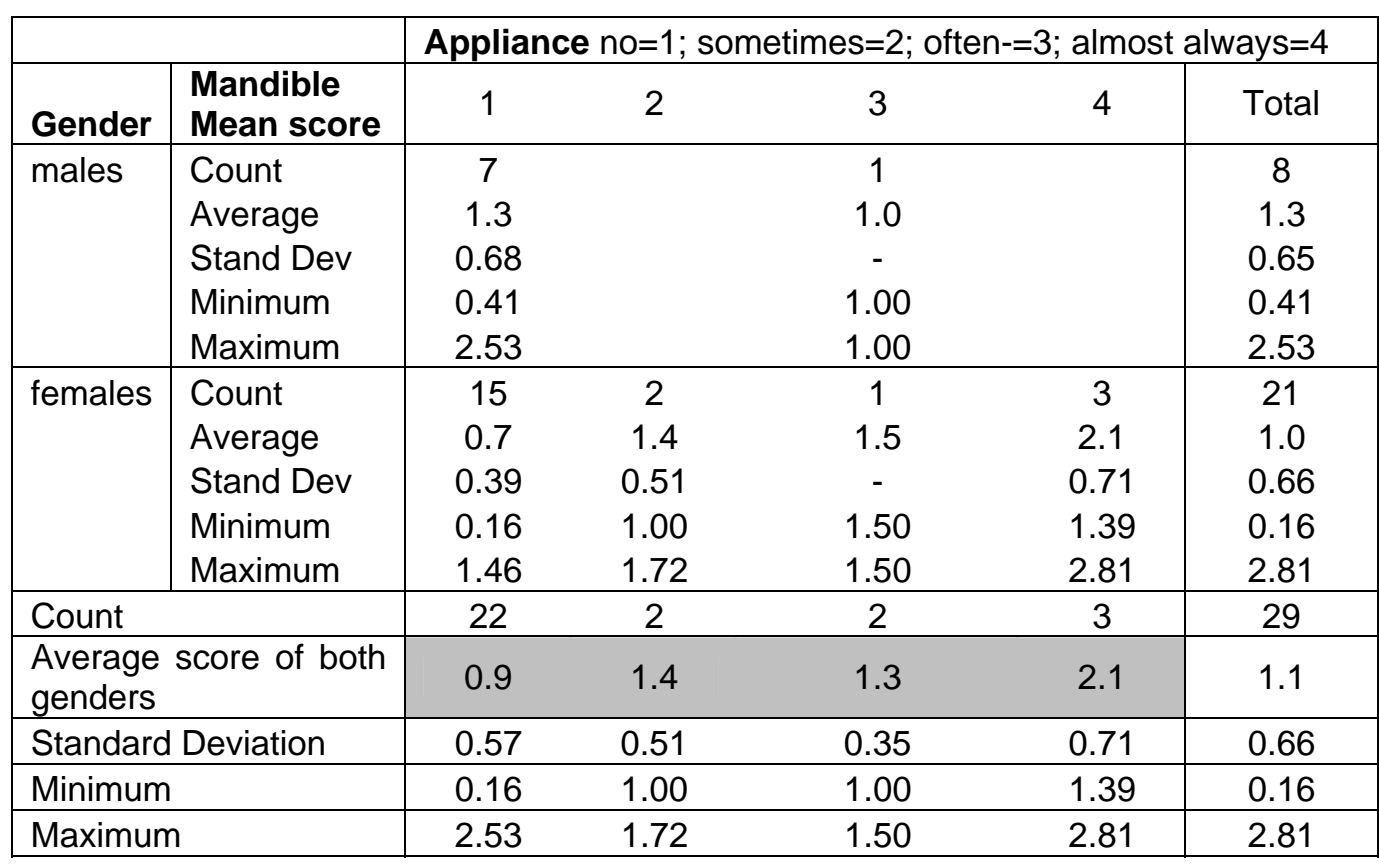


A good counter-example was provided in the Table 14. The second highest tooth wear score (2.53) occurred in a male not wearing any appliance. The highest tooth wear score (2.81) occurred in a female who used an appliance extensively.

In the lower part of the table, gender is ignored as classifier.

Twenty-two subjects did not use any appliance and the mean tooth wear measure equalled 0.9. In total 7 subjects used an appliance for pain and had means, (respectively $1.4 ; 1.3 ; 2.1$ ), larger than those who did not use any appliance. 
Table 15. Table indicating the relation between appliance, gender and the Total Average of Maxilla Mean Score

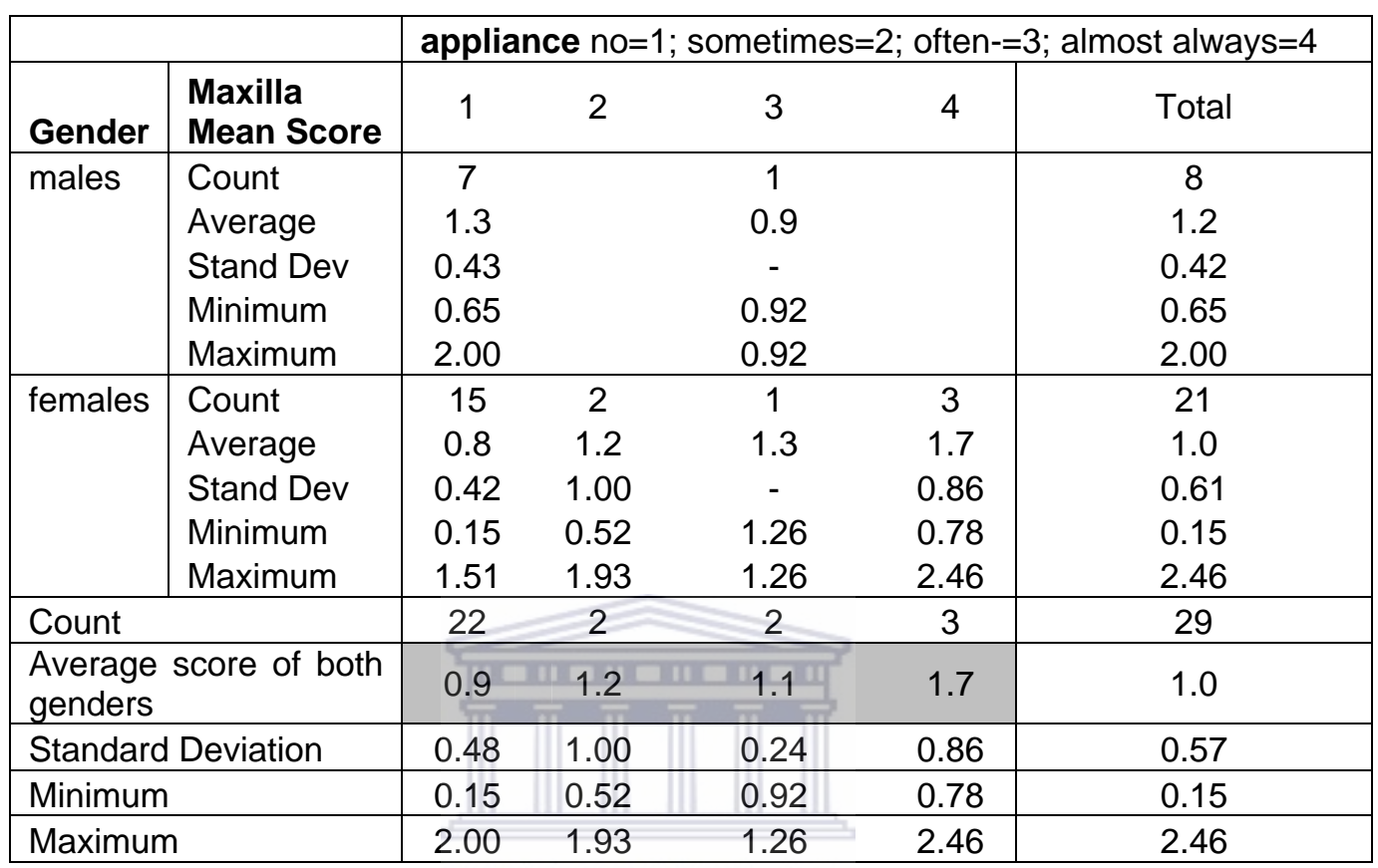

Table 15 shows that 22 subjects did not use any appliance and the mean tooth wear measure $=0.9$. In total 7 subjects used an appliance for pain and had means, (respectively $1.2 ; 1.1 ; 1.7)$, larger than those who did not use any appliance. 
Table 16. Table indicating the relation between the combined Diagnosis of Bruxism and TMJ Sensitivity (\#Yes) (defined by the number of "yes" answers to these questions), gender and Total Average of Mandible Mean Score

\begin{tabular}{|c|c|c|c|c|c|}
\hline & & \#Yes & & & \\
\hline Gender & $\begin{array}{l}\text { Mandible } \\
\text { Mean Score }\end{array}$ & $\begin{array}{c}\text { Both } \\
\text { questions } \\
\text { no - } 0\end{array}$ & $\begin{array}{c}\text { One } \\
\text { question } \\
\text { Yes -1 }\end{array}$ & $\begin{array}{c}\text { Both } \\
\text { questions } \\
\text { Yes - } 2\end{array}$ & Total \\
\hline males & $\begin{array}{l}\text { Count } \\
\text { Average } \\
\text { Stand Dev } \\
\text { Minimum } \\
\text { Maximum }\end{array}$ & $\begin{array}{c}3 \\
1.1 \\
0.38 \\
0.69 \\
1.34 \\
\end{array}$ & $\begin{array}{c}3 \\
1.2 \\
0.67 \\
0.41 \\
1.63 \\
\end{array}$ & $\begin{array}{c}2 \\
1.8 \\
1.08 \\
1.00 \\
2.53 \\
\end{array}$ & $\begin{array}{c}8 \\
1.3 \\
0.65 \\
0.41 \\
2.53 \\
\end{array}$ \\
\hline females & $\begin{array}{l}\text { Count } \\
\text { Average } \\
\text { Stand Dev } \\
\text { Minimum } \\
\text { Maximum }\end{array}$ & $\begin{array}{c}4 \\
0.8 \\
0.49 \\
0.38 \\
1.46\end{array}$ & \begin{tabular}{|c|}
11 \\
0.9 \\
0.73 \\
0.16 \\
2.81
\end{tabular} & $\begin{array}{c}6 \\
1.5 \\
0.46 \\
0.75 \\
2.11 \\
\end{array}$ & $\begin{array}{c}21 \\
1.0 \\
0.66 \\
0.16 \\
2.81 \\
\end{array}$ \\
\hline Count & & 7 & 14 & 8 & 29 \\
\hline $\begin{array}{l}\text { Average } \\
\text { genders }\end{array}$ & score of both & 0.9 & 0.9 & 1.5 & 1.1 \\
\hline Standaro & Deviation & 0.45 & 0.70 & 0.58 & 0.66 \\
\hline Minimum & & 0.38 & 0.16 & 0.75 & 0.16 \\
\hline Maximun & & 1.46 & 2.81 & 2.53 & 2.81 \\
\hline
\end{tabular}

A slight increase in the mandible mean scores (1.5) was evident in subjects (both male and female) with a positive diagnosis of bruxism and TMJ sensitivity according to Table 16 . 
Table 17. Table indicating the relation between the combined Diagnosis of Bruxism and TMJ Sensitivity (\#Yes) (defined by the number of "yes" answers to these questions), gender and Total Average of Maxilla Mean Score

\begin{tabular}{|c|c|c|c|c|c|}
\hline \multirow[b]{2}{*}{ Gender } & \multirow[b]{2}{*}{$\begin{array}{l}\text { Maxilla } \\
\text { Mean Score }\end{array}$} & \multicolumn{4}{|l|}{ \#Yes } \\
\hline & & $\begin{array}{c}\text { Both } \\
\text { questions } \\
\text { no }-0\end{array}$ & $\begin{array}{c}\text { One } \\
\text { question } \\
\text { Yes -1 }\end{array}$ & $\begin{array}{c}\text { Both } \\
\text { questions } \\
\text { Yes }-2\end{array}$ & Total \\
\hline \multirow[t]{5}{*}{ males } & \multirow{5}{*}{$\begin{array}{l}\text { Count } \\
\text { Average } \\
\text { Stand Dev } \\
\text { Minimum } \\
\text { Maximum }\end{array}$} & 3 & 3 & 2 & 8 \\
\hline & & 1.2 & 1.1 & 1.5 & 1.2 \\
\hline & & 0.23 & 0.43 & 0.77 & 0.42 \\
\hline & & 0.92 & 0.65 & 0.92 & 0.65 \\
\hline & & 1.36 & 1.50 & 2.00 & 2.00 \\
\hline \multirow[t]{5}{*}{ females } & \multirow{5}{*}{$\begin{array}{l}\text { Count } \\
\text { Average } \\
\text { Stand Dev } \\
\text { Minimum } \\
\text { Maximum }\end{array}$} & 4 & 11 & 6 & 21 \\
\hline & & 0.9 & 0.9 & 1.3 & 1.0 \\
\hline & & 0.39 & 0.69 & 0.56 & 0.61 \\
\hline & & 0.51 & 0.15 & 0.63 & 0.15 \\
\hline & & 1.41 & 2.46 & 1.93 & 2.46 \\
\hline \multicolumn{2}{|c|}{ Count } & 7 & 14 & 8 & 29 \\
\hline \multicolumn{2}{|c|}{$\begin{array}{l}\text { Average of both } \\
\text { genders }\end{array}$} & 1.0 & 0.9 & 1.3 & 1.0 \\
\hline \multicolumn{2}{|c|}{ Standard Deviation } & 0.35 & 0.64 & 0.56 & 0.57 \\
\hline \multicolumn{2}{|c|}{ Minimum } & 0.51 & 0.15 & 0.63 & 0.15 \\
\hline \multicolumn{2}{|c|}{ Maximum } & 1.41 & 2.46 & 2.00 & 2.46 \\
\hline
\end{tabular}

Table 17 showed that a slight increase in the maxilla mean scores was evident in subjects (both male and female) with a positive diagnosis of bruxism and TMJ sensitivity. 
Table 18. Table indicating the relation between Restless Legs, gender and Total Average of Mandible Mean Score

\begin{tabular}{|c|c|c|c|c|c|c|}
\hline & \multicolumn{5}{|l|}{$\begin{array}{l}\text { Restless } \\
\text { legs }\end{array}$} \\
\hline Gender & $\begin{array}{l}\text { Mandible } \\
\text { Mean Score }\end{array}$ & $\begin{array}{c}\text { Never } \\
1\end{array}$ & $\begin{array}{c}\text { Somewhat } \\
2\end{array}$ & $\begin{array}{c}\text { Moderately } \\
3\end{array}$ & $\begin{array}{l}\text { Very much } \\
\text { so } 4\end{array}$ & Total \\
\hline \multirow[t]{5}{*}{ males } & Count & 3 & 3 & 1 & 1 & 8 \\
\hline & Average & 0.9 & 1.8 & 1.3 & 1.0 & 1.3 \\
\hline & Stand Dev & 0.64 & 0.65 & \#DIV/O! & \#DIV/O! & 0.65 \\
\hline & Minimum & 0.41 & 1.33 & 1.34 & 1.00 & 0.41 \\
\hline & Maximum & 1.63 & 2.53 & 1.34 & 1.00 & 2.53 \\
\hline \multirow{5}{*}{ females } & Count & 8 & 6 & 4 & 3 & 21 \\
\hline & Average & 0.8 & 1.2 & 1.0 & 1.4 & 1.0 \\
\hline & Stand Dev & 0.46 & 0.92 & 0.78 & 0.13 & 0.66 \\
\hline & Minimum & 0.16 & 0.38 & 0.38 & 1.25 & 0.16 \\
\hline & Maximum & 1.46 & 2.81 & 2.11 & 1.50 & 2.81 \\
\hline \multicolumn{2}{|c|}{ Count } & 11 & 9 & 5 & 4 & 29 \\
\hline \multicolumn{2}{|c|}{$\begin{array}{l}\text { Average of both } \\
\text { genders }\end{array}$} & 0.8 & 1.4 & 1.1 & 1.3 & 1.1 \\
\hline \multicolumn{2}{|c|}{ Standard Deviation } & 0.48 & 0.85 & 0.69 & 0.22 & 0.66 \\
\hline \multicolumn{2}{|c|}{ Minimum } & 0.16 & 0.38 & 0.38 & 1.00 & 0.16 \\
\hline \multicolumn{2}{|c|}{ Maximum } & 1.63 & 2.81 the & 2.11 & 1.50 & 2.81 \\
\hline
\end{tabular}

The mean Mandible tooth wear score and restless legs showed that Mandible tooth wear changes with the ordinal measurement restless legs, but inconsistently (not monotone) in Table 18.

A positive correlation between age and tooth wear was found. Increased tooth wear was related to increase in age.

The correlation matrix using the Pearson product moment correlation coefficient ( $r$ ) was performed. Trismus was related to tooth wear. The same variables were compared in the correlation matrix using the Spearman Rank Order Sum $\left(r^{s}\right)$. Trismus was found to be weakly related to tooth wear $(p=0.10)$. 


\section{Bruxism versus other physiological variables}

Table 19. Table showing the relation between Diagnosis of Bruxism /TMJ Sensitivity (\#Yes) (defined by the number of "yes" answers to these questions) and Average Bruxism Score

\begin{tabular}{|l|ccc|c|}
\hline & \#Yes & & & \\
& $\begin{array}{c}\text { Both } \\
\text { questions } \\
\text { No }\end{array}$ & $\begin{array}{c}\text { One } \\
\text { question } \\
\text { Yes }\end{array}$ & $\begin{array}{c}\text { Both } \\
\text { questions } \\
\text { Yes }\end{array}$ & Total \\
\hline Count & 0 & 1 & 2 & \\
Average & 7 & 14 & 8 & 29 \\
Stand Dev & 12.6 & 15.2 & 18.8 & 15.6 \\
Minimum & 3.10 & 3.51 & 4.23 & 4.18 \\
Maximum & 9 & 11 & 13 & 9 \\
\hline
\end{tabular}

A steady increase in the average bruxism score accompanied the diagnosis of bruxism and $\mathrm{TMJ}$ sensitivity. With regard to the relation between TMJ sensitivity and Bruxism score, the group was split on TMJ sensitivity and compared to the Bruxism score. The median was 12 for "No" answers and 16.5 for "Yes" (one or more "yes" answers to the 2 questions) answers.

These results partially confirm the necessity of adding weights to the variables: "Diagnosis of bruxism" and "TMJ sensitivity".

Using the Wilcoxon Rank Sum Test with and without a weighted score showed a significant difference with a 1\% probability of error between the diagnosis of bruxism and the Bruxism score (Bruiser; BruxscrW1; BruxscrW2). The influence of weighting was determined on the index BruxWideWeighted in relation to the Diagnosis of bruxism. The difference increases and is more definite using weighted scores. The medians differ more in the weighted score.

The variables Diagnosis of bruxism and TMJ sensitivity were weighted. These variables were related to Brux, BruxW1, BruxW2. A possible 
relation exists between TMJ sensitivity and bruxism. The Wilcoxon Rank Sum Test is a very conservative test, thus if there is a difference it will show.

Table 20. Table indicating the relation between Restless Legs; Diagnosis of Bruxism /TMJ Sensitivity (\#Yes) (defined by the number of "yes" answers to these questions) and Total Average of Bruxism Score

\begin{tabular}{|c|c|c|c|c|c|}
\hline \multirow[b]{2}{*}{ Restless legs } & \multirow[b]{2}{*}{$\begin{array}{l}\text { Bruxism } \\
\text { Score }\end{array}$} & \multicolumn{4}{|l|}{ \#Yes } \\
\hline & & $\begin{array}{c}\text { Both } \\
\text { questions } \\
\text { No } \\
0\end{array}$ & $\begin{array}{c}\text { One } \\
\text { question } \\
\text { Yes } \\
1\end{array}$ & $\begin{array}{l}\text { Both } \\
\text { questions } \\
\text { Yes } \\
2\end{array}$ & Total \\
\hline & \multirow{5}{*}{$\begin{array}{l}\text { Count } \\
\text { Average } \\
\text { Stand Dev } \\
\text { Minimum } \\
\text { Maximum }\end{array}$} & 3 & 6 & 2 & 11 \\
\hline & & 14.7 & 14.8 & 18.5 & 15.5 \\
\hline \multirow[t]{5}{*}{1} & & 3.79 & 3.25 & 3.54 & 3.42 \\
\hline & & 12 & 12 & 16 & 12 \\
\hline & & 19 & 19 & 21 & 21 \\
\hline & \multirow{5}{*}{$\begin{array}{l}\text { Count } \\
\text { Average } \\
\text { Stand Dev } \\
\text { Minimum } \\
\text { Maximum }\end{array}$} & 3 & 4 & 2 & 9 \\
\hline & & 11.7 & 16.0 & 16.5 & 14.7 \\
\hline \multirow[t]{5}{*}{2} & & 0.58 & 4.69 & 4.95 & 4.06 \\
\hline & & 11 & 11 & 13 & 11 \\
\hline & & 12 & 22 & 20 & 22 \\
\hline & \multirow{5}{*}{$\begin{array}{l}\text { Count } \\
\text { Average } \\
\text { Stand Dev } \\
\text { Minimum } \\
\text { Maximum }\end{array}$} & 1 & 3 & 1 & 5 \\
\hline & & 9.0 & 15.7 & 26.0 & 16.4 \\
\hline \multirow[t]{5}{*}{3} & & - & 4.04 & - & 6.73 \\
\hline & & 9 & 12 & 26 & 9 \\
\hline & & 9 & 20 & 26 & 26 \\
\hline & \multirow{5}{*}{$\begin{array}{l}\text { Count } \\
\text { Average } \\
\text { Stand Dev } \\
\text { Minimum } \\
\text { Maximum }\end{array}$} & & 1 & 3 & 4 \\
\hline & & & 13.0 & 18.0 & 16.8 \\
\hline 4 & & & - & 3.46 & 3.77 \\
\hline & & & 13 & 16 & 13 \\
\hline & & & 13 & 22 & 22 \\
\hline \multirow{5}{*}{$\begin{array}{l}\text { Count } \\
\text { Average of } \\
\text { group } \\
\text { Stand Dev } \\
\text { Minimum } \\
\text { Maximum }\end{array}$} & & 7 & 14 & 8 & 29 \\
\hline & & 12.6 & 15.2 & 18.8 & 15.6 \\
\hline & & 3.10 & 3.51 & 4.23 & 4.18 \\
\hline & & 9 & 11 & 13 & 9 \\
\hline & & 19 & 22 & 26 & 26 \\
\hline
\end{tabular}

-- = no value can be given

A slight upward trend was evident in the bruxism scores of subjects who displayed restless legs behaviour in Table 20. 


\section{Wearing of an appliance versus other variables}

A possible relation was found between wearing of an appliance and Diagnosis of bruxism/ TMJ sensitivity (\#Yes), $r=0.535$ ( $p<0.01$ ). A relation between wearing of an appliance and tooth wear was also shown, $r=0.41$ $(p=0.03)$ as well as with the Bruxism Score, $r=0.48(p=0.01)$.

\subsubsection{Psychological versus physiological variables}

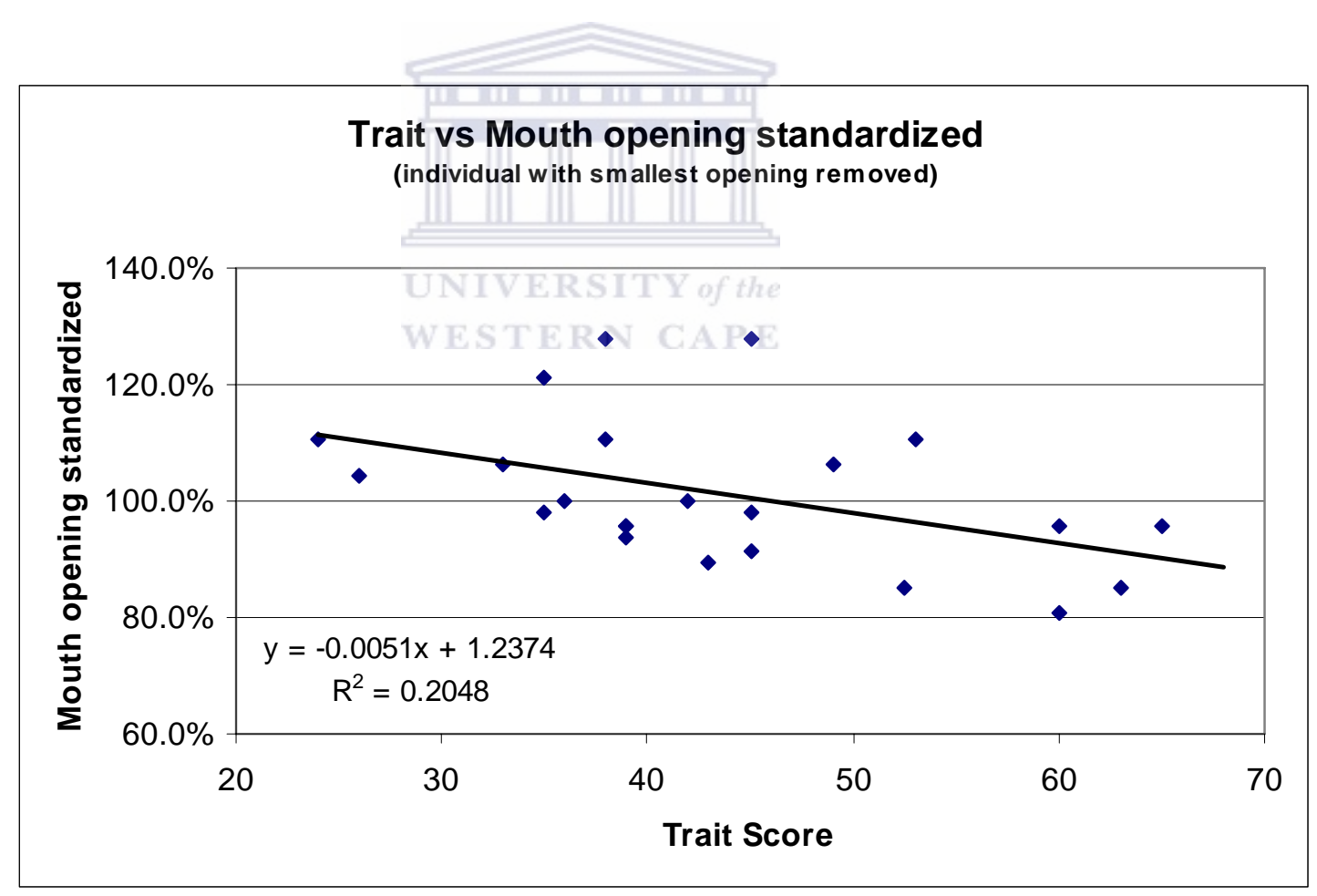

Figure 6. Scatter plot showing the relation between Trismus (mouth opening) and the Trait Score

Trait scores explain approximately $20 \%$ of the variability present in the mouth opening. The Trait score increased as the mouth opening decreased. 
The correlation matrix using the Pearson product moment correlation coefficient ( $r$ ) was performed. Trismus was related to Trait Anxiety and Kessler 10. The same variables were compared in the correlation matrix using the Spearman Rank Order Sum $\left(r^{s}\right)$. Trismus was found to be weakly related to Kessler 10 ( $p=0.12$ ). However, a significant relation was found between trismus and Trait Anxiety, $r=-0.408(p<0.05)$. The smaller the mouth opening, the higher the tooth wear, Trait anxiety and Kessler 10 scores.

\section{Bruxism score versus the anxiety and stress scores}

Although the p-values between the bruxism score and the anxiety and stress scores were too large to be statistically significant in this study, the scatter plots showed interesting $\mathrm{V}$-formations. A further study using a larger sample is required to determine the statistical significance of these findings.

Approximately $50 \%$ of subjects scored above the mean scores for the tests, respectively (State Y1 (34); Trait Y2 (44.43): Kessler 10 (22.83) and BruxW2Score (17.41).

Of the approximately $50 \%$ of subjects with higher anxiety and stress scores, $28 \%$ of the total group of subjects scored above the BruxW2 Score, while $22 \%$ of the total group of subjects scored below (these percentages represent an estimate of the 3 psychological tests).

This $50 \%$ of subjects was thus divided into 2 groups. In $28 \%$ of the total group of subjects a higher BruxW2 Score was related to a higher mean anxiety and stress score, while in $22 \%$ of the total group of subjects a higher mean anxiety and stress score was not related to a higher BruxW2 Score. This tendency can be seen in the following three scatter plots (Figures 7, 8, 9). 


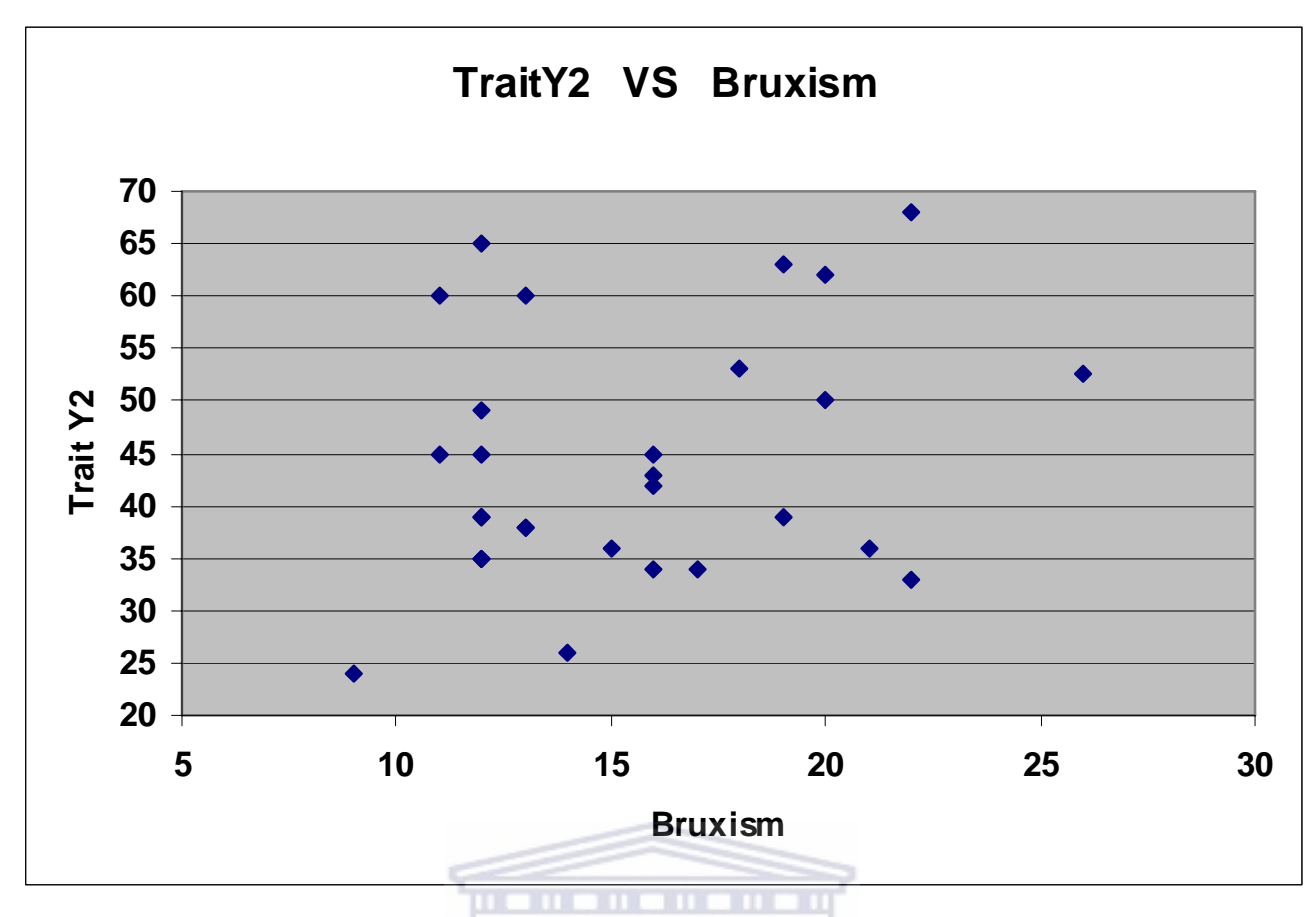

Figure 7. Scatter plot indicating the relation between the TraitY2 scores and the Bruxism Score

The sample can be divided into two groups, those with a very low bruxism score and those with a bruxism score of 14 and more. In the second group it is evident that as the bruxism score increases the Trait Y2 score also increases. 


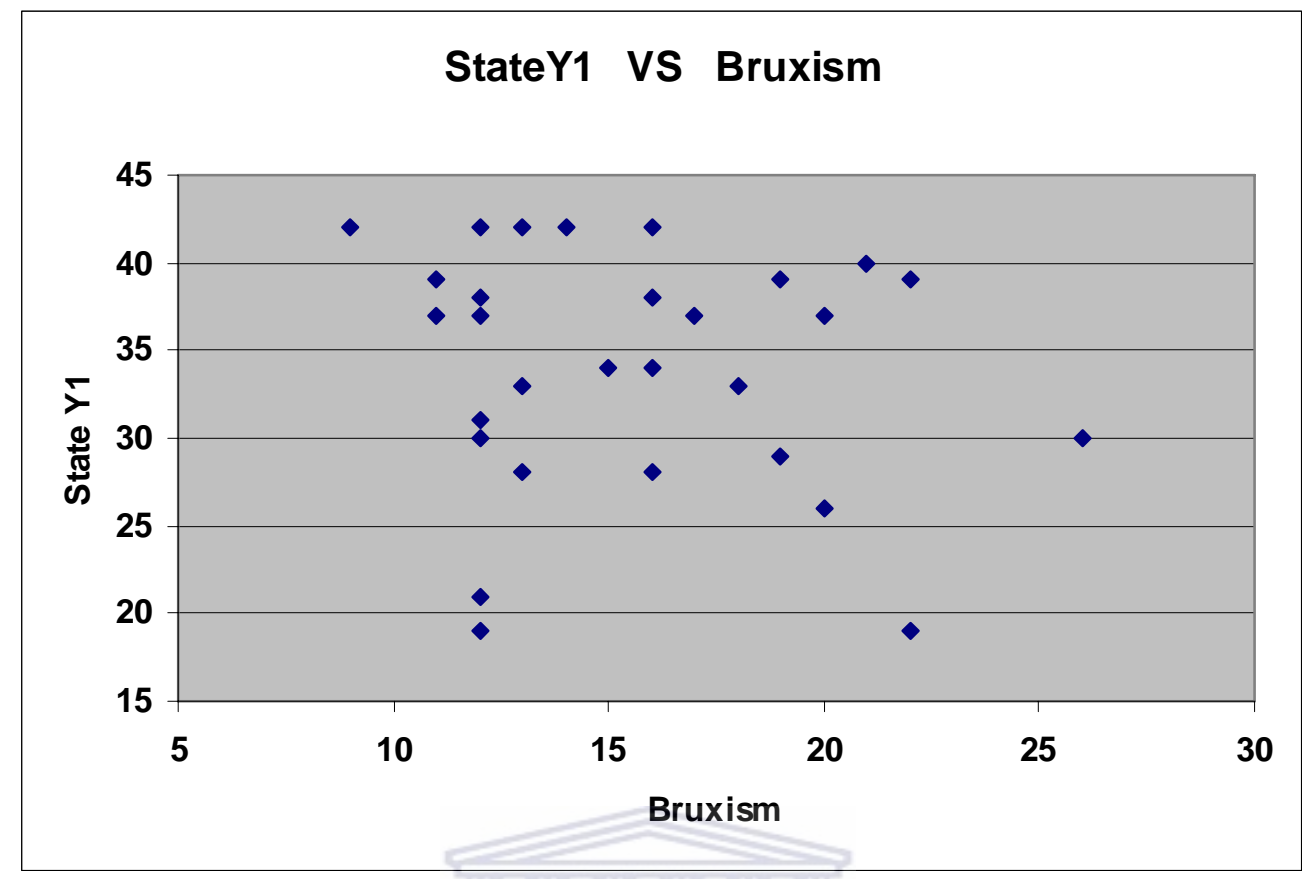

Figure 8. Scatter plot indicating the relation between the State Y1 scores and the Bruxism Score.

The scatter plot indicates that the values above the State Y1 average score (34) are divided into two groups, namely one group with lower than average Bruxism index scores and one with higher than average Bruxism index scores (BruxW2 average $=17.41)$. 


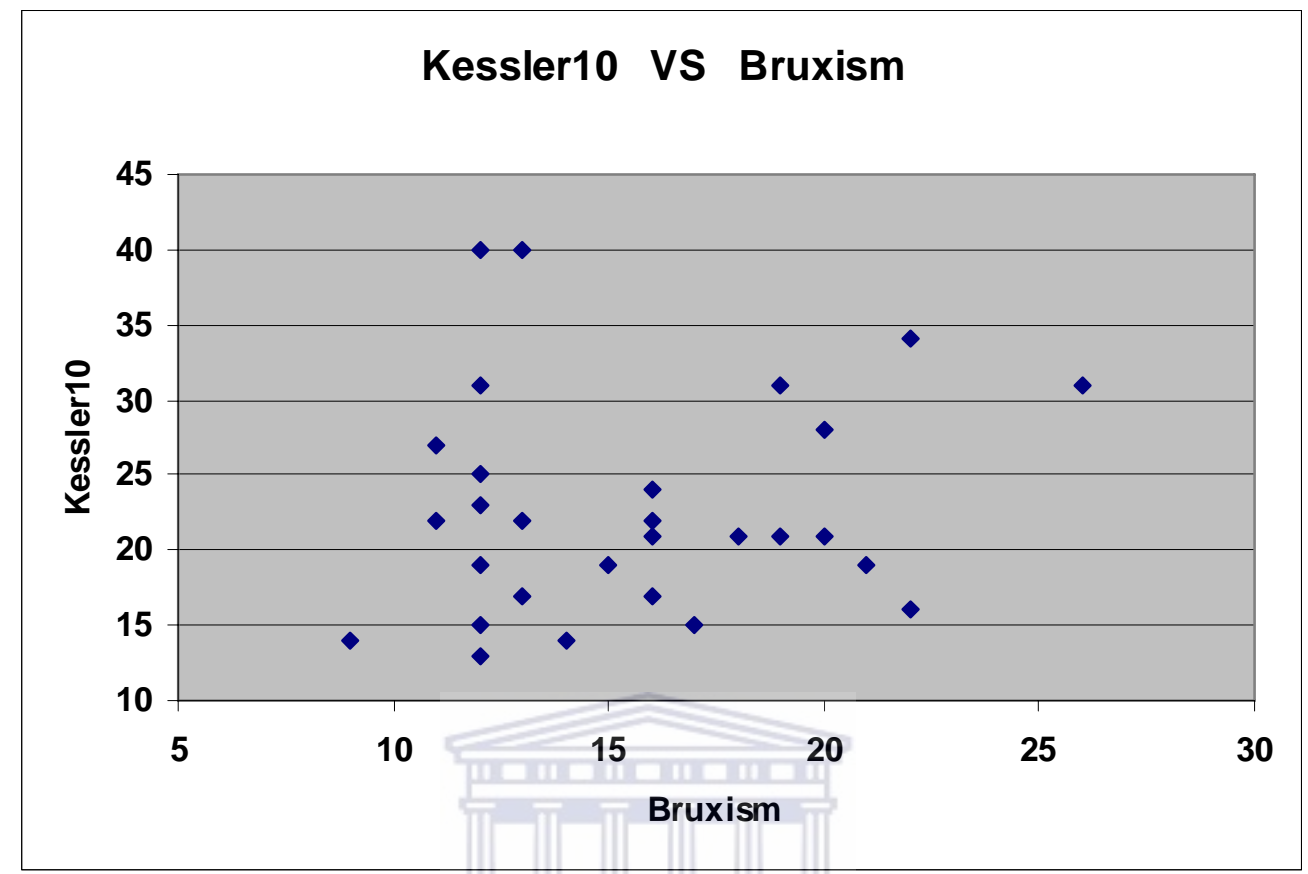

Figure 9. Scatter plot indicating the relation between the Kessler 10 score and the Brux Index

The scatter plot indicates that the values above the Kessler 10 average score (22.83) are divided into two groups, namely one group with lower Brux index scores and one with higher Brux index scores (BruxW2 average $=17.41)$.

Kessler 10 provides a general measure of stress, anxiety and depression for the previous 4-week period. State Y1 provides a measure of anxiety for a specific situation, while Trait Y2 provides an anxiety score for the previous 4-week period. 


\subsubsection{Psychological versus psychological variables}

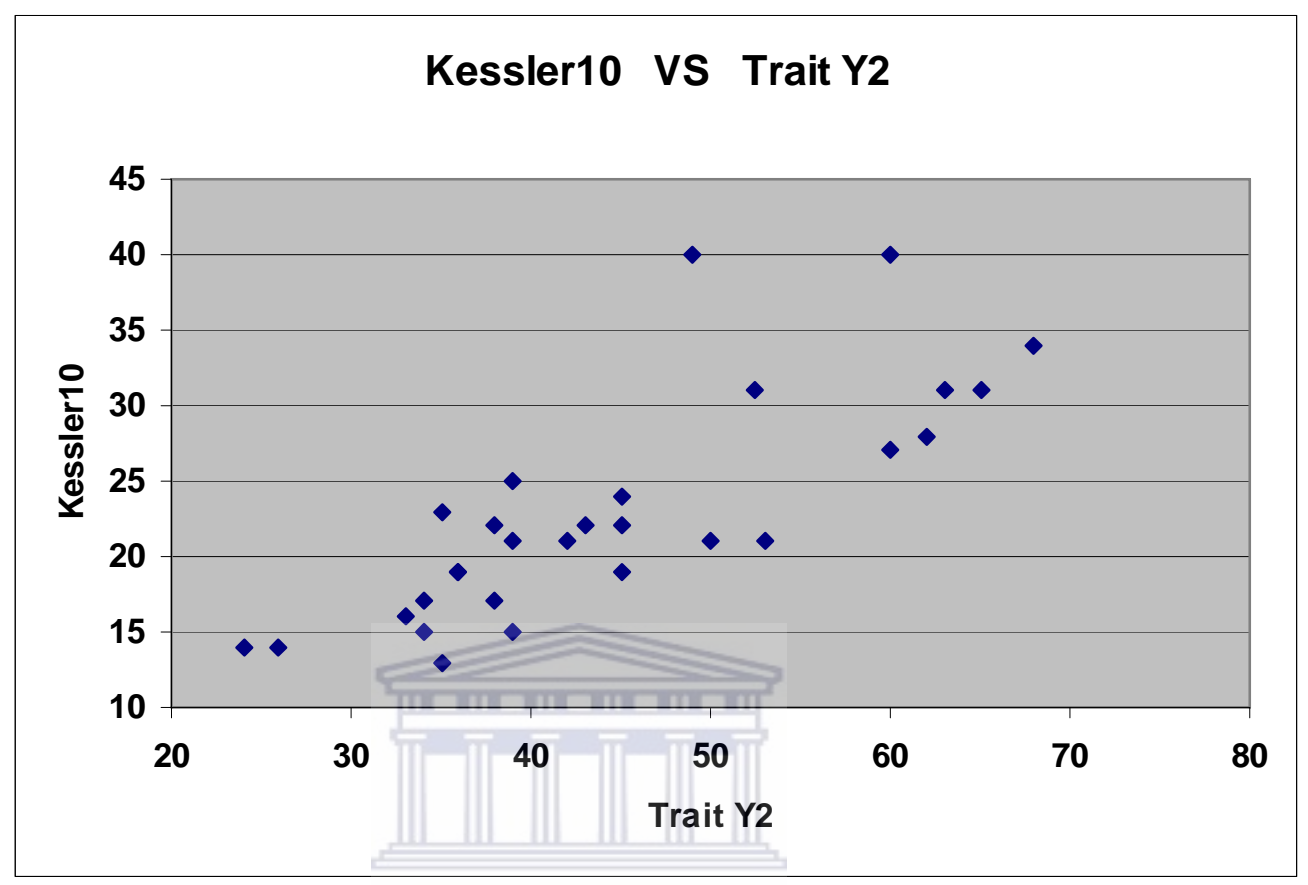

Figure 10. Scatter plot on the relation between Kessler 10 and Trait Y2 scores

The dualistic character of the sample is confirmed by the relationship between Kessler 10 and Bruxism (refer to Figure 9) and the strong positive correlation between the Kessler 10 and Trait $Y 2$ scores shown in Figure 10.

Two unusual values can be observed above the trend due to high Kessler 10 scores. 


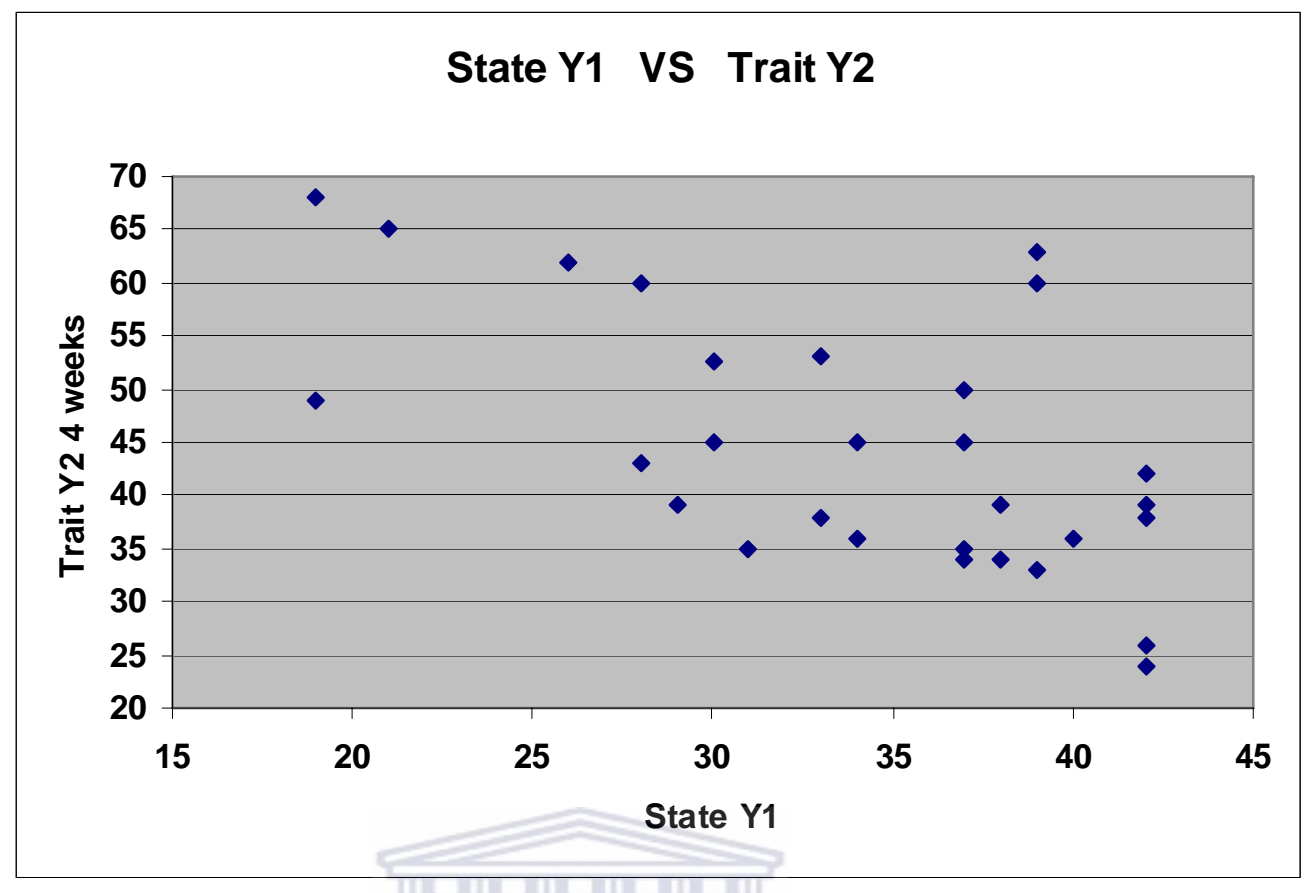

Figure 11. Scatter plot of the relation between the Trait $Y 2$ and State $Y 1$ scores

A negative trend was present in the above scatter plot (Figure 11), indicating that subjects with higher Trait Y2 scores were less anxious in the State Y1 test. Three of the measurements do not fit in with the negative trend visible in the plot above.

The negative trend is possibly due to the difference in test focus. State Y1 provides a measure of anxiety for a specific situation, while Trait Y2 provides an anxiety score for the previous 4-week period.

The lower scores on the State $\mathrm{Y} 1$ test in the study could possibly be due to the fact that the test environment was familiar to the majority of subjects who were dentistry and oral hygiene students. 


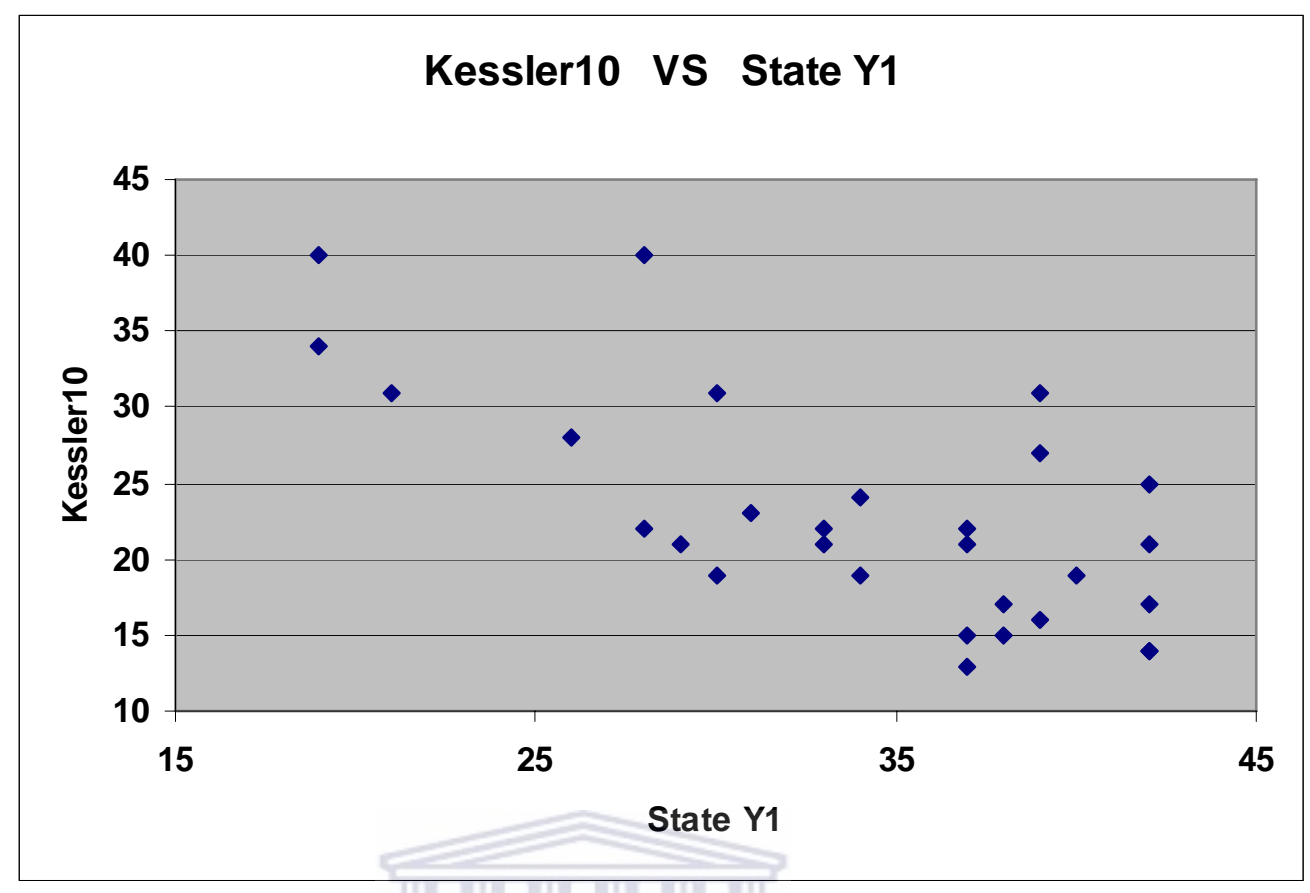

Figure 12. Scatter plot of the relation between the Kessler 10 and State Y1 scores

A negative trend was observed between Kessler 10 and State Y1, but the dispersion about the line was wider over the complete scale than in the relationship between State Y1 and Trait Y2.

The negative trend is possibly due to the difference in test focus. Kessler 10 provides a general measure of stress, anxiety and depression for the previous 4-week period, whereas the State $\mathrm{Y} 1$ provides a measure of anxiety for a specific situation.

\section{Possible nuisance variables}

The results of this study showed no significant relation between tooth wear and exposure to a dusty environment; acid regurgitation; and coke and fruit juice consumption. The influence of other possible latent variables should however always be considered. 


\subsection{Bruxers versus non-bruxers}

The diagnosis of bruxism according to specified criteria was performed.

Forty one percent $(n=12)$ of the sample of 29 subjects was diagnosed as bruxers, while 17 were non-bruxers. 


\section{Chapter 5 \\ Discussion}

The main aim of the study was to determine whether there was a relation between the psychological variables, anxiety and stress, and the physiological variable bruxism. The main trends, patterns and connections that emerged from the results will be discussed and summarized.

Firstly, the results on the relations between the physiological variables related to bruxism and tooth wear will be discussed, secondly the relations between the three psychological tests, thirdly the results regarding the relations between the psychological and physiological variables with reference to other research findings and fourthly the determination of the number of bruxers according to the definition of bruxism. The multifactorial nature of bruxism and tooth wear should be emphasized when considering the results of the study.

In order to avoid confusion it should be noted that for the purpose of this study the term "Bruxism Score" refers to the score on the "Demographic and Clinical Criteria " Questionnaire (Refer to Addendum 1). 


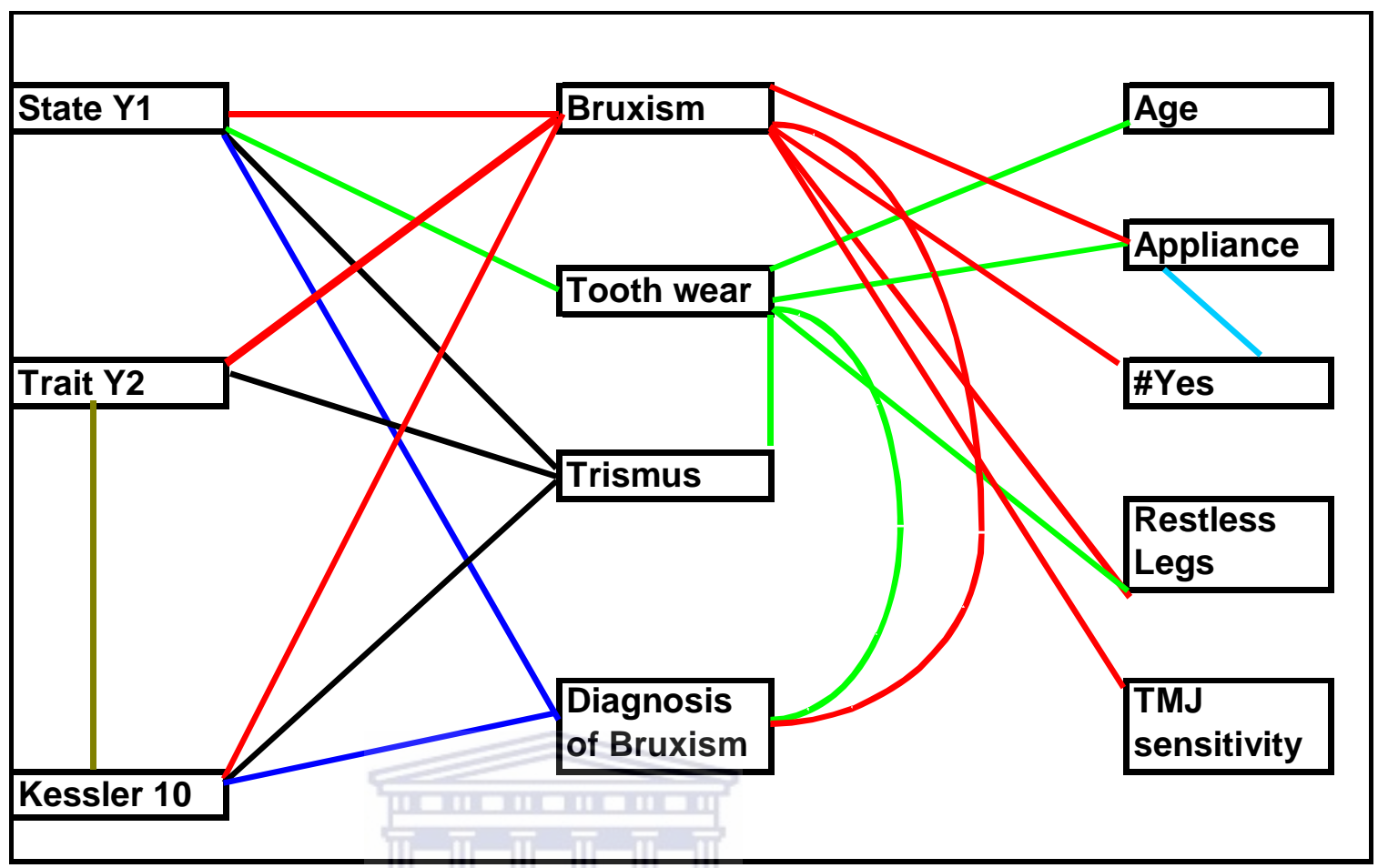

Figure 13. Mind map showing the relations between the variables in the study

\subsection{Relations between physiological variables}

The bruxism questionnaire used in this study was formulated to provide a score on a continuum, because all individuals display signs of bruxism according to Abrahamsen (2005) who reported 33 years of continuous study of tooth wear on dental casts (Abrahamsen, 2005). The Bruxism Questionnaire score was determined separate form the tooth wear score as tooth wear cannot be used a sole indicator of bruxism.

A steady increase in the average bruxism score accompanied the combined score: Diagnosis of Bruxism/TMJ sensitivity (\#Yes). There was a significant difference between TMJ sensitivity and the bruxism score for subjects who answered "Yes" compared to "No" for TMJ sensitivity ( $p=$ 0.01). Other findings (Kampe, Tagdae et al., 1997) also indicate a relation 
between bruxism and TMJ sensitivity. Research (Manfredini, Cantini et al., 2003) confirms the existence of a strong association between bruxism and TMD, particularly between bruxism and myofascial pain. The same trend was observed between the Diagnosis of bruxism Score and the Bruxism Score in the present study. Noting the association between bruxism and TMD in the study is important because the recognition of the role of subthreshold symptoms of anxiety and stress in the etiology of bruxism also has an impact on treatment of symptoms of TMD such as myofascial pain and TMJ sensitivity. Research results indicating improvement in TMD symptoms such as MFP by means of psychological intervention (De Laat et al., 2003; Kalamir et al., 2006; Morishige et al., 2006) confirm the clinical importance of the findings of this study.

A slight upward trend was evident in the bruxism scores of subjects who displayed restless legs behaviour. Research by (Ahlberg et al., 2005) showed that restless legs may have a negative influence on sleep quality which could lead to more frequent bruxism. "Restless legs" was included in the questionnaire as a variable to determine the possibility of muscular hyperactivity in other parts of the body other than in the masseter muscles. Restless legs and bruxism are considered as sleep-related movement disorders (Porvazova \& Bassetti, 2007). Subjects who displayed some restless leg behaviour showed more tooth wear in the mandible but not consistently in the maxillary teeth.

Considering that the mean age of the study population was 24.3 , the tooth wear score was expected to be relatively low. The results of the study show more tooth wear on the maxillary anterior teeth accompanied by wear on the opposing mandibular anterior teeth than on the posterior teeth. This tendency in bruxers was also observed by other researchers (Abrahamsen, 2005; Johansson, Haraldson et al., 1993) of which the latter two used the same ordinal scale for tooth wear as used in the present study. According to research results (Pigno et al., 2001), maxillary tooth wear was significantly greater in males and in subjects with reported teeth 
clenching/grinding. However, more bruxism was found in women than men in another study (Koyano et al., 2005). No constant result is portrayed in the studies on gender differences in the incidence of bruxism. Gender was not examined extensively as a variable in this study due to the small number of male subjects $(8: 21)$ who participated.

Regarding the nature of the dental wear, plane surfaces in accordance with research findings (Restrepo et al., 2006), were observed especially on incisors.

In this study tooth wear was shown to be a pathognomonic sign of bruxism, but it cannot be used as the only sign for diagnosis. Only a slight increase in the maxilla and mandible mean tooth wear scores was observed in subjects with a positive diagnosis of bruxism/TMJ sensitivity (\#Yes). This was also confirmed in another finding (Pergamalian et al., 2003), where tooth wear was not significantly correlated with bruxism or TMJ pain. Since there was only a slight increase in both the mandibular and maxillary mean tooth wear scores in subjects with a positive diagnosis of bruxism and TMJ sensitivity (\#Yes), tooth wear can not be considered a definite indicator of bruxism.

A relation between wearing of an appliance and the Bruxism score was shown. A possible relation was found between wearing of an appliance and Diagnosis of Bruxism/TMJ sensitivity (\#Yes), $r=0.535$ ( $p=0.01$ ).

A relation between use of an appliance and tooth wear in the maxilla and mandible was observed. In the case of both the maxilla and mandible, the wearing of an appliance is related to higher mean tooth wear score. This is contrary to what one would expect. The higher mean average tooth wear scores for subjects wearing an appliance as indicated in Table 14 and 15 can be explained in terms of the following: Tooth wear in bruxers may not be diagnosed early enough and as a result no appliance is prescribed or an appliance is prescribed after tooth wear had occurred. The effects of bruxism in terms of degrees of tooth wear are dependent on additional 
factors such as severity of the parafunctional habit and time. The young subjects in this study might not yet have developed symptoms such as tooth sensitivity or aesthetic complaints due to abnormal tooth wear to prompt them to visit a dentist for treatment. This illustrates the importance of early diagnosis of Bruxism for the prevention of tooth wear.

Trismus was found to be weakly related to tooth wear. The TMD-related symptom, trismus (difficulty in opening the mouth) was found in bruxers by (Ciancaglini et al., 2001).

The results showed a reasonably strong tendency for tooth wear to increase with age. This is expected because of the increased use of teeth over time. A modest correlation was also noted in other studies (Pergamalian et al., 2003). Pigno et al (2001) found a moderate correlation between maxillary tooth wear and age.

The possible effect of influencing variables like acid regurgitation; consumption of fruit juice and exposure to a dusty environment on tooth wear should be noted even though the relation between these variables and bruxism was not found to be significant in this study. The average age of the subjects (mostly students) was 24.3 years. Another study (Pigno et al., 2001) concluded that diet, number of daily snacks/meals, saliva, regurgitation/vomiting and environmental conditions are potential factors that may have contributed to tooth wear in their study sample. Even though they used a larger sample size $(n=71)$ compared to this study, no relationship was found between maxillary tooth wear and soft drink consumption, despite the fact that the majority of the subjects were $36-$ 55 years of age. This indicates the multifactorial nature of the etiology of bruxism.

\subsection{Relations between psychological variables}

A strong positive correlation was observed between the Kessler 10 and Trait Y2 scores. This is to be expected since the two tests measure general distress and anxiety, respectively, over the previous four-week 
period. A negative trend was evident when Trait Y2 and State Y1 scores were compared, indicating that subjects with higher Trait Y2 scores were less anxious in the State $\mathrm{Y} 1$ test. A negative trend was also observed between Kessler 10 and State Y1. The State Y1 measures anxiety in a specific situation, therefore one could expect a weaker relation between the State Y1 and both the Trait Y2 and K10.

The dualistic character of the sample is confirmed by the relationship between Kessler 10 and Bruxism and the strong positive correlation between the Kessler 10 and Trait Y2 scores.

\subsection{Relations between psychological and physiological variables}

The results of the study indicate that the values above the State Y1 average score (34) are divided into two groups, namely one group with lower than average Bruxism index scores and one with higher than average Bruxism index scores (BruxW2 average $=17.41)$. The results also showed a relation between State Y1 scores and the Tooth wear score.

The results showed that while higher State and Trait anxiety scores corresponded with a higher bruxism score in certain subjects, in others the scores did not correspond to a higher bruxism score. These results could indicate that different subjects experience stress differently, and while masticatory muscle tension could be an indication of stress in certain individuals, stress could be manifested differently in others. The physiological manifestation of anxiety and stress differs form person to person. The principle of individual response specificity could explain why certain individuals clench or grind their teeth as a response to stress (Nevid et al., 2003).

The results show that the research sample can be divided into two groups, those with a very low bruxism score and those with a bruxism score of 14 and more. In the second group it is evident that as the bruxism score increases, the Trait Y2 score also increases. Da Silva et al (1997) also 
used the STAI and found that higher tooth wear scores corresponded with higher trait anxiety than controls.

A positive relation was observed between the Kessler 10 score and the Bruxism Score. The results of the study indicate that the values above the Kessler 10 average score are divided into two groups, namely one group with lower Bruxism scores and one with higher Bruxism scores.

The fact that the size of the mouth opening becomes smaller as the Trait and Kessler 10 score increases may appear to indicate an association between anxiety, stress and muscle tension. However, the size of the mouth opening differs from subject to subject and the criteria of a "normal mouth opening" does not apply due to the uniqueness of every subject's mandible. A small mouth opening may be normal for some subjects; therefore one cannot necessarily deduce a relation between anxiety, stress and muscle tension from the mouth opening measurement. A subject with a large mouth opening measurement does not necessarily experience lower anxiety and stress. However, the size of the mouth opening is considered an indication of muscle tension and TMD by certain researchers (Ciancaglini et al., 2001). The cutoff values for restricted opening are less than $40 \mathrm{~mm}$ for muscular disorders and less than $35 \mathrm{~mm}$ for joint-related disorders (Zawawi, Al-Badawi, Lobo, Melis, \& Mehta, 2003). Four of the subjects in the present study had mouth-opening scores of $40 \mathrm{~mm}$ or less.

\subsection{Bruxers versus non-bruxers}

Twelve of the sample of 29 subjects met the criteria for bruxers, while 17 were non-bruxers. The literature indicates different sets of criteria used for the definition of bruxism, thus the number of subjects considered to brux will differ depending on the criteria. This is evident from the literature presenting widely varying prevalence rates, from $5-10 \%$ to $90-95 \%$ 
(Bader \& Lavigne, 2000; Hicks \& Chancellor, 1987; Lobbezoo et al., 2004).

It should be noted that the statistical analysis for the study was done on the pretext of rating all variables on a continuum according to the Spectrum approach because according to the literature (Abrahamsen, 2005) all people brux and therefore analysing the data on a continuum was considered more meaningful than comparing it against a control group.

All people experience anxiety and stress and rating these variables on a continuum is useful to determine the subthreshold levels which are important in the Spectrum approach used in this study.

\subsection{Significance of the results}

More tooth wear on maxillary anterior and opposing mandibular anterior teeth than on the posterior teeth was observed in this and other studies (Abrahamsen, 2005; Johansson, Haraldson et al., 1993). This is significant because it is considered to be indicative of bruxism and thus adds to the value of the results.

Research studies (Manfredini, Landi et al., 2004; Monaco et al., 2002) confirm the results found in this study indicating a possible link between anxiety and bruxism. The relation between subthreshold symptoms of anxiety and bruxism must be interpreted according to the theory that bruxism is a centrally mediated multifactorial disorder which could share certain neurological deficits with other centrally mediated disorders. Central etiological factors associated with bruxism are pathophysiological and psychological factors. Results based on the PAS-SR indicate a relation between sub clinical symptoms (e.g. stress sensitivity) of the anxiety spectrum and bruxism. Certain subthreshold manifestations of anxiety as indicated on the PAS-SR are more prevalent in bruxers. Bruxers may thus be more sensitive to stress than non-bruxers, indicating that bruxism may represent an inadequate method of coping with stress (Manfredini, Landi et al., 2005). This relates to the Type A personality's 
limited coping style in which stress could be expressed through bruxism (Hicks et al., 1990; Pierce et al., 1995; Pingitore et al., 1991).

The relation found between stress and bruxism is confirmed by other studies (Ahlberg et al., 2002; Harness \& Rome, 1989). Symptoms of TMD such as TMJ sensitivity, trismus and pain were included in the bruxism score in this study and found to be related to stress and anxiety. This finding is supported by findings on an association between chronic muscle pain around the TMJ, stress and bruxism (Harness \& Rome, 1989). Another study also found a correlation between TMD, stress and anxiety using the Spielberger State-Trait anxiety inventory (STAI) as part of a questionnaire battery (De Leeuw et al., 1994) that was also used in the present study.

The fact that certain neurotransmitters are implicated in bruxism, stress and anxiety (Bracha, Person et al., 2005; Mascaro et al., 2005; Nevid et al., 2003; Wood \& Toth, 2001) underscores the problem and confirms the research findings of this study on the relations between these factors.

Facial or jaw pain and/or chewing muscle tension was one of the criteria for defining a bruxer in this study. The fact that bruxers showed higher anxiety and stress scores emphasizes the need to consider masticatory muscle tension as a reaction to life stress and anxiety as confirmed by research (Perry et al., 1960; Yemm, 1969, 1971). A relation between bruxism and muscle tension was also found by other researchers (Rosales et al., 2002; Slavicek \& Sato, 2004; Van Selms et al., 2004). Masticatory muscle tension was also considered as a characteristic response to life stress in MFP subjects (Yemm, 1971). The fact that masticatory muscle tension is related to both bruxism and MFP indicates a possible connection. This is in accord with a stress-related muscular hyperactivity theory of TMD that was supported by Perry et al., 1960 who found increases in activity in masseter and temporal muscles of dental students due to experimentally induced stress. A link between TMD and bruxism could therefore be considered. The possible interrelation between bruxism, 
TMD and MFP and the effect of anxiety and stress illustrates the extent of the clinical picture.

\subsection{Limitations of the study}

It is possible that the volunteers in this study were more anxious by nature than the non-volunteers. This would bias the sample and possibly influence its randomness.

The relatively small sample size could limit the generalizability of the results. The inevitable subjectivity of many answers could have an effect on the results. The few outliers also influenced the results (refer to Figures 9 and 10). It would therefore be advisable to restrict the range of the age group.

The subjects were mostly students. The State Y1 scores showed that they were not overly stressed in their own learning environment, which is a positive finding. However, this tendency would possibly not show if subjects were all patients at the faculty of dentistry. The generalizability of the results of the study would therefore be limited.

Several factors may explain the poor reliabilities for identification of tooth wear also found by other researchers. These are: Insufficient training regarding signs of bruxism and the fact that standards have not been widely established for clinical detection of bruxism on the basis of wear patterns on dental casts (Marbach et al., 2003).

\subsection{Strengths of the study}

Results of the study are confirmed by other studies and could possibly lead to improved treatment planning. The results, when reported, could lead to more awareness of dentists to the interaction between soma and psych regarding the complexity of the patient and the role of stress and anxiety in affecting the body. The need for referral to other disciplines, i.e. a multidisciplinary approach, is underscored by the findings. 
The inclusion of a question in the bruxism questionnaire on whether the subject is conscious of clenching or grinding the teeth when concentrating or stressed during the day is supported by Olkinuora (1972) whose term "strain bruxism" refers to subjects who admit a connection between bruxism and mental efforts and worries.

The validity of using tooth-grinding as indicator of nocturnal bruxism in this study is supported by EMG recordings (Piquero \& Sakurai, 2000; Yemm, 1969, 1971) and polysomnographic studies (Lavigne et al., 1996).

The validity of several items (numbers 1,6,7,8,9,14) (Refer to Addendum 1) in the "Diagnostic and clinical criteria" questionnaire is also supported by the fact that they were used by other researchers (Khan et al., 1998).

Subjects come to a better understanding of themselves and their problem e.g. pain due to clenching/grinding and the role of stress. Self-awareness is an important factor in treatment.

The understanding and insight gained by the patient and the clinician leads to better cooperation of the patient and more empathy from the clinician. Both gain a sense of empowerment. The clinician feels in a position to orchestrate assistance e.g. appliance made, referral to TMJ clinic, stress-management, counseling, therapy, etc. The patient also experiences a feeling of empowerment e.g. wearing of appliance to reduce pain and tooth wear and realization of his/her role and choice in deciding to do something about stress and anxiety. The problem can thus be externalised and handled more effectively.

This study compares a population sample of South Africans to those of other countries and the results of the study are supported by other research findings.

The relation between the variables in this study was effectively portrayed by means of the Spectrum approach in which the variables were scored on a continuum. 


\subsection{Generalizability}

It should be noted that the results of this study pertain to a population of mostly dentistry students and that generalization of the results to the general population should be done with care. The homogeneity of the population with regard to type of stressor (academic stress); age; study and training environment; exposure to environmental stressors; etc could be considered a positive factor in the evaluation of the anxiety and stress questionnaires. This could however restrict the generalizability of the results.

While the generalizability of the results may be restricted due to the small sample used in the study and the fact that it consisted mainly of students subjected to examination stressors, it could be argued that all individuals are subject to normal life stressors and that the nature of the stress is of lesser importance than the individual's subjective perception of the event as stressful. 


\section{Chapter 6}

\section{Conclusions and recommendations}

\subsection{Conclusions}

The importance of recognizing the close relationship between the soma and psych was confirmed by the findings in this study. The results of the study indicated that anxiety and stress was physiologically manifested as bruxism in certain individuals. Psychological factors therefore play a role in the aetiology of bruxism.

The results of the study can be summarized as follows:-

- A possible relation between subthreshold symptoms of anxiety, stress and bruxism was observed in the results. In approximately half of the subjects with higher than average anxiety and stress scores, bruxism behaviour was found. Anxiety and stress can be physiologically expressed in different ways.

- A tooth wear score should not be used as sole indicator of bruxism.

- Several physiological variables were related to bruxism (e.g. TMJ sensitivity; diagnosis of bruxism; use of an appliance; restless legs, etc).

- The inclusion of symptoms of TMD in the questionnaire (pain or tenderness in TMJ; trismus; jaw or muscle pain or fatigue on awakening) and their relation to the bruxism and tooth wear score indicate a possible relation between bruxism and TMD.

- Use of a Spectrum approach in determining subthreshold symptoms of anxiety, stress and bruxism (scored on a continuum) was found to be effective, since subclinical symptoms of anxiety 
and stress (as measured in the STAI and Kessler 10 tests) were found to be related to bruxism in the study.

\subsection{Recommendations}

The need for a universally accepted quantitative definition of bruxism with valid diagnostic criteria is evident in this study as suggested by other researchers (Koyano et al., 2005).

There is a need for further investigation of flat planes on occlusal surfaces (e.g. on anterior teeth and canines) as found in this study, as indication of bruxism. Restrepo, Palaez et al. (2006) observed plane surfaces on incisors and Khan, Young et al (1998) found tooth wear facets on anterior teeth to be characterized by flat planes of wear with well-defined margins in enamel of incisal edges or as step-like areas. The nature of the dental wear could thus be an indication of parafunctional activity and alert the dentist to a subject's bruxing behaviour.

Better understanding of the definition, aetiology, pathophysiology, consequences and management of the parafunctional behaviour bruxism should be considered essential in the curriculum for dental students. The recognition of bruxism in the clinical setting and the effects of bruxism on MFP, TMD and prosthodontic treatment should be emphasized.

The inclusion of physiological symptoms of bruxism in the DSM V as part of the criteria for the diagnoses of anxiety-based disorders (e.g. PSTD), considered an important recommendation by researchers (Bracha, Ralston et al., 2005), was supported by the results of the study, since approximately half of individuals with higher than average anxiety and stress scores expressed their anxiety and stress in their masticatory muscles, resulting in bruxing behaviour. 


\subsection{Practical implications and possible treatment approaches}

Information on the physiological manifestation of stress and anxiety in the form of bruxism and TMD symptoms such as myofascial pain would alert the dentist to the possibility that psychological factors may play a role in the aetiology of bruxism or may exacerbate the condition.

The dentist could also play a role in recognizing that a patient may be experiencing stress or anxiety expressed through bruxing behaviour and refer the patient for therapy or counseling or alert a parent to the possibility that a child's grinding and clenching behaviour may indicate that the child is anxious or experiencing stress (e.g. at school; peer pressure; abuse; bullying, etc). Research results (Monaco et al., 2002) indicated that an anxiety state is a prominent factor in the development of bruxism in children.

Knowledge of the multifaceted nature of the aetiology of bruxism as a continuous reciprocal interplay of psychological and physiological factors, could lead to improved treatment planning.

An inter-disciplinary approach is therefore recommended for the treatment of bruxism (as a possible physiological manifestation of anxiety and stress). The dentist specialization area called oral kinesiology focuses on the treatment of bruxism, TMD, tooth wear and sleep disorders.

While the wearing of an appliance could reduce the extent of tooth wear and myofascial pain, the management of stress and treatment of anxiety is important in reducing the incidence of TMD symptoms (myofascial pain and TMJ sensitivity) and frequency of bruxism (De Laat et al., 2003; Kalamir et al., 2006; Morishige et al., 2006; Restrepo et al., 2001), once the presence of anatomo-morphological factors have been ruled out.

Relaxation techniques (Restrepo et al., 2001), cognitive-restructuring (Kalamir et al., 2006; Morishige et al., 2006) and medication for anxiety 
could form part of the holistic approach to treating bruxism as a physiological manifestation of stress and anxiety.

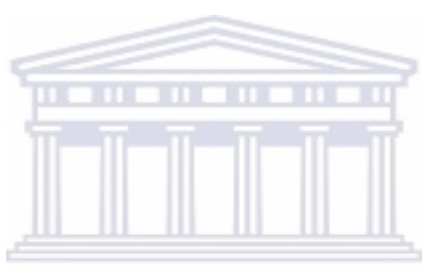

UNIVERSITY of the 


\section{References}

Abrahamsen, T. C. (2005). The worn dentition - pathognomonic patterns of abrasion and erosion. International dental journal, 55, 268-276.

Ahlberg, J., Rantala, M., Savolainen, A., Suvinen, T., Nissinen, M., Sarna, S., et al. (2002). Reported bruxism and stress experience. Community dentistry and oral epidemiology, 30, 405-408.

Ahlberg, K., Ahlberg, J., Kanonen, M., Partinen, M., Hublin, C., \& Savolainen, A. (2005). Reported bruxism and restless leg syndrome in media personnel with or without irregular shift work. Acta odontologica Scandinavica, 63(2), 94 -98.

Baba, K., Haketa, T., Clark, G. T., \& Ohyama, T. (2004). Does tooth wear status predict ongoing sleep bruxism in 30-year-old Japanese subjects? The international journal of prosthodontics, 17(1), 39-44.

Bader, G., \& Lavigne, G. (2000). Sleep bruxism; an overview of an oromandibular sleep movement disorder. Sleep medicine reviews, 4(1), 2743.

Balatsouras, D., Kaberos, A., Psaltakos, V., Papaliakos, E., \& Economou, N. (2004). Bruxism: two case reports. Acta otorhinolaryngologica Italica, 24, $165-170$.

Beaton, R. D., Egan, K. J., Nagakawa-Kogan, H., \& Morrison, K. N. (1991). Selfreported symptoms of stress with temporomandibular disorders: Comparison to healthy men and women. The Journal of prosthetic dentistry, 65(2), 289-293.

Beroccal, C., Ruiz Moreno, M. A., Gil Villa, M., Hermoso, P., Rucci, P., \& Cassano, G. B. (2005). Multidimensional assessment of the PanicAgoraphobic Spectrum: Reliability and validity of the Spanish version of the PAS-SR. Anxiety disorders, Article in Press.

Biondi, M., \& Picardi, A. (1993). Temporomandibular joint pain-dysfunction syndrome and bruxism: etiopathogenesis and treatment from a psychosomatic integrative viewpoint. Psychotherapy and psychosomatics, 59(2), 84-98.

Bracha, H. S., Person, D. A., Bernstein, D. M., Flaxman, N. A., \& Masukawa, N. K. (2005). Combat and warfare in the early Paleolithic and medically unexplained musculo-facial pain in the 21st century war veterans and actve-duty military personnel. Hawaii dental journal, Nov/Dec, 16 - 18.

Bracha, H. S., Ralston, T. C., Williams, A. E., Yamashita, J. M., \& Bracha, A. S. (2005). The clenching-grinding spectrum and fear circuitry disorders: clinical insights from the neuroscience/paleoanthropology interface. CNS spectrums, 10(4), 311 - 318.

Brooks, R. T., Beard, J., \& Steel, Z. (2006). Factor structure and interpretation of the K10. Psychological assessment, 18(1), 62 - 70.

Cassano, G. B., Frank, E., Miniati, M., Rucci, P., Fagiolini, A., Pini, S., et al. (2002). Conceptual underpinnings and empirical support for the mood spectrum. The Psychiatric clinics of North America, 25(4), 699 - 712. 
Cassano, G. B., Michelini, S., Shear, M. K., Coli, E., Maser, J. D., \& Frank, E. (1997). The panic-agoraphobic spectrum: a descriptive approach to the assessment and treatment of subtle symptoms. American journal of psychiatry, 154(6), 27 - 38.

Chen, W. H., Lu, Y. C., Lui, C. C., \& Lui, J. S. (2005). A proposed mechanism for diurnal/nocturnal bruxism: hypersensitivity of presynaptic dopamine receptors in the frontal lobe. Journal of clinical neuroscience, 12(2), 161163.

Ciancaglini, R., Gherlone, E. F., \& Radaelli, G. (2001). The relationship of bruxism with craniofacial pain and symptoms from the masticatory system in the adult population. Journal of oral rehabilitation, 28, 842 - 848.

Da Silva, A. M., Oakley, D. A., Hemmings, K. W., Newman, H. N., \& Watkins, S. (1997). Psychosocial factors and tooth wear with a significant component of attrition. The European journal of prosthodontics and restorative dentistry, 5(2), 51 - 55.

De Laat, A., Stappaerts, K., \& Papy, S. (2003). Counseling and physical therapy for myofascial pain of the masticatory system. Journal of Orofacial Pain, 17(1), 42 - 49.

De Leeuw, J. R. J., Steenks, M. H., Ros, W. J. G., Bosman, F., Winnubst, J. A. M., \& Scholte, A. M. (1994). Psychosocial aspects of craniomandibular dysfunction. An assessment of clinical and community findings. Journal of oral rehabilitation, 21, 127 - 143.

Dell'Osso, L., Armani, A., Rucci, P., Frank, E., Fagiolini, A., Corretti, G., et al. (2002). Measuring mood spectrum: comparison of interview (SCIMOODS) and self-report (MOODS-SR) instruments. Comprehensive psychiatry, 43(1), 69 - 73.

Fischer, W. F., \& O’toole, E. T. (1993). Personality characteristics of chronic bruxers. Behavioural medicine, 19(2), 82-86.

Funch, D. P., \& Gales, E. N. (1980). Factors associated with nocturnal bruxism and its treatment. Journal of behavioural medicine, 3, 385 - 397.

Glaros, A. G. (1981). Incidence of diurnal and nocturnal bruxism. The Journal of prosthetic dentistry, 45, 545.

Glaros, A. G., Williams, K., \& Lausten, L. (2005). The role of parafunctions, emotions and stress in predicting facial pain. Journal of the American Dental Association, 136(4), 451-458.

Glaros, A. G., Williams, K., Lausten, L., \& Friesen, L. R. (2005). Tooth contact in patients with temporomandibular disorders. Cranio, 23(3), 188 - 193.

Gomez, F. M., Giralt, M. T., Sainz, B., Arrue, A., Prieto, M., \& Garcia-Vallejo, P. (1999). A possible attentuation of stress-induced increases in striatal dopamine metabolism by the expression of non-functional masticatory activity in the rat. European Journal of oral sciences, 107, 461 - 467.

Haber, J. D., Moss, R. A., Kuczmierczyk, A. R., \& Garrett, J. C. (1983). Assessment and treatment of stress in myofascial pain-dysfunction syndrome: a model for analysis. Journal of oral rehabilitation, 10, 187 196.

Hagberg, C., Hagberg, M., \& Kopp, S. (1994). Musculoskeletal symptoms and psychosocial factors among patients with craniomandibular disorders. Acta odontologica Scandinavica, 52, 170 - 177. 
Harness, D. M., \& Rome, H. P. (1989). Psychological and behavioral aspects of chronic facial pain. Otorlaryngologic clinics of North America, 22(6), 1073 - 1094.

Hartmann, E., Mehta, N., Forgione, A., Brune, P., \& LaBrie, R. (1987). Bruxism: Personality traits and other characteristics. Sleep Research, 16, 350.

Heller, R. F., \& Forgione, A. G. (1975). An evaluation of bruxism control: massed negative practice and automated relaxation training. Journal of Dental Research, 54(6), 1120 - 1123.

Hicks, R. A., \& Chancellor, C. (1987). Nocturnal bruxism and Type A-B behaviour in college students. Psychological reports, 60, 1211 - 1214.

Hicks, R. A., Conti, P. A., \& Bragg, H. R. (1990). Increases in nocturnal bruxism among college students implicate stress. Medical hypotheses, 33, 239-240.

Hidaka, O., Yanagi, M., \& Takada, K. (2004). Mental stress-induced physiological changes in the human masseter muscle. Journal of dental research, 83(3), 227-231.

Johansson, A., Haraldson, T., Omar, R., Kiliaridis, S., \& Carlsson, G. E. (1993). A system for assessing the severity and progression of occlusal tooth wear. Journal of oral rehabilitation, 20, 125-131.

Johansson, A., Omar, R., Fareed, K., Haraldson, T., Kiliaridis, S., \& Carlsson, G. E. (1993). Comparison of the prevalence, severity and possible causes of occlusal tooth wear in two young adult populations. Journal of oral rehabilitation, 20, 463-471.

Kalamir, A., Pollard, H., Vitiello, A. L., \& Bonello, R. (2006). TMD and the problem of bruxism. A review. Journal of Bodywork and Movement Therapies, In press.

Kampe, T., Edman, G., Bader, G., Tagdae, T., \& Karlsson, S. (1997). Personality traits in a group of subjects with long-standing bruxing behaviour. Journal of oral rehabilitation, 24, 588-593.

Kampe, T., Hannerz, H., \& Ström, P. (1996). Ten-year follow-up study of signs and symptoms of craniomandibular disorders in adults with intact and restored dentitions. Journal of oral rehabilitation, 23, 416 - 423.

Kampe, T., Tagdae, T., Bader, G., Edman, G., \& Karlsson, S. (1997). Reported symptoms and clinical findings in a group of subjects with longstanding bruxing behaviour. Journal of oral rehabilitation, 24, 581 - 587.

The Kessler Psychological Distress Scale (K10). (No. 2002-14)(2002). Department of Human Services, Centre for Population Studies in Epidemiology.

Kessler, R. C., Andrews, G., Colpe, L. J., Hiripe, E., Mroczek, D. K., Normand, S. L., et al. (2002). Short screening scales to monitor population prevalences and trends in non-specific psychological distress. Psychological medicine, 32(6), 959 - 976.

Khan, F., Young, W. G., \& Daley, T. J. (1998). Dental erosion and bruxism. A tooth wear analysis from South East Queensland. Australian dental journal, 43(2), 117-127.

Koyano, K., Tsukiyama, Y., \& Ichiki, R. (2005). Local factors associated with parafunction and prosthodontics. The international journal of prosthodontics, 18(4), 293-294. 
Laskin, D. M. (1969). Etiology of the pain dysfunction syndrome. J American Dent Assoc, 79, 147.

Laskin, D. M. (1980). Myofacial pain dysfunction syndrome: etiology. In D. M. Laskin (Ed.), The TMJ; a Biological Basis for Clinical Practice (pp. 289). Springfield Illinois: Thomas, Charles C.

Lavigne, G. J., Kato, T., Kolta, A., \& Sessle, B. J. (2003). Neurobiological mechanisms involved in sleep bruxism. Oral biological medicine, 14(1), 30 - 46.

Lavigne, G. J., Rompre, P. H., \& Montplaisir, J. Y. (1996). Sleep bruxism: validity of clinical research diagnostic criteria in a controlled polysomnographic study. Journal of dental research, 75(1), 546 - 552.

Lobbezoo, F., \& Naeije, M. (2001). Review: Bruxism is mainly regulated centrally, not peripherally. Journal of oral rehabilitation, 28, 1085 - 1091.

Lobbezoo, F., Soucy, J. P., Montplaisir, J. Y., \& Lavigne, G. J. (1996). Striatal D2 receptor binding in sleep bruxism: a controlled study with iodine-123iodobenzamide and single-photon-emission computed tomography. Journal of dental research, 75(10), 1804 -1810.

Lobbezoo, F., Van der Zaag, J., \& Naeije, M. (2006). Bruxism: its multiple causes and its effects on dental implants - an updated review. Journal of oral rehabilitation, 33(4), 293-300.

Lobbezoo, F., Van der Zaag, J., Visscher, C. M., \& Naeije, M. (2004). Oral kinesiology. A new postgraduate programme in the Netherlands. Journal of oral rehabilitation, 31, 192 - 198.

Lundeen, T. F., George, G. M., \& Sturdevant, J. R. (1988). Stress in patients withn pain in the muscles of mastication and the temporomandibular joints. Journal of Oral Rehabilitation, 15, 631.

Manfredini, D., Bandettini di Poggio, A., Cantini, E., Dell’Osso, L., \& Bosco, M. (2004). Mood and anxiety psychopathology and temporomandibular disorder: a spectrum approach. Journal of oral rehabilitation, 31(10), 933 $-940$.

Manfredini, D., Cantini, E., Romagnoli, M., \& Bosco, M. (2003). Prevalence of bruxism in patients with different research diagnostic criteria for temporomandibular disorders (RCD/TMD) diagnosis. Cranio, 21(4), 279285.

Manfredini, D., Ciapparelli, A., Dell'Osso, L., \& Bosco, M. (2005). Mood disorders in subjects with bruxing behavior. Journal of dentistry, 33(6), 485-490.

Manfredini, D., Landi, N., Fantoni, F., Segu, M., \& Bosco, M. (2005). Anxiety symptoms in clinically diagnosed bruxers. Journal of oral rehabilitation, 32, $584-588$.

Manfredini, D., Landi, N., Romagnoli, M., \& Bosco, M. (2004). Psychic and occlusal factors in bruxers. Australian dental journal, 49(2), 84 - 89.

Manfredini, D., Landi, N., Romagnoli, M., Cantini, E., \& Bosco, M. (2003). Etiopathogenesis of parafunctional habits of the stomatognathic system. Minerva stomatologica, 52(7 - 8), 339 - 345, 345 - 349.

Marbach, J. J. (1996). Temporomandibular pain and dysfunction syndrome. History, physical examination, and treatment. Rheumatic diseases clinics of North America, 22, 477 - 498. 
Marbach, J. J., Raphael, K. G., Janal, M. N., \& Hirschkorn-Roth, R. (2003). Reliability of clinician judgements of bruxism. Journal of oral rehabilitation, 30, 113 - 118.

Mascaro, M. B., Bittencourt, J. C., Casatti, C. A., \& Elias, C. F. (2005). Alternative pathways for catecholamine action in oral motor control. Neuroscience letters, 386(1), 34-39.

Menapace, S. E., Rinchuse, D. J., Zullo, T., Pierce, C. J., \& Shnorhokian, H. (1994). The dentofacial morphology of bruxers versus non-bruxers. The Angle orthodontist, 64(1), 43 - 52.

Mikami, D. B. (1977). A review of psychogenic aspects and treatment of bruxism. The Journal of prosthetic dentistry, 37(4), 411 - 419.

Monaco, A., Ciammella, N. M., Marci, M. C., Pirro, R., \& Giannoni, M. (2002). The anxiety in bruxer child. A case-control study. Minerva Stomatologica, 51(6), 247-250.

Moore, K. L. (1980). Clinically Oriented Anatomy. London: Williams \& Wilkens.

Morishige, E., Yatani, H., \& Hirokawa, M. (2006). Clinical effectiveness of Cognitive Behavior Therapy in the management of TMD. International Journal of Prosthodontics, 19(1), 31 - 33.

Moss, R. A., Garrett, J., \& Chiodo, J. F. (1982). Temporomandibular joint dysfunction and myofacial pain dysfunction syndromes: parameters, etiology and treatment. Psychological Bulletin, 92, 331.

Moulton, R., E. (1955). Psychiatric considerations in maxillofacial pain. Journal of the American Dental Association, 51, 408 - 414.

Neumeister, A., Daher, R. J., \& Charney, D. S. (2005). Anxiety disorders: noradrenergic neurotransmission. Handbook of experimental pharmacology, 169, 205 - 223.

Nevid, J. S., Rathus, S. A., \& Greene, B. (2003). Abnormal Psychology in a changing world. International Edition (5th ed.). New Jersey: Pearson Education, Inc.

Ohayon, M. M., Li, K. K., \& Guilleminault, C. (2001). Risk factors for sleep bruxism in the general population. Chest, 119, 53 - 61.

Okeson, J. P. (1996). Orofacial pain. Guidelines for assessment, diagnosis and management. Chicago (IL): Quintessence Publishing Co. Inc.

Olkinuora, M. (1969). Bruxism: a review of the literature on and a discussion of studies and its psychogenesis and some new psychological hypotheses. Suomen Hammaslaakariseuran Toimituksia, 65, 312 - 325.

Olkinuora, M. (1972). Psychosomatic study of bruxism with emphasis on mental strain and familiar predisposition factors. Suomen Hammaslaakariseuran Toimituksia, 68, 112 - 123.

Pergamalian, A., Rudy, T. E., Zaki, H. S., \& Greco, C. M. (2003). The association between wear facets, bruxism, and severity of facial pain in patients with temporomandibular disorders. The journal of prosthetic dentistry, 90, 194 $-200$.

Perry, H. T., Lammie, G. A., Main, J., \& Teuscher, G. W. (1960). Occlusion in a stress situation. Journal of the American Dental Association, 60, 626.

Pierce, C. J., Chrisman, K., M.E., B., \& J.M., C. (1995). Stress, anticipatory stress, and psychologic measures related to sleep bruxism. Journal of orofacial pain, 9(1), 51 - 56. 
Pigno, M. A., Hatch, J. P., Rodrigues-Garcia, R. C. M., Sakai, S., \& Rugh, J. D. (2001). Severity, distribution, and correlates of occlusal tooth wear in a sample of Mexican-American and European-American adults. The international journal of prosthodontics, 14(1), 65-70.

Pingitore, G., Chrobak, V., \& Petrie, J. (1991). The social and psychologic factors of bruxism. The journal of prosthetic dentistry, 65(3), 443 - 446.

Piquero, K., \& Sakurai, K. (2000). A clinical diagnosis of diurnal (non-sleep) bruxism in denture wearers. Journal of oral rehabilitation, 27, 473 - 482.

Pond, D. A. (1968). The tooth and the psyche. British dental Journal, 123, 457 460.

Porvazova, R., \& Bassetti, C. L. (2007). Sleep and movement disorders. Therapeutische Umschau, 64(1), 63 -72.

Reding, G. R., Zepelin, H., \& Monroe, L. J. (1968). Personality study of nocturnal teeth-grinders. Perceptual and motor skills, 26, 523 - 531.

Restrepo, C., Pelaez, A., Alvarez, E., Paucar, C., \& Abad, P. (2006). Digital imaging of patterns of dental wear to diagnose bruxism in children. International journal of paediatric dentistry, 16, 278-285.

Restrepo, C. C., Alvarez, E., Jaramillo, C., Velez, C., \& Valencia, I. (2001). Effects of psychological techniques on bruxism in children with primary teeth. Journal of Oral rehabilitation, 28, 354 - 360.

Rosales, V. P., Ikeda, K., Hizaki, K., Naruo, T., Nozoe, S., \& G., I. (2002). Emotional stress and brux-like activity of the masseter muscle in rats. European journal of orthodontics, 24, 107 - 117.

Rosenbaum, M. S., \& Ayllon, T. (1981). Treating Bruxism with the HabitReversal Technique. Behavior Research \& Therapy, 19, 87 - 96.

Rugh, J. D. (1987). Psychological components of pain. Dental Clinics of North America, 31, 579.

Rugh, J. D., \& Solberg, W. K. (1975). Electromyographic studies of bruxist behavior before and during treatment. Journal - California Dental Association, 3, 56.

Schachter, S., \& Singer, J. E. (1962). Cognitive, social and physiological determinants of emotional state. Psychological review, 69, 379 - 399.

Shear, M. K., Cassano, G. B., Frank, E., Rucci, P., Rotondo, A., \& Fagiolini, A. (2002). The panic-agoraphobic spectrum: development, description, and clinical significance. The Psychiatric clinics of North America, 25(4), 739 $-756$.

Shear, M. K., Frank, E., Rucci, P., Fagiolini, D. A., Grochocinski, V. J., Houck, P., et al. (2001). Panic-agoraphobic spectrum: reliability and validity of assessment instruments. Journal of psychiatric research, 35(1), 59 - 66.

Slavicek, R., \& Sato, S. (2004). Bruxism - a function of the masticatory organ to cope with stress. Wiener Medizinische Wochenschrift, 154(23-24), 584 589.

Solberg, D. K. (1986). Temporomandibular disorders: background and the clinical problems. British Dental Journal, 160, 157.

Solomon, E. P., Schmidt, R. R., \& Adragna, P. J. (1990). Human Anatomy and Physiology (2nd ed.). USA: Saunders College Publishing.

Spielberger, C. D. (1983). Manual for the State-Trait Anxiety Inventory (STAI). Palo Alto, CA: Consulting Psychologists Press. 
Stephenson, C. P., Hunt, G. E., Topple, A. N., \& McGregor, I. S. (1999). The distribution of 3,4-methylenedioxymethamphetamine "Ecstasy"-induced cfos expression in rat brain. Neuroscience, 92(3), 1011-1023.

Thaller, J. L., Rosen, G., \& Saltzman, S. (1967). Study of the relationship of frustration and anxiety to bruxism. Journal of periodontology, 38, 193 197.

Theorell, T., Harms-Ringdahl, K., Ahlberg-Hultén, G., \& Westin, B. (1991). Psychosocial job factors and symptoms from the locomotor system - a multicausal analysis. Scandinavian journal of rehabiltation medicine, 23, 165 - 173.

Tobias, P. V., \& Arnold, M. (1977). Man's Anatomy. A study in dissection. (3rd ed.). Johannesburg: Witwatersrand University Press.

Tyrer, P., \& Seivewright, N. (1985). Anxiety. In J. A. M. Frederiks (Ed.), Handbook of Clinical Neurology (Vol. 1(45), pp. 265 - 269): Elsevier Science Publishers B.V.

Van Selms, M. K., Lobbezoo, F., Wicks, D. J., Hamburger, H. L., \& Naeije, M. (2004). Craniomandibular pain, oral parafunctions, and psychological stress in a longitudinal case study. Journal of oral rehabilitation, 31(8), 738 - 745.

Vanderas, A. P., Menenakou, M., Kouimtzis, T., \& Papagiannoulis, L. (1999). Urinary catecholamine levels and bruxism in children. Journal of oral rehabilitation, 26(2), $103-110$.

Velly, A. M., Gornitsky, M., \& Philippe, P. (2003). Contributing factors to chronic myofascial pain: a case-control study. Pain, 104(3), 491 - 499.

Wood, S. J., \& Toth, M. (2001). Molecular pathways of anxiety revealed by knockout mice. Molecular neurobiology, 23(2-3), 101-119.

Yemm, R. (1969). Variations in the electrical acitivity of the human masseter muscle occurring in association with emotional stress. Archives of oral biology, 14, 873.

Yemm, R. (1971). A comparison of the electrical activity of masseter and temporal muscles of human subjects during experimental stress. Archives of oral biology, 16, 269.

Young, D. V., Rinchuse, D. J., Pierce, C. J., \& Zullo, T. (1999). The craniofacial morphology of bruxers versus nonbruxers. The Angle orthodontist, 69(1), 14 - 18.

Zawawi, K. H., Al-Badawi, E. A., Lobo, S. L., Melis, M., \& Mehta, N. R. (2003). An index for the measurement of normal maximum mouth opening. Journal of the Canadian Dental Association, 69(11), 737 - 741. 


\begin{abstract}
Addendum 1
PATIENT INFORMATION AND INFORMED CONSENT DOCUMENT

TITLE OF RESEARCH PROJECT: The significance of subthreshold symptoms of anxiety in the aetiology of Bruxism.
\end{abstract}

REFERENCE NUMBER:

PRINCIPAL INVESTIGATOR: Mrs RA Basson

Address: $\quad$ Faculty of Dentistry

University of the Western Cape

Private Bag XI

Tygerberg 7505

\title{
DECLARATION BY THE PATIENT.
}

I ..................................... agree to participate in a study conducted by Reneda Basson (MA Research Psy - UWC).

1. The following aspects were explained to me, the patient:

1.1 Aim

1.2 Procedures

1.3 Possible advantages

I understand that there are no risks involved in participating in this study.

All personal information I disclose to Reneda Basson will be considered strictly confidential. Only information relevant to the results of the study will be published.

My participation in the project is voluntary and I have been informed that I can withdraw from the study at any moment, without any explanation. My withdrawal from this project will have no negative impact on any current or future treatment at this or any other institution.

I have been informed that the researcher will provide counseling referral if there is a need for counseling.

Name (Participant):

ID no:

Tel:

Signature (Participant):

Date:

Signature RABasson: 


\section{Demographic and Clinical criteria}

Reference No:

Age:

Please complete the form and insert an $\mathbf{X}$ in the blocks that apply to you.

\begin{tabular}{|c|c|c|c|c|c|}
\hline & Marital Status & \multicolumn{2}{|l|}{ Married } & \multicolumn{2}{|l|}{ Single } \\
\hline & Gender & \multicolumn{2}{|l|}{ Male } & \multicolumn{2}{|l|}{ Female } \\
\hline 1 & $\begin{array}{l}\text { Have you been diagnosed } \\
\text { as clenching/grinding your } \\
\text { teeth? }\end{array}$ & & Yes & \multicolumn{2}{|c|}{ No } \\
\hline 2 & $\begin{array}{l}\text { How often do you } \\
\text { experience soreness of your } \\
\text { teeth in the morning? }\end{array}$ & Never & Sometimes & Often & $\begin{array}{l}\text { Almost } \\
\text { always }\end{array}$ \\
\hline 3 & $\begin{array}{l}\text { Do you clench your teeth } \\
\text { during the day? }\end{array}$ & Never & Sometimes & Often & $\begin{array}{l}\text { Almost } \\
\text { always }\end{array}$ \\
\hline 4 & $\begin{array}{l}\text { How often do you wake at } \\
\text { night due to clenching- } \\
\text { induced pain? }\end{array}$ & Never & Sometimes & Often & $\begin{array}{l}\text { Almost } \\
\text { always }\end{array}$ \\
\hline 5 & $\begin{array}{l}\text { Do you suffer from } \\
\text { headaches? }\end{array}$ & Never & Sometimes & Often & $\begin{array}{l}\text { Almost } \\
\text { always }\end{array}$ \\
\hline 6 & $\begin{array}{l}\text { Are you conscious of } \\
\text { clenching or grinding your } \\
\text { teeth when concentrating or } \\
\text { stressed during the day? }\end{array}$ & Never & Sometimes & Often & $\begin{array}{l}\text { Almost } \\
\text { always }\end{array}$ \\
\hline 7 & $\begin{array}{l}\text { Do you experience pain, } \\
\text { tenderness or clicking } \\
\text { sounds in the } \\
\text { temporomandibular joint or } \\
\text { muscles when opening and } \\
\text { closing your mouth? } \\
\text { Specify which symptom } \\
\text { please. }\end{array}$ & Never & Sometimes & $\ldots \ldots \ldots \ldots \ldots$ & $\begin{array}{l}\text { Almost } \\
\text { always } \\
\\
\ldots \ldots \ldots \text {...... }\end{array}$ \\
\hline
\end{tabular}




\begin{tabular}{|c|c|c|c|c|c|}
\hline 8 & $\begin{array}{l}\text { Approximately how many } \\
\text { nights per week do you } \\
\text { grind/clench your teeth as } \\
\text { reported by a partner or } \\
\text { family member during the } \\
\text { last } 6 \text { months? }\end{array}$ & 0 & $1-2$ & $3-4$ & $5-7$ \\
\hline 9 & $\begin{array}{l}\text { Did you or do you } \\
\text { experience facial or jaw } \\
\text { pain / chewing muscle } \\
\text { fatigue or stiffness in the } \\
\text { morning? }\end{array}$ & No & $\begin{array}{l}\text { Yes: } \\
\text { Somewhat }\end{array}$ & $\begin{array}{l}\text { Yes: } \\
\text { Moderately }\end{array}$ & $\begin{array}{l}\text { Yes:Very } \\
\text { much so }\end{array}$ \\
\hline 10 & $\begin{array}{l}\text { Did you or do you ever } \\
\text { experience having restless } \\
\text { legs when sitting or lying } \\
\text { down? }\end{array}$ & No & $\begin{array}{l}\text { Yes: } \\
\text { Somewhat }\end{array}$ & $\begin{array}{l}\text { Yes: } \\
\text { Moderately }\end{array}$ & $\begin{array}{l}\text { Yes:Very } \\
\text { much so }\end{array}$ \\
\hline 11 & $\begin{array}{l}\text { Did you or do you spend } \\
\text { much time in a dusty or } \\
\text { polluted environment? }\end{array}$ & Never & Sometimes & Often & $\begin{array}{l}\text { Almost } \\
\text { always }\end{array}$ \\
\hline 12 & $\begin{array}{l}\text { Did you or do you suffer } \\
\text { from frequent acid } \\
\text { regurgitation or vomiting? }\end{array}$ & $\begin{array}{l}\text { Not at } \\
\text { all }\end{array}$ & Somewhat & $\begin{array}{l}\text { Moderately } \\
\text { so }\end{array}$ & $\begin{array}{l}\text { Very } \\
\text { much so }\end{array}$ \\
\hline 13 & $\begin{array}{l}\text { How often do you drink } \\
\text { coke, fizzy cooldrinks, fruit } \\
\text { juice per week? }\end{array}$ & Never & Sometimes & Often & $\begin{array}{l}\text { Very } \\
\text { often }\end{array}$ \\
\hline 14 & $\begin{array}{l}\text { Did you or do you have an } \\
\text { appliance/splint to prevent } \\
\text { tooth wear and do you wear } \\
\text { it? }\end{array}$ & No & $\begin{array}{l}\text { Yes: } \\
\text { Sometimes }\end{array}$ & $\begin{array}{l}\text { Yes: } \\
\text { Often }\end{array}$ & $\begin{array}{l}\text { Yes: } \\
\text { Almost } \\
\text { always }\end{array}$ \\
\hline
\end{tabular}

Total Score:

Clinician's comment:

Presence of TMJ sensitivity

Opening measurement 
STAI Form Y-1

Reference No:.......

A number of statements which people have used to describe themselves are given below. Read each statement and then circle the appropriate number to the right of the statement to indicate how you feel right now, that is, at this moment. There are no right or wrong answers. Do not spend too much time on any one statement, but give the answer which seems to describe your present feelings best.

\begin{tabular}{|c|c|c|c|c|c|}
\hline & & Not at all & Somewhat & $\begin{array}{c}\text { Moderately } \\
\text { So }\end{array}$ & $\begin{array}{c}\text { Very } \\
\text { much so }\end{array}$ \\
\hline 1 & I feel calm. & 1 & 2 & 3 & 4 \\
\hline 2 & I feel secure. & 1 & 2 & 3 & 4 \\
\hline 3 & I am tense. & 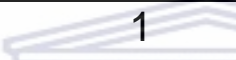 & 2 & 3 & 4 \\
\hline 4 & I feel strained. & 1 & 2 & 3 & 4 \\
\hline 5 & I feel at ease. & 1 & 2 & 3 & 4 \\
\hline 6 & I feel upset. & 1 & 2 & 3 & 4 \\
\hline 7 & $\begin{array}{l}\text { I am presently } \\
\text { worrying over } \\
\text { possible } \\
\text { misfortune. }\end{array}$ & WESIER & 2 & 3 & 4 \\
\hline 8 & I feel satisfied. & 1 & 2 & 3 & 4 \\
\hline 9 & I feel frightened. & 1 & 2 & 3 & 4 \\
\hline 10 & I feel comfortable. & 1 & 2 & 3 & 4 \\
\hline & I feel self-confident. & 1 & 2 & 3 & 4 \\
\hline & I feel nervous. & 1 & 2 & 3 & 4 \\
\hline & I am jittery. & 1 & 2 & 3 & 4 \\
\hline 14 & I feel indecisive. & 1 & 2 & 3 & 4 \\
\hline & I am relaxed. & 1 & 2 & 3 & 4 \\
\hline & I feel content. & 1 & 2 & 3 & 4 \\
\hline & I am worried. & 1 & 2 & 3 & 4 \\
\hline & I feel confused. & 1 & 2 & 3 & 4 \\
\hline 19 & I feel steady. & 1 & 2 & 3 & 4 \\
\hline 20 & I feel pleasant. & 1 & 2 & 3 & 4 \\
\hline
\end{tabular}


STAI Form Y-2

Reference No:......

A number of statements which people have used to describe themselves are given below. Read each statement and then circle the appropriate number to the right of the statement to indicate how you generally feel. There are no right or wrong answers. Do not spend too much time on any one statement, but give the answer, which seems to describe how you generally feel.

\begin{tabular}{|c|c|c|c|c|c|}
\hline & & $\begin{array}{l}\text { Almost } \\
\text { never }\end{array}$ & Sometimes & Often & $\begin{array}{l}\text { Almost } \\
\text { always }\end{array}$ \\
\hline 1 & I feel pleasant. & 1 & 2 & 3 & 4 \\
\hline 2 & I feel nervous and restless. & 1 & 2 & 3 & 4 \\
\hline 3 & I feel satisfied with myself. & 1 & 2 & 3 & 4 \\
\hline 4 & $\begin{array}{l}\text { I wish I could be as happy as } \\
\text { others seem to be. }\end{array}$ & 1 & 2 & 3 & 4 \\
\hline 5 & I feel like a failure. & 1 & 2 & 3 & 4 \\
\hline 6 & In & 1 & 2 & 3 & 4 \\
\hline 7 & I am "cool, calm and collected". ITY & of th 1 & 2 & 3 & 4 \\
\hline 8 & $\begin{array}{l}\text { I feel that difficulties are piling up } \\
\text { so that I cannot overcome them. }\end{array}$ & 1 & 2 & 3 & 4 \\
\hline 9 & $\begin{array}{l}\text { I worry too much over something } \\
\text { that doesn't really matter. }\end{array}$ & 1 & 2 & 3 & 4 \\
\hline 10 & I am happy. & 1 & 2 & 3 & 4 \\
\hline 11 & I have disturbing thoughts. & 1 & 2 & 3 & 4 \\
\hline 12 & I lack self-confidence. & 1 & 2 & 3 & 4 \\
\hline 13 & I feel secure. & 1 & 2 & 3 & 4 \\
\hline & I make decisions easily. & 1 & 2 & 3 & 4 \\
\hline & I feel inadequate. & 1 & 2 & 3 & 4 \\
\hline & I am content. & 1 & 2 & 3 & 4 \\
\hline 17 & $\begin{array}{l}\text { Some unimportant thoughts run } \\
\text { through my mind and bother me. }\end{array}$ & 1 & 2 & 3 & 4 \\
\hline 18 & $\begin{array}{l}\text { I take disappointments so keenly } \\
\text { that I can't put them out of my } \\
\text { mind. }\end{array}$ & 1 & 2 & 3 & 4 \\
\hline 19 & I am a steady person. & 1 & 2 & 3 & 4 \\
\hline 20 & $\begin{array}{l}\text { I get in a state of tension or turmoil } \\
\text { as I think over my recent concerns } \\
\text { and interests. }\end{array}$ & 1 & 2 & 3 & 4 \\
\hline
\end{tabular}


Reference No:

The following questions ask about how you have been feeling during the past four weeks. For each question, please circle the number that best describes how often you had this feeling.

\begin{tabular}{|c|c|c|c|c|c|c|}
\hline \multicolumn{2}{|c|}{ In the past 4 weeks: } & $\begin{array}{l}\text { None } \\
\text { of the } \\
\text { time }\end{array}$ & $\begin{array}{l}\text { A little } \\
\text { of the } \\
\text { time }\end{array}$ & $\begin{array}{l}\text { Some } \\
\text { of the } \\
\text { time }\end{array}$ & $\begin{array}{l}\text { Most of } \\
\text { the } \\
\text { time }\end{array}$ & $\begin{array}{l}\text { All of } \\
\text { the } \\
\text { time }\end{array}$ \\
\hline 1 & $\begin{array}{l}\text { About how often did you } \\
\text { feel tired out for no good } \\
\text { reason? }\end{array}$ & 1 & 2 & 3 & 4 & 5 \\
\hline 2 & $\begin{array}{l}\text { About how often did you } \\
\text { feel nervous? }\end{array}$ & 1 & 2 & 3 & 4 & 5 \\
\hline 3 & $\begin{array}{l}\text { About how often did you } \\
\text { feel so nervous that } \\
\text { nothing could calm you } \\
\text { down? }\end{array}$ & 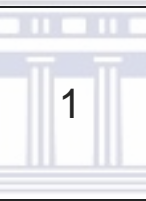 & 2 & 3 & 4 & 5 \\
\hline 4 & $\begin{array}{l}\text { About how often did you } \\
\text { feel hopeless? }\end{array}$ & 1 & 2 & 3 & 4 & 5 \\
\hline 5 & $\begin{array}{l}\text { About how often did you } \\
\text { feel restless or fidgety? }\end{array}$ & 1 & 2 & 3 & 4 & 5 \\
\hline 6 & $\begin{array}{l}\text { About how often did you } \\
\text { feel so restless you } \\
\text { could not sit still? }\end{array}$ & 1 & 2 & 3 & 4 & 5 \\
\hline 7 & $\begin{array}{l}\text { About how often did you } \\
\text { feel depressed? }\end{array}$ & 1 & 2 & 3 & 4 & 5 \\
\hline 8 & $\begin{array}{l}\text { About how often did you } \\
\text { feel that everything is an } \\
\text { effort? }\end{array}$ & 1 & 2 & 3 & 4 & 5 \\
\hline 9 & $\begin{array}{l}\text { About how often did you } \\
\text { feel so sad that nothing } \\
\text { could cheer you up? }\end{array}$ & 1 & 2 & 3 & 4 & 5 \\
\hline 10 & $\begin{array}{l}\text { About how often did you } \\
\text { feel worthless? }\end{array}$ & 1 & 2 & 3 & 4 & 5 \\
\hline
\end{tabular}

Score: 


\title{
Addendum 2
}

\author{
Tooth wear Score
}

Reference No:....

Maxillary cast

\begin{tabular}{|l|l|l|l|l|l|l|l|l|l|l|l|l|l|l|}
\hline Teeth & 17 & 16 & 15 & 14 & 13 & 12 & 11 & 21 & 22 & 23 & 24 & 25 & 26 & 27 \\
\hline Score & & & & & & & & & & & & & & \\
\hline Area & & & & & & & & & & & & & & \\
\hline
\end{tabular}

MT - missing tooth

$\mathrm{L}-$ lingual

D - distal

B -

buccal

$\mathrm{R}$ - restoration

O - occlusal

M - Mesial

$X-$

cannot be scored (e.g. bundling of teeth; large restoration

Check photos to confirm score

Anterior mean/median score

Posterior mean/median score

Dental arch mean/median score -

Mandibular cast

\begin{tabular}{|l|l|l|l|l|l|l|l|l|l|l|l|l|l|l|}
\hline Teeth & 47 & 46 & 45 & 44 & 43 & 42 & 41 & 31 & 32 & 33 & 34 & 35 & 36 & 37 \\
\hline Score & & & & & & & & & & & & & & \\
\hline Area & & & & & & & & & & & & & & \\
\hline
\end{tabular}

MT - missing tooth

$\mathrm{L}$ - lingual

D - distal

B -

buccal

$\mathrm{R}$ - restoration

O - occlusal

M - Mesial

$1-$

Incisal

C - Cervical

(MT and R are not scored)

Anterior mean/median score -

Posterior mean/median score -

Dental arch mean/median score: -

Serious malocclusion:

Yes No

Comments: 


\section{Addendum 3}

Raw data on Demographic and Clinical Criteria, defining a bruxer and tooth wear score

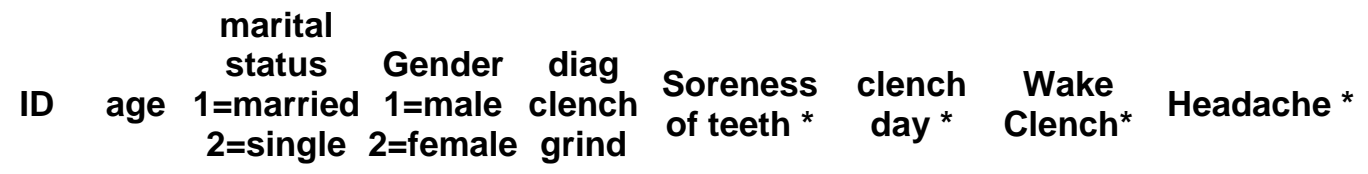

$\begin{array}{ccccccccc}1 & 21 & 2 & 2 & \text { No } & 2 & 2 & 1 & 2 \\ 2 & 22 & 2 & 2 & \text { yes } & 2 & 1 & 1 & 2 \\ 3 & 22 & 2 & 2 & \text { no } & 1 & 2 & 1 & 1 \\ 4 & 35 & 1 & 1 & \text { No } & 1 & 2 & 1 & 1 \\ 7 & 26 & 2 & 2 & \text { no } & 2 & 2 & 3 & 2 \\ 8 & 22 & 2 & 2 & \text { Yes } & 2 & 1 & 2 & 3 \\ 10 & 22 & 2 & 2 & \text { no } & 2 & 4 & 3 & 3 \\ 11 & 22 & 2 & 2 & \text { no } & 1 & 2 & 1 & 2 \\ 12 & 32 & 1 & 2 & \text { yes } & 3 & 3 & 3 & 4 \\ 13 & 21 & 2 & 1 & \text { no } & 2 & 1 & 1 & 2 \\ 14 & 24 & 2 & 2 & \text { no } & 2 & 3 & 1 & 3 \\ 15 & 19 & 2 & 2 & \text { yes } & 1 & 3 & 1 & 3 \\ 16 & 18 & 2 & 2 & & 3 & 2 & 3 & 2 \\ 17 & 26 & 2 & 2 & \text { no } & 2 & 3 & 1 & 1 \\ 18 & 18 & 2 & 1 & \text { no } & 3 & 3 & 1 & 2 \\ 19 & 19 & 2 & 2 & \text { yes } & 1 & 4 & 1 & 2 \\ 20 & 21 & 2 & 1 & \text { yes } & 2 & 1 & 2 & 2 \\ 21 & 22 & 2 & 2 & \text { no } & 1 & 4 & 1 & 4 \\ 22 & 20 & 2 & 2 & \text { no } & 1 & 2 & 1 & 2 \\ 23 & 50 & 2 & 1 & \text { no } & 1 & 2 & 1 & 3 \\ 24 & 21 & 2 & 2 & \text { yes } & 2 & 4 & 1 & 2 \\ 25 & 29 & 2 & 2 & \text { No } & 1 & 2 & 1 & 1 \\ 26 & 46 & 2 & 2 & \text { yes } & 1 & 2 & 1 & 2 \\ 27 & 21 & 2 & 1 & \text { yes } & 2 & 2 & 2 & 1 \\ 28 & 19 & 2 & 2 & \text { no } & 2 & 1 & 1 & 2 \\ 29 & 23 & 2 & 2 & \text { yes } & 3 & 3 & 1 & 3 \\ 30 & 18 & 2 & 2 & \text { yes } & 4 & 1 & 1 & 3 \\ 31 & 25 & 2 & 1 & \text { yes } & 2 & 2 & 2 & 2 \\ 32 & 22 & 2 & 1 & \text { no } & 1 & 1 & 1 & 1\end{array}$

* 1 , never; 2 , sometimes; 3 , often; 4 , almost always. 


\begin{tabular}{|c|c|c|c|c|c|c|c|c|}
\hline ID & $\begin{array}{l}\text { conscious } \\
\text { clench * }\end{array}$ & $\begin{array}{l}\text { pain } \\
\text { tmj * }\end{array}$ & $\begin{array}{l}\text { Sounds } \\
\text { reported } l \\
\text { nights } \\
\text { per week }\end{array}$ & 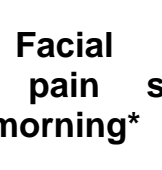 & $\begin{array}{c}\text { tmj } \\
\text { sensitive } \\
*\end{array}$ & \#Yes & Brux Scr & $\begin{array}{l}\text { Weighte } \\
\text { Brux Sc }\end{array}$ \\
\hline 1 & 4 & 3 & 2 & 1 & yes & 1 & 17 & 19 \\
\hline 2 & 4 & 2 & 3 & 1 & yes & 2 & 16 & 20 \\
\hline 3 & 1 & 2 & 3 & 1 & yes & 1 & 12 & 14 \\
\hline 4 & 4 & 1 & 1 & 1 & No & 0 & 12 & 12 \\
\hline 7 & 2 & 2 & 1 & 2 & Yes & 1 & 16 & 18 \\
\hline 8 & 2 & 1 & 2 & 2 & no & 1 & 15 & 17 \\
\hline 10 & 2 & 3 & 3 & 2 & Yes & 1 & 22 & 24 \\
\hline 11 & 2 & 1 & 2 & 1 & no & 0 & 12 & 12 \\
\hline 12 & 3 & 3 & 3 & 4 & yes & 2 & 26 & 30 \\
\hline 13 & 2 & 2 & 1 & 1 & yes & 1 & 12 & 14 \\
\hline 14 & 4 & 2 & 3 & 2 & yes & 1 & 20 & 22 \\
\hline 15 & 2 & 1 & 1 & 1 & no & 1 & 13 & 15 \\
\hline 16 & 3 & 3 & & 3 & yes & 1 & 19 & 21 \\
\hline 17 & 2 & 1 & 2 & 1 & no & 0 & 13 & 13 \\
\hline 18 & 3 & 2 & 2 & 2 & yes & 1 & 18 & 20 \\
\hline 19 & 2 & 1 & 4 & 1 & yes & 2 & 16 & 20 \\
\hline 20 & 1 & 1 & 1 & 1 & no & 1 & 11 & 13 \\
\hline 21 & 2 & 2 & 4 & 1 & no & 0 & 19 & 19 \\
\hline 22 & 2 & 1 & 1 & 1 & no & 0 & 11 & 11 \\
\hline 23 & 2 & 1 & 1 & 1 & no & 0 & 12 & 12 \\
\hline 24 & 3 & 4 & 4 & 2 & yes & 2 & 22 & 26 \\
\hline 25 & 2 & 3 & 1 & 1 & Yes & 1 & 12 & 14 \\
\hline 26 & 2 & 1 & 4 & 1 & no & 1 & 14 & 16 \\
\hline 27 & 3 & 2 & 2 & 2 & yes & 2 & 16 & 14 \\
\hline 28 & 1 & 2 & 1 & 2 & yes & 1 & 12 & 14 \\
\hline 29 & 2 & 3 & 1 & 4 & yes & 2 & 20 & 24 \\
\hline 30 & 1 & 4 & 4 & 3 & yes & 2 & 21 & 25 \\
\hline 31 & 1 & 2 & & 2 & yes & 2 & 13 & 17 \\
\hline 32 & 1 & 1 & 2 & 1 & no & 0 & 9 & 9 \\
\hline
\end{tabular}

${ }^{\star}$ 1, never; 2 , sometimes; 3 , often; 4, almost always.

\#Yes, 1 - either Diagnosis of bruxism or TMJ sensitivity

\#Yes, 2 - both Diagnosis of bruxism or TMJ sensitivity 


\begin{tabular}{|c|c|c|c|c|c|c|c|c|}
\hline ID & $\begin{array}{l}\text { restless } \\
\text { legs * }\end{array}$ & $\begin{array}{c}\text { dusty } \\
\text { environ * }\end{array}$ & $\begin{array}{l}\text { acid } \\
\text { * regurg* }\end{array}$ & $\begin{array}{l}\text { coke pe } \\
\text { week }^{*}\end{array}$ & Appliance* & $\begin{array}{c}\text { tmj } \\
\text { sensitive }\end{array}$ & $\begin{array}{c}\text { opening } \\
\text { meas } \\
\text { mm }\end{array}$ & $\begin{array}{l}\text { open mea } \\
\text { Stand }\end{array}$ \\
\hline 1 & 2 & 1 & 1 & 4 & 1 & yes & & \\
\hline 2 & 4 & 2 & 1 & 1 & 1 & yes & & \\
\hline 3 & 1 & 2 & 1 & 4 & 1 & yes & 44 & 0.94 \\
\hline 4 & 1 & 1 & 1 & 3 & 1 & No & 45 & 0.96 \\
\hline 7 & 1 & 2 & 1 & 3 & 1 & Yes & 42 & 0.89 \\
\hline 8 & 3 & 1 & 1 & 3 & 2 & No & 35 & 0.74 \\
\hline 10 & 2 & 1 & 1 & 2 & 1 & Yes & & \\
\hline 11 & 2 & 1 & 3 & 3 & 1 & no & 45 & 0.96 \\
\hline 12 & 3 & 1 & 2 & 2 & 4 & yes & 40 & 0.85 \\
\hline 13 & 1 & 3 & 2 & 3 & 1 & yes & 57 & 1.21 \\
\hline 14 & 3 & 1 & 1 & 2 & 1 & yes & & \\
\hline 15 & 4 & 1 & 1 & 2 & 1 & no & 38 & 0.81 \\
\hline 16 & 1 & 1 & 1 & 2 & 1 & yes & 40 & 0.85 \\
\hline 17 & 1 & 1 & 1 & 3 & 1 & no & 52 & 1.11 \\
\hline 18 & 1 & 2 & 1 & 2 & 1 & yes & 52 & 1.11 \\
\hline 19 & 1 & 1 & 1 & 3 & 1 & yes & 47 & 1.00 \\
\hline 20 & 2 & 2 & 2 & 2 & 1 & no & 60 & 1.28 \\
\hline 21 & 1 & 1 & 2 & 2 & 1 & no & 45 & 0.96 \\
\hline 22 & 2 & 1 & 1 & 2 & 1 & no & 45 & 0.96 \\
\hline 23 & 2 & 2 & 1 & 1 & 1 & no & 46 & 0.98 \\
\hline 24 & 4 & 3 & 1 & 3 & 3 & yes & 50 & 1.06 \\
\hline 25 & 3 & 3 & 4 & 2 & 1 & Yes & 50 & 1.06 \\
\hline 26 & 2 & 1 & 1 & 2 & $\mathrm{CAP}_{4}$ & no & 49 & 1.04 \\
\hline 27 & 4 & 2 & 1 & 3 & 3 & yes & 46 & 0.98 \\
\hline 28 & 1 & 2 & 1 & 2 & 1 & yes & 43 & 0.91 \\
\hline 29 & 2 & 1 & 2 & 1 & 2 & yes & & \\
\hline 30 & 1 & 2 & 1 & 3 & 4 & yes & 47 & 1.00 \\
\hline 31 & 2 & 2 & 1 & 2 & 1 & yes & 60 & 1.28 \\
\hline 32 & 3 & 2 & 1 & 3 & 1 & no & 52 & 1.11 \\
\hline
\end{tabular}

*1, never; 2, sometimes; 3, often; 4, almost always. 


\begin{tabular}{|c|c|c|c|c|c|c|c|c|}
\hline ID & $\begin{array}{c}\text { Defined } \\
\text { as } \\
\text { Bruxer }\end{array}$ & $\begin{array}{c}\text { MxAnt } \\
\text { Mean Scr }\end{array}$ & $\begin{array}{l}\text { MxPost } \\
\text { Mean Scr }\end{array}$ & $\begin{array}{c}\text { Max } \\
\text { Mean Scr }\end{array}$ & $\begin{array}{c}\text { MdAnt } \\
\text { Mean Scr }\end{array}$ & $\begin{array}{l}\text { MdPos } \\
\text { t Mean } \\
\text { Scr }\end{array}$ & $\begin{array}{c}\text { Mand } \\
\text { Mean Scr }\end{array}$ & $\begin{array}{l}\text { All canine } \\
\text { score }\end{array}$ \\
\hline 1 & No & 0.67 & 0.88 & 0.77 & 1.00 & 0.83 & 0.92 & 1.00 \\
\hline 2 & Yes & 1.67 & 0.50 & 1.08 & 2.00 & 0.50 & 1.25 & 2.00 \\
\hline 3 & No & 2.17 & 0.86 & 1.51 & 1.33 & 0.13 & 0.73 & 1.00 \\
\hline 4 & No & 0.83 & 1.00 & 0.92 & 1.00 & 0.38 & 0.69 & 1.00 \\
\hline 7 & No & 0.17 & 0.13 & 0.15 & 0.00 & 0.75 & 0.38 & 0.00 \\
\hline 8 & Yes & 0.83 & 0.20 & 0.52 & 1.33 & 0.67 & 1.00 & 0.50 \\
\hline 10 & Yes & 0.83 & 0.13 & 0.48 & 0.50 & 0.75 & 0.63 & 1.75 \\
\hline 11 & No & 1.00 & 0.75 & 0.88 & 0.50 & 0.25 & 0.38 & 0.75 \\
\hline 12 & Yes & 2.42 & 1.42 & 1.92 & 2.17 & 2.06 & 2.11 & 2.25 \\
\hline 13 & No & 1.17 & 0.13 & 0.65 & 0.40 & 0.43 & 0.41 & 0.67 \\
\hline 14 & No & 0.42 & 0.38 & 0.40 & 0.50 & 0.25 & 0.38 & 0.75 \\
\hline 15 & No & 1.83 & 1.00 & 1.42 & 1.67 & 1.14 & 1.40 & 1.75 \\
\hline 16 & No & 0.25 & 0.25 & 0.25 & 0.00 & 0.31 & 0.16 & 0.00 \\
\hline 17 & No & 1.75 & 1.06 & 1.41 & 1.92 & 1.00 & 1.46 & 1.88 \\
\hline 18 & Yes & 2.13 & 0.88 & 1.50 & 2.00 & 1.25 & 1.63 & 1.50 \\
\hline 19 & Yes & 1.00 & 0.25 & 0.63 & 1.00 & 0.50 & 0.75 & 1.00 \\
\hline 20 & No & 1.42 & 1.00 & 1.21 & 2.00 & 1.00 & 1.50 & 1.50 \\
\hline 21 & No & 0.17 & 0.86 & 0.51 & 0.00 & 1.00 & 0.50 & 0.00 \\
\hline 22 & No & 0.67 & 0.63 & 0.65 & 0.67 & 0.69 & 0.68 & 1.00 \\
\hline 23 & No & 2.17 & 0.56 & 1.36 & 2.17 & 0.50 & 1.33 & 1.50 \\
\hline 24 & Yes & 1.33 & 1.19 & 1.26 & 1.00 & 2.00 & 1.50 & 1.13 \\
\hline 25 & No & 0.42 & 0.88 & 0.65 & 0.42 & 0.69 & 0.55 & 1.13 \\
\hline 26 & Yes & 3.00 & 1.93 & 2.46 & 3.00 & 2.63 & 2.81 & 2.25 \\
\hline 27 & Yes & 1.50 & 0.33 & 0.92 & 1.25 & 0.75 & 1.00 & 1.88 \\
\hline 28 & No & 1.50 & 0.25 & 0.88 & 1.00 & 0.33 & 0.67 & 0.88 \\
\hline 29 & Yes & 1.50 & 2.36 & 1.93 & 1.00 & 2.44 & 1.72 & 1.50 \\
\hline 30 & Yes & 0.80 & 0.75 & 0.78 & 1.08 & 1.69 & 1.39 & 0.88 \\
\hline 31 & Yes & 2.25 & 1.75 & 2.00 & 2.50 & 2.56 & 2.53 & 2.25 \\
\hline 32 & No & 1.58 & 0.81 & 1.20 & 2.00 & 0.69 & 1.34 & 1.75 \\
\hline
\end{tabular}




\section{Abbreviations}

\begin{tabular}{|c|c|}
\hline TMD & temporomandibular disorder \\
\hline CMD & craniomandibular dysfunction \\
\hline \#Yes & Diagnosis of Bruxism/TMJ Sensitivity \\
\hline All_ Mean Tooth Wear Score & mean tooth wear score of full dentition \\
\hline AllmeanScr & mean tooth wear score of full dentition \\
\hline Bruxscr & Bruxism Score \\
\hline BruxscrW1 & Bruxism Score Weighted x1 \\
\hline BruxScrW2 & Bruxism Score weighted x2 \\
\hline DectotStateY1 & Decreasing Totals for State Anxiety Scores \\
\hline DectotTraitY1 & Decreasing Totals for Trait Anxiety Scores \\
\hline InctotStateY1 & Increasing totals for State Anxiety Scores \\
\hline InctotTraitY1 & Increasing totals for Trait Anxiety Scores \\
\hline K 10 & Kessler 10 \\
\hline Mand Mean Scr & Mandible Mean tooth wear Score \\
\hline Max Mean Scr & Maxilla Mean tooth wear Score \\
\hline MdAnt Mean Scr & Mandible Anterior Mean tooth wear Score \\
\hline MdPost Mean Scr & Mandible Posterior Mean tooth wear Score \\
\hline MFP & myofascial pain disorder \\
\hline MxAnt Mean Scr & Maxilla Anterior Mean Score \\
\hline MxPost Mean Scr & Maxilla Posterior Mean score \\
\hline State Y1 & State anxiety Scale \\
\hline TMJ & tempomandibular joint \\
\hline Trait Y2 & Trait Anxiety Scale \\
\hline
\end{tabular}




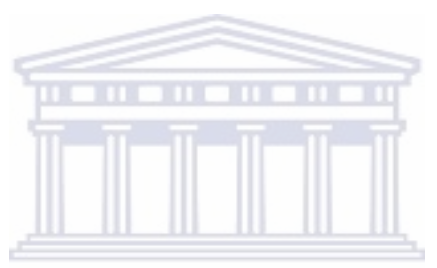

UNIVERSITY of the WESTERN CAPE 